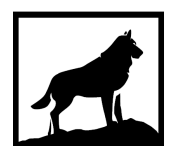

Michigan

Technological

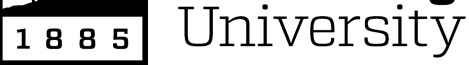

Michigan Technological University

Digital Commons @ Michigan Tech

2016

\title{
A CHARACTERIZATION OF THE WATER QUALITY CONDITIONS AND POLLUTANT LOADS IN SURFACE WATERS NEAR THE NORTHEAST OHIO REGIONAL SEWER DISTRICT'S COMBINED SEWER SYSTEM IN CLEVELAND, OHIO
}

Nathan Zgnilec

Michigan Technological University, ndzgnile@mtu.edu

Copyright 2016 Nathan Zgnilec

Recommended Citation

Zgnilec, Nathan, "A CHARACTERIZATION OF THE WATER QUALITY CONDITIONS AND POLLUTANT LOADS IN SURFACE WATERS NEAR THE NORTHEAST OHIO REGIONAL SEWER DISTRICT'S COMBINED SEWER SYSTEM IN CLEVELAND, OHIO", Open Access Master's Thesis, Michigan Technological University, 2016. https://doi.org/10.37099/mtu.dc.etdr/118

Follow this and additional works at: https://digitalcommons.mtu.edu/etdr

Part of the Civil Engineering Commons, Environmental Engineering Commons, and the Hydraulic Engineering Commons 


\title{
A CHARACTERIZATION OF THE WATER QUALITY CONDITIONS AND POLLUTANT LOADS IN SURFACE WATERS NEAR THE NORTHEAST OHIO REGIONAL SEWER DISTRICT'S COMBINED SEWER SYSTEM IN CLEVELAND, OHIO
}

By

Nathan D. Zgnilec

\begin{abstract}
A THESIS
Submitted in partial fulfillment of the requirements for the degree of MASTER OF SCIENCE

In Environmental Engineering
\end{abstract}

MICHIGAN TECHNOLOGICAL UNIVERSITY

2016

(C) 2016 Nathan D. Zgnilec 
This thesis has been approved in partial fulfillment of the requirements for the Degree of MASTER OF SCIENCE in Environmental Engineering.

Department of Civil and Environmental Engineering

Thesis Advisor: Dr. Martin T. Auer

Committee Member: Dr. Guy Meadows

Committee Member: Dr. Pengfei Xue

Department Chair: Dr. David Hand 


\section{Table of Contents}

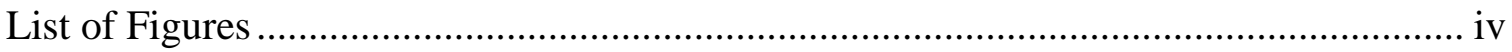

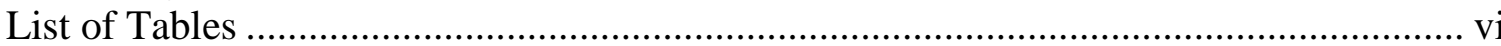

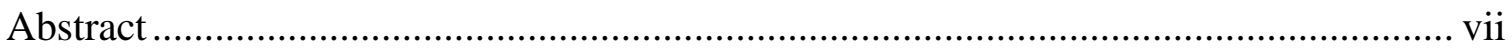

1. Introduction: History, Infrastructure and Water Quality Management ......................1

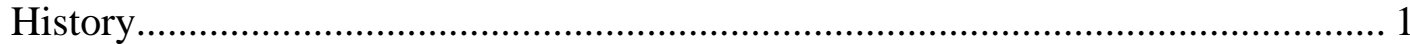

Location, area, population ......................................................................... 7

Overview of NEORSD Operations .............................................................

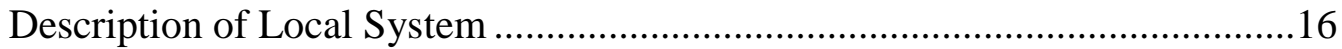

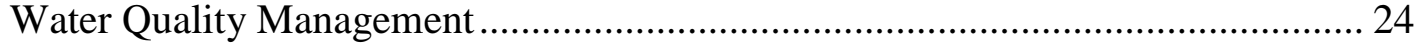

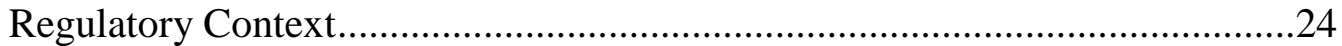

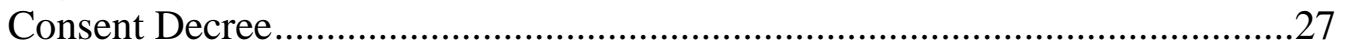

Community Infrastructure Program ........................................................29

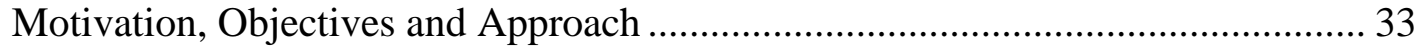

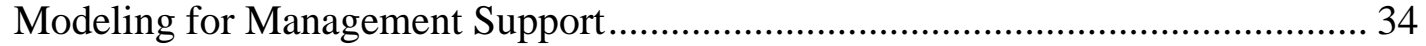

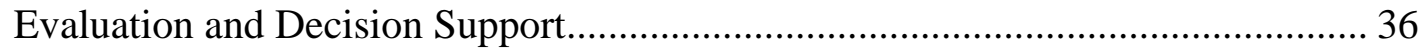

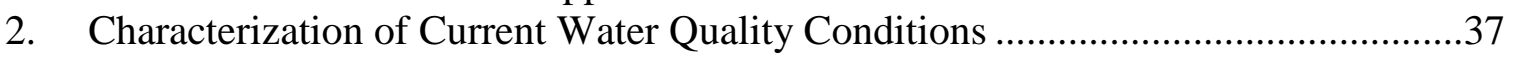

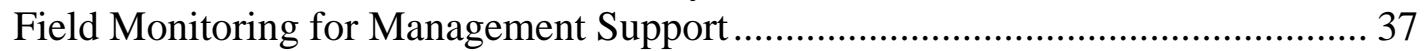

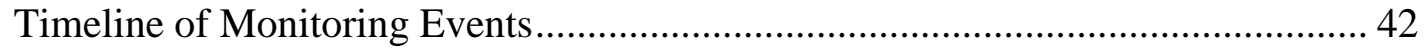

a. Pre-sampling - initial observations and sampling logistics.......................43

b. Dry-weather sampling ...................................................................43

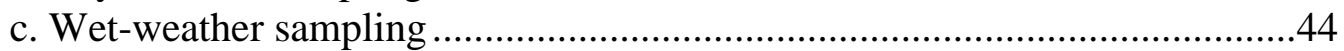

Water Quality Monitoring - Lessons Learned .............................................. 45

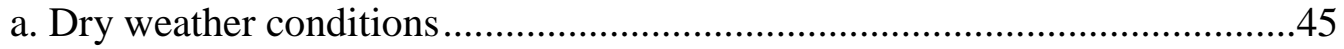

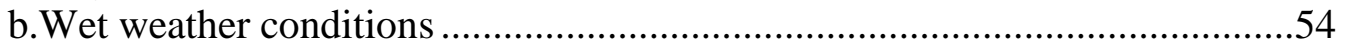

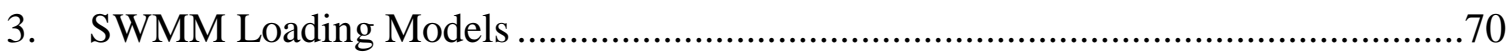

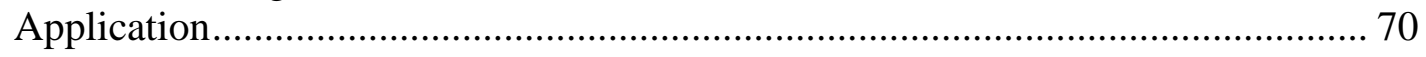

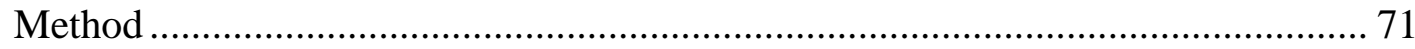

Calibration and Confirmation ............................................................................. 72

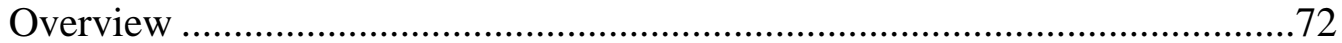

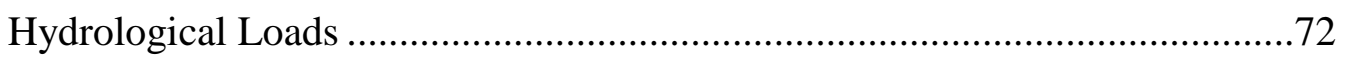

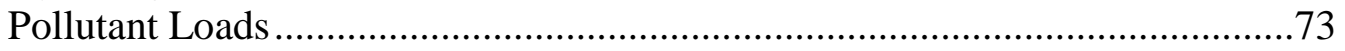

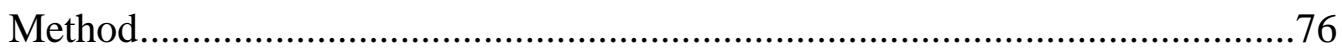

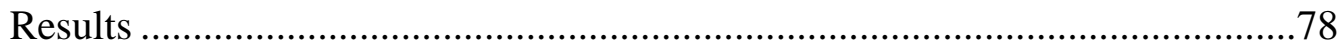

4. Evaluation of Pollutant Load Reductions .............................................................89

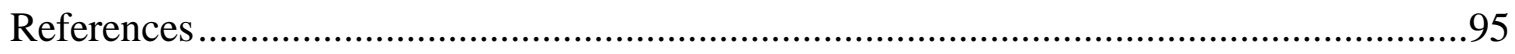




\section{List of Figures}

Figure 1-1: Cuyahoga River Fire, November 3, 1952 - fires occurred on thirteen occasions between 1868 and 1969. The fire shown above caused \$1.3 million in damages (James

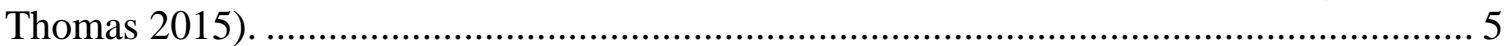

Figure 1-2: Extent of the NEORSD Service Area and its three WWTPs.......................... 8

Figure 1-3: Location of NEORSD's 126 CSOs.......................................................... 9

Figure 1-4: The spatial layout of NEORSD's various system types which handle sanitary

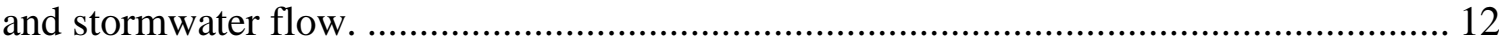
Figure 1-5: The location of WWTPs operated by communities surrounding NEORSD.. 14 Figure 1-6: Tributaries within NEORSD's service area............................................... 17

Figure 1-7: Eastern tributaries and local CSOs............................................................ 19

Figure 1-8: Edgewater Beach and Euclid Beach relative to local inputs.......................... 21 Figure 1-11: Location of the seven storage tunnels, as required by the Consent Decree. 28 Figure 1-12: Overview of Project Tasks and those discussed in this thesis ..................... 34 Figure 1-13: Approach taken in modeling the water quality impacts of the Consent Decree and CIP to guide the allocation of financial resources. .................................................... 35

Figure 2-1: Upstream and Downstream sampling stations along local tributaries. .......... 39 Figure 2-2: Nearshore Lake Erie sampling stations...................................................... 41 Figure 2-3: Sampling stations near Edgewater Beach and Euclid Beach. ....................... 42 Figure 2-4: Dry weather pollutant levels observed at upstream and downstream tributary

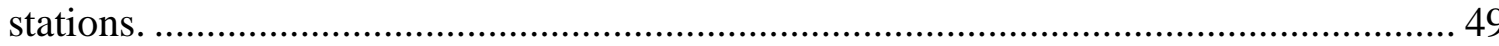

Figure 2-5: Observed dry weather pollutant levels at Lake Erie nearshore ( $0.5 \mathrm{~km}$ offshore)

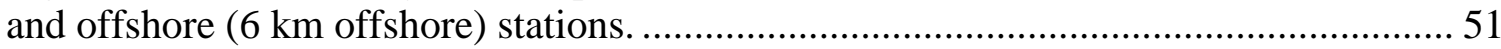

Figure 2-6: Lake transect stations relative to tributaries discharge points....................... 52 Figure 2-7: Observed pollutant levels at Edgewater Beach and Euclid Beach during dry weather sampling. ............................................................................................... 54

Figure 2-8: Hydrologic response of Euclid Creek following Storm 1 rainfall on September

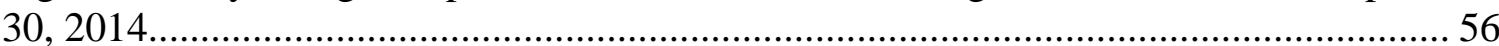

Figure 2-9: Water quality response of Euclid Creek following Storm 1 rainfall on September 30, 2014 ........................................................................................... 58

Figure 2-10: Hydrologic response of Cuyahoga River following Storm 1 rainfall on

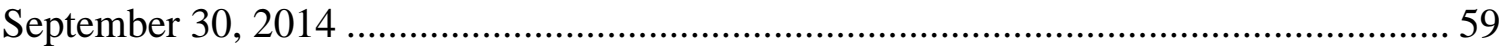

Figure 2-11: Water quality response of Cuyahoga River following Storm 1 rainfall on

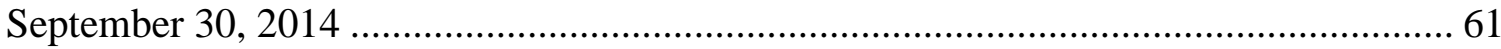

Figure 2-12: Observed pollutant levels in upstream and downstream waters from Storm 1

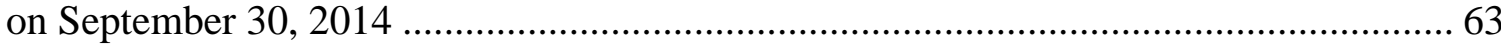
Figure 2-13: Observed pollutant levels in upstream and downstream waters from Storm 1

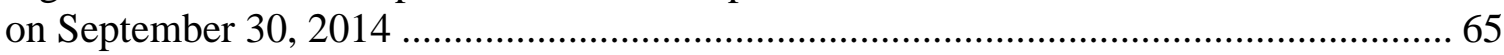

Figure 2-14: Observed pollutant levels resulting from Storm 1 rainfall................................. 67

Figure 2-15: Average nearshore pollutant levels following Storm 2 rainfall.................... 69

Figure 3-1: Characterization of tributary pollutant levels during rainfall events. ............ 74 Figure 3-2: Comparison of Euclid Creek PC-SWMM loads and observed loads during 2014 and 2015 wet weather events. 83 
Figure 3-3: Comparison of Big Creek PC-SWMM loads and observed loads during 2014 and 2015 wet weather events.

Figure 3-4: Comparison of Eastern Tributary Pollutant Loads Predicted by PC-SWMM87 Figure 3-5: Comparison of Western Tributary Pollutant Loads Predicted by PC-SWMM

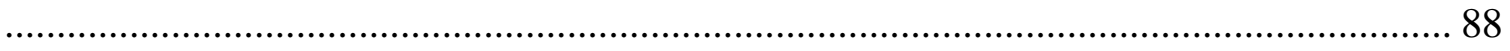

Figure 4-1: Euclid Creek System Types and Pollutant Inputs. ..................................... 90

Figure 4-2: Baseline and Consent Decree E.coli contributions during 2014 Beach Season

91

Figure 4-3: Big Creek System Types and Pollutant Inputs......................................... 92

Figure 4-4: Baseline and Consent Decree E.coli Loads during 2014 Beach Season........ 93 


\section{List of Tables}

Table 1-1: Standards for pollutants of concern within NEORSD (A. Scott 2015).......... 26 Table 3-1: Pollutant Input Concentrations Resulting from Confirmation of the PC-SWMM

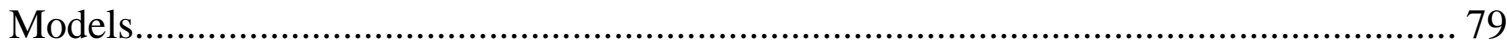




\begin{abstract}
The Northeast Ohio Regional Sewer District (NEORSD, Cleveland, OH) serves over one million citizens through the operation of three waste water treatment plants. NEORSD provides this service through combined and separated sewer systems, which, during rainfall events, are known to deliver large volumes of untreated wastewater containing high concentrations of Escherichia coli (E.coli), ammonia nitrogen, and phosphorus. NEORSD is currently investing $\$ 3$ billion over the next 25 years to mitigate its combined sewer overflows and plans to allocate additional funds to improve remaining pollutant sources related to its system, e.g. separated sewers. A suite of PC-SWMM pollutant loading models have been confirmed for their ability to represent the environmental impacts of NEORSD's sewer system. The environmental benefits associated with infrastructure improvements are then predicted by the models to assist NEORSD in most efficiently spending financial resources.
\end{abstract}




\section{Introduction: History, Infrastructure and Water Quality}

\section{Management}

\section{History}

The Northeast Ohio Regional Sewer District (NEORSD) was created in 1972 to assume the operation and management of wastewater collection, treatment and disposal facilities serving the Cleveland metropolitan area (Consent Decree, 2010). Presently, NEORSD is responsible for operation and maintenance of three Wastewater Treatment Plants (WWTPs) and serves all or part of 62 communities and over one million people in a 350 square-mile tributary area. NEORSD also operates a Combined Sewer Overflow Treatment Facility located near the Westerly WWTP. As one of the largest sewer districts in the country, NEORSD and the City of Cleveland have had to respond to over 100 years of economic, social, and environmental challenges surrounding their handling of raw sewage.

Prior to the establishment of NEORSD, the City of Cleveland struggled through the $19^{\text {th }}$ and $20^{\text {th }}$ centuries to provide sewer services which met the needs of its surging population and industrial economy (NEORSD, 2008). In these early days, it was common practice for growing cities to discharge untreated sewage into local surface waters. For Cleveland, this meant the Cuyahoga River and Lake Erie. Combined Sewer Overflows (CSOs) were often used to transport the city's raw sewage and storm water to a point of discharge into surface waters. Carrying raw sewage, industrial waste and street runoff, CSO discharges introduced large volumes of potentially harmful pathogens and toxic substances into Lake Erie and the Cuyahoga River. In addition to being the recipient of CSO discharges, these 
waters often served a dual purpose, by also providing a source of drinking water. It was largely believed that dilution of discharges in surface waters would mitigate environmental impacts. Further, common belief in the early 1800s did not associate diseases, like typhoid, to human contact with raw sewage (Alewitz 1997). However, as populations grew through the industrial revolution, incidents like the cholera outbreak of 1832 exposed Cleveland's handling of sewage as causing a major public health concern (Alewitz 1997).

With increasing health concerns related to the high levels of raw sewage in Cleveland's surface waters, the Cleveland Water Works were begun in 1854 (Jackson 1912). Shortly after establishing the Cleveland Water Works, the city installed its first drinking water intake in 1856, providing unfiltered water from Lake Erie, 300 feet offshore and four feet below the surface (Flower 1957). At the time of its construction, the intake served well in providing drinking water that did not contain visible signs of pollution. However, it wasn't long before the cities increasing sewage and industrial discharges began to impact the waters surrounding the intake. In the winter of 1866, a strong buildup of ice had caused outflow at the Cuyahoga River mouth to move in the direction of the intake. This caused the waters surrounding the intake to become highly contaminated and undesirable for drinking. After several similar occurrences over the following winters, it became clear that the intake could no longer provide suitable drinking water. In hopes of escaping these polluted waters, the intake was further extended in 1874 to one and one quarter miles into Lake Erie. 
In the decades following, the city continued its efforts in extending its drinking water intake beyond the area impacted by sewage and industrial discharges. On multiple occasions, the city extended its drinking water intake further offshore in an effort to escape the expanding area impacted by the city's discharges (NEORSD 2008). To further alleviate the impacts of raw sewage discharges within the city, an interceptor sewer was constructed along the Lake Erie shoreline to extend the sewers discharge to 10 miles from the water intake (Flower 1957). At this point, the interceptor was able to carry over fifty-percent of the city's sewage away from the intake. Despite these efforts, citizens remained at risk of contracting typhoid fever and waters from the Cuyahoga River delivered strong odors of petroleum. As these concerns increased it was noted in 1881, by the Mayor of Cleveland, that the Cuyahoga riverfront was "an open sewer through the center of the city" (NEORSD 2008). While statements like this expose an awareness to the city's degraded water quality, improvements were slow in coming and the situation persisted. By the early $20^{\text {th }}$ century, there remained 50 sewers discharging forty-percent of the city's sewage into the Cuyahoga River (NEORSD 2008, Jackson 1912).

In response to growing concerns surrounding the health risks associated with the city's drinking water, the Water Works Division installed a disinfection (chlorination) plant in 1918 (Flower 1957). Further acknowledgement of the poor water quality became evident in 1922 with construction of the Easterly Sewage Testing Station. The station was intended to serve as a testing site for potential treatment methods (e.g. grit chambers, sedimentation basins). By 1938, the city had constructed three treatment facilities: Easterly, which served as the Cleveland's first activated sludge plant, and Westerly and Southerly, which served 
as primary treatment facilities. Over the next four decades, these WWTPs were continuously upgraded and expanded. The city observed a drastic decline in the number of waterborne illnesses, following the construction of wastewater treatment plants and the chlorination and filtering of drinking water (Alewitz 1997).

At the time of World War II, annual water consumption had doubled to 118 billion gallons (Flower 1957). It was beginning to become apparent that the millions of dollars invested in the early $20^{\text {th }}$ century to improve the handling of raw sewage were falling short of still growing demands (Flower 1957). In addition, unregulated industrial discharges of toxic substances were leading to further degradation of local surface waters (NEORSD 2008). It was stated by the Federal Water Pollution Control Administration (FWPCA) that the Cuyahoga River held "no visible life". On thirteen occasions through the first half of the $20^{\text {th }}$ century, fires occurred on the river (Figure 1-1). The first of these fires occurred in 1936 and the largest in 1952, causing over \$1 million in damages. The last of these fires, in 1969 , caused by a spark landing on the oil-ridden surface, drew national attention and led to a reformation of local and federal regulations (James Thomas 2015). 


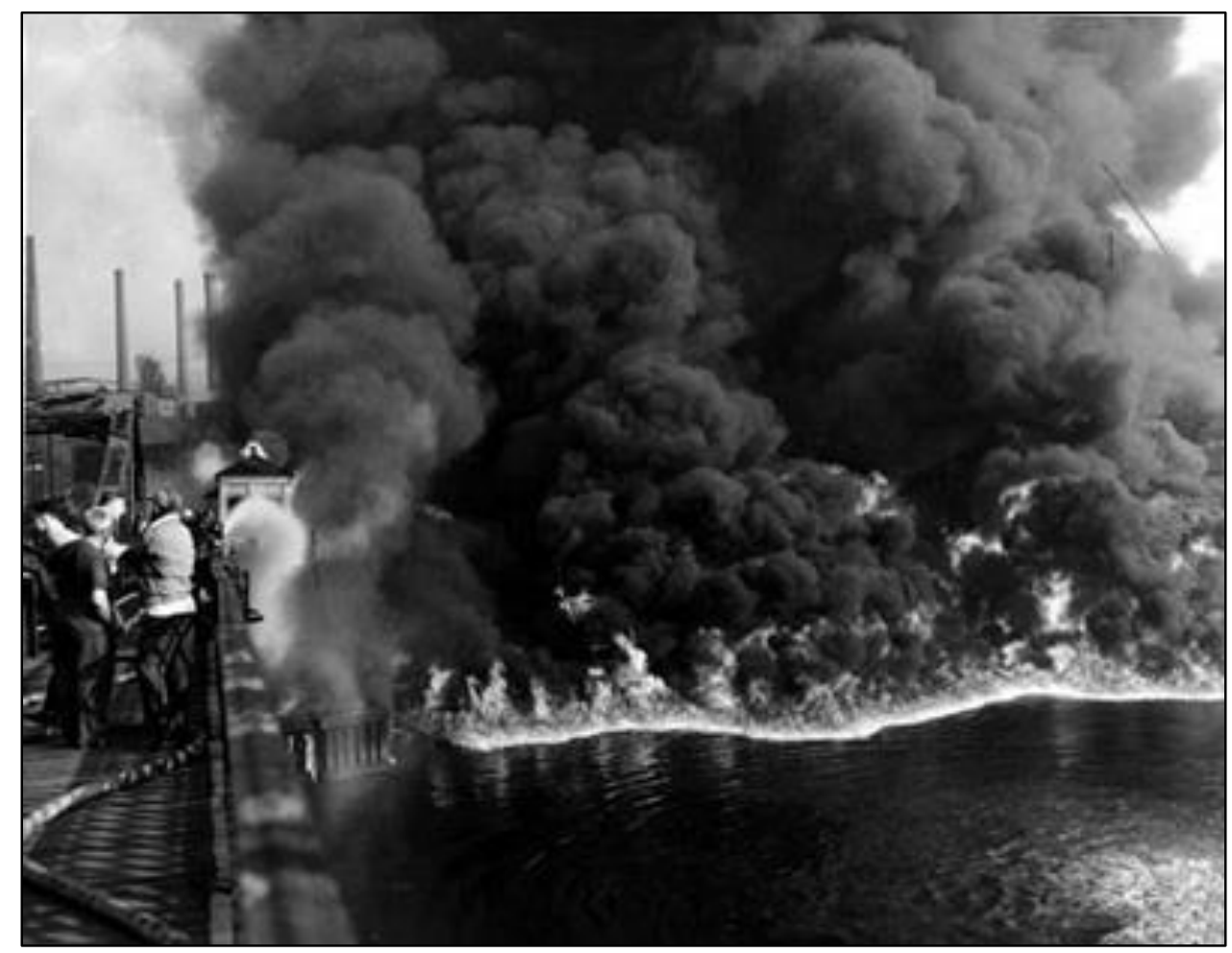

Figure 1-1: Cuyahoga River Fire, November 3, 1952 - fires occurred on thirteen occasions between 1868 and 1969. The fire shown above caused $\$ 1.3$ million in damages (James Thomas 2015).

In the years following the 1969 fire, Congress passed legislation establishing the Environmental Protection Agency (EPA) and amended the FWPCA of 1948 to form the Clean Water Act (CWA) of 1972 (NEORSD 2008). Having the objective to restore and maintain the chemical, physical, and biological integrity of the Nation's waters by eliminating pollutant discharges into navigable waters by 1985, the CWA required municipalities like the City of Cleveland to improve upon their current methods for handling wastewaters (U.S. EPA 1972). 
At this same time, the city of Cleveland was being challenged by suburban communities for discriminative sewer rates and the Ohio Water Pollution Control Board for failing to adequately treat sewage prior to discharge. As a result of these claims it was decided in 1972, by Cuyahoga County Common Pleas Court, that a regional sewer district was needed "to establish a total wastewater control system for the collection, treatment, and disposal of wastewater within and without the District" (Plan of Operation, 1972). This led to the conception of the Cleveland Regional Sewer District (CRSD) which initially served the City of Cleveland and 38 surrounding communities. The CRSD later became known as the North East Ohio Regional Sewer District (NEORSD) in 1979 and has since grown to serve over one million customers from 62 communities.

Since its inception, in 1972, northeast Ohio, in particular Cleveland, have experience a dramatic improvement in the health of is local waters. Much of this improvement can be attributed to investments made to NEORSD's sewer system. In 1972, the combined sewer system was delivering an average of 9 billion gallons of raw sewer discharges per year into Lake Erie and local streams. Today, that volume has been reduced by over $50 \%$, following the investment of $\$ 2.5$ billion, by NEORSD, in their sewer infrastructure (NEORSD 2013). The reduction in annual sewage discharges has provided a healthier environmental for those who call northeast Ohio home. Once described by comedian Johnny Carson as "the place fish go to die", the Cuyahoga River now provides a stable environment for sensitive aquatic species like walleye and freshwater mussels (Scott 2009). 


\section{$\underline{\text { Location, area, population }}$}

Presently, NEORSD provides service to a 350 square-mile area consisting of 62 communities and over one million customers. It serves an area located primarily in Cuyahoga County, with small sections in Lorain and Summit Counties. To the north, NEORSD is bounded by the Lake Erie shoreline. The Cuyahoga River runs through the center of NEORSD and Rocky River forms its western boundary. To the east, NEORSD is bounded by the city of Euclid, Ohio.

\section{Overview of NEORSD Operations}

NEORSD operates three WWTPs which, together, handle over 200 million gallons per day (MGD) (Figure 1-2). The Easterly WWTP, NEORSD's first WWTP, is located on the Lake Erie shoreline in the northeast corner of the service area. It serves 334,000 residents located from downtown Cleveland to the city's eastern border at Euclid, Ohio. Easterly treats over 94 MGD of wastewater, which is discharged directly into Lake Erie (Northeast Ohio Regional Sewer District 2015). The Westerly WWTP is also located on the shore of Lake Erie, near downtown Cleveland and the mouth of the Cuyahoga River. The smallest of the three WWTPs, Westerly serves 103,000 residents and treats an average of 26 MGD, with discharge directly to Lake Erie. In addition, Westerly houses NEORSD's CSO Treatment Facility which provides storage during wet weather periods (Northeast Ohio Regional Sewer District 2015). The largest of the three WWTPs, the Southerly WWTP is centrally located in NEORSD's service area, along the Cuyahoga River. This plant serves over 600,000 residents and is designed to treat up to 400 MGD. Southerly also has the ability to 
provide primary treatment to an additional 335 MGD of stormwater, during periods of heavy rainfall or snowmelt (Northeast Ohio Regional Sewer District 2015).

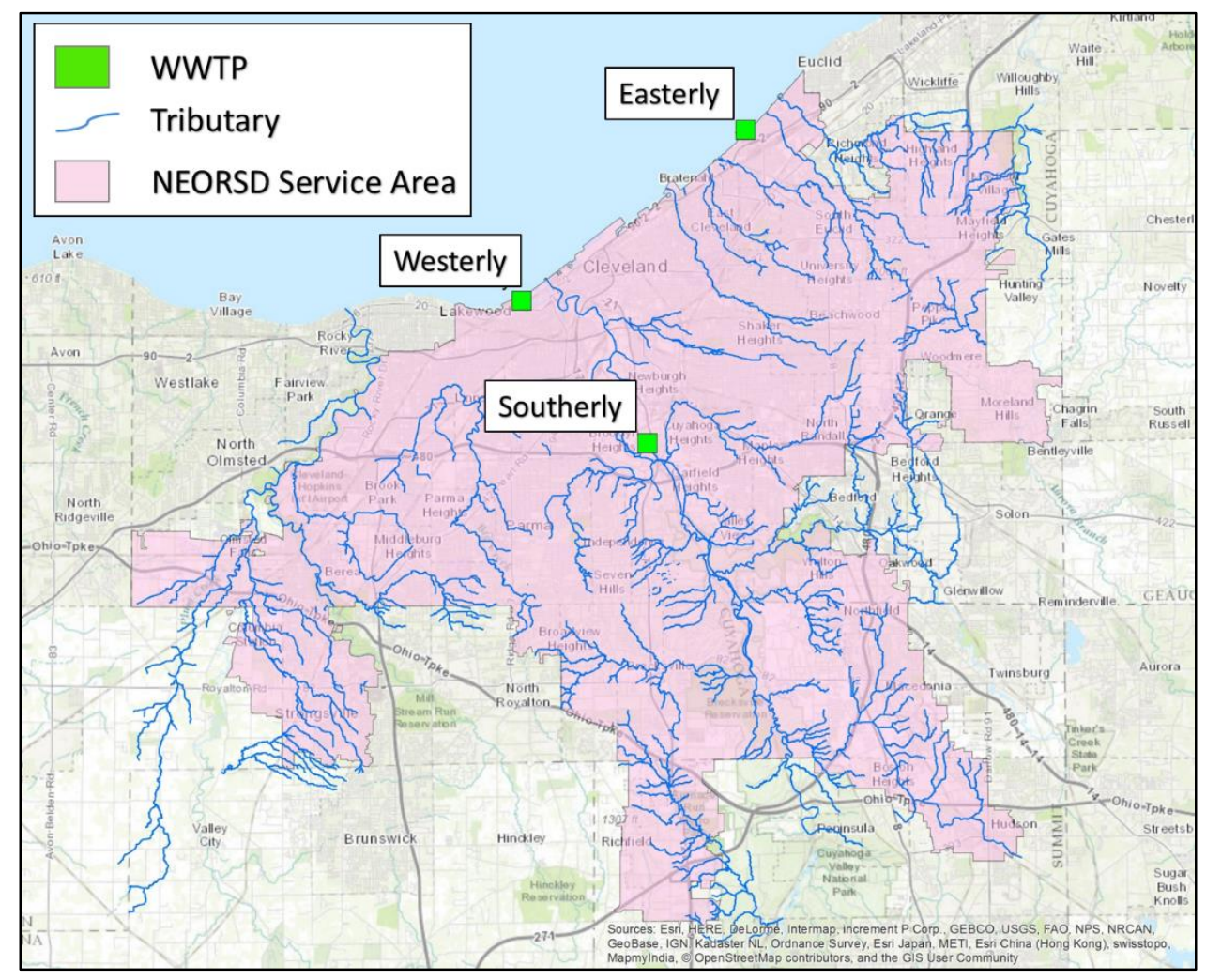

Figure 1-2: Extent of the NEORSD Service Area and its three WWTPs. (Produced in ArcGIS 10.3 by Nathan Zgnilec)

As discussed previously, Cleveland was heavily developed in the $19^{\text {th }}$ and $20^{\text {th }}$ centuries. As a result, CSOs were constructed throughout NEORSD and most heavily concentrated in the downtown-Cleveland area, as this was the region first populated (Figure 1-3). The construction of CSOs began in the late 1800s and continued until the mid-1900s (NEORSD 2008). Today, NEORSD is responsible for 1,000 miles of combined sewers with 126 outfalls. On average, these CSOs discharge 4.5 billion gallons per year (United States 
District Court 2010). The majority of CSOs discharge to tributaries and the remainder to Lake Erie.

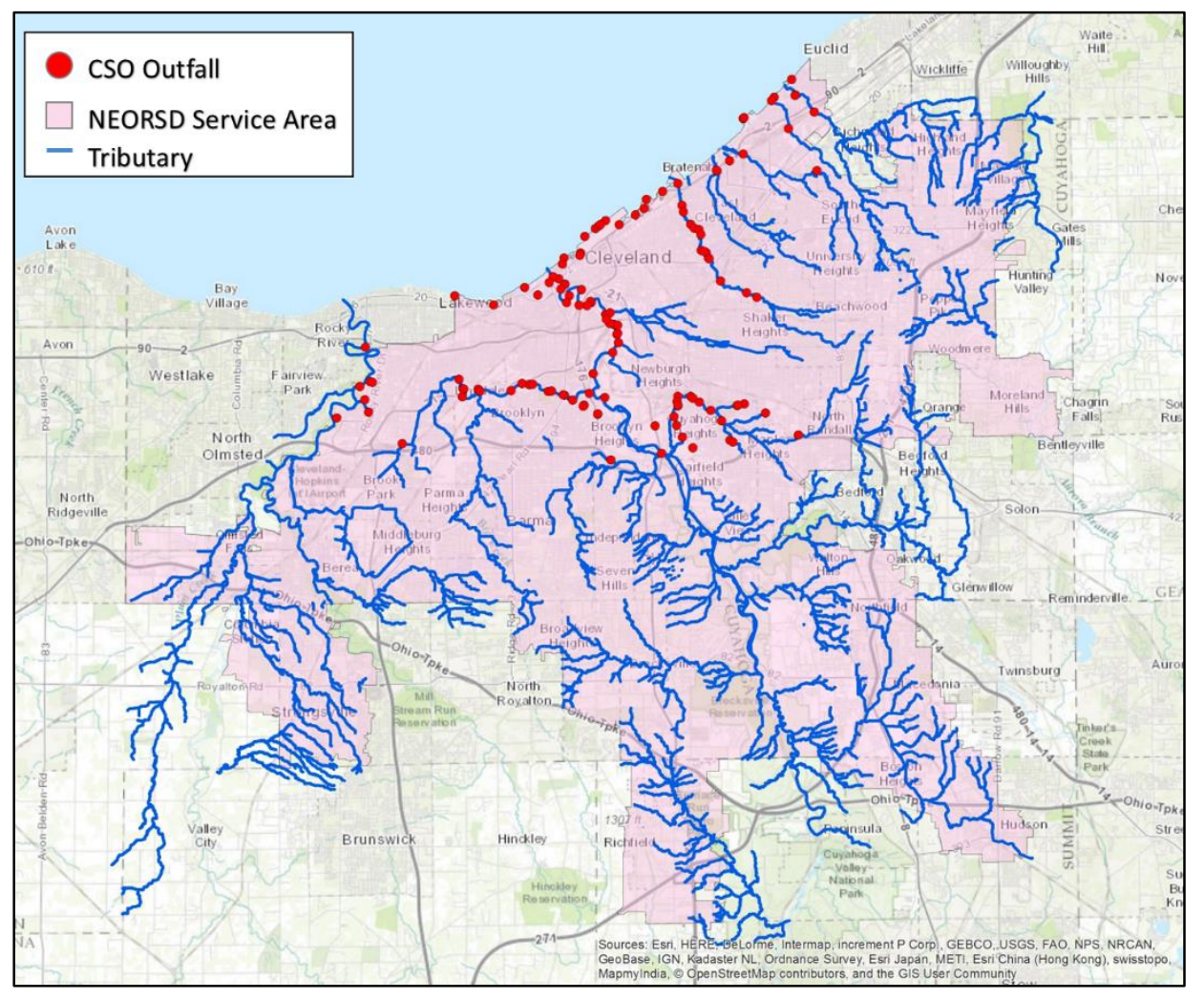

Figure 1-3: Location of NEORSD's 126 CSOs.

(Produced in ArcGIS 10.3 by Nathan Zgnilec) 
At the time of their construction, combined sewers were considered an acceptable means for handling raw sewage and stormwater. In the early days of combined sewers, the primary objective for their construction was to divert sewage away from drinking water sources and collect stormwater to avoid flooding in towns (Jon C. Schladweiler 2002). Combined sewers were designed to collect sanitary flow, from households and business, as well as stormwater runoff, during periods of rainfall. These flows were then transported to streams or lakes where they were discharged, without any treatment. This method of handling sewage and stormwater became common in many American cities throughout the $19^{\text {th }}$ and $20^{\text {th }}$ centuries.

Today, over 700 communities in the United States operate combined sewers (U.S. EPA 2014). Unlike the days of their construction, combined sewers are now directed to WWTPs, where they receive disinfection before being discharged to streams or lakes. However, during wet periods, when rainfall is present, the stormwater often overwhelms the combined sewer and results in the flow to the WWTP to exceed the plant's capacity. As a result, the additional flow and the mixture of stormwater and sewage is discharged to streams and lakes at designed overflow locations. In addition, this increase in flow can cause sewers to back up, resulting in basement flooding and street flooding. 
While 20\% NEORSD's service area is served by combined sewers, many areas have their waste handled through other system types (Figure 1-4). These non-combined system types include separate trench separated sewers, common trench separated sewers and septic systems. As with NEORSD's combined sewer system, deterioration of these non-combined systems has resulted in increasing environmental impacts during dry and wet weather periods.

Separated sewers are the most common of these non-combined system types. They account for 39\% of NEORSD's service area. Contrary to combined sewers, separated sewers handle sewage and stormwater in isolated pipes, hence separated. Separated sewers carry wastewater to WWTPs for treatment and discharge and stormwater to a predetermined point of discharge, without any treatment. Under proper performance, separated sewers offer a reduction in environmental impacts since they rarely exceed their design capacity. However, the deterioration of NEORSD's infrastructure has allowed interaction between the sanitary and stormwater pipes, resulting in additional environmental contamination.

Two types of separated sewers were constructed: common and separate trenches. Common trench, separated sewers have the storm and sanitary sewers in individual pipes located within the same trench. This method is more commonly found in older communities and accounts for 580 miles of NEORSD's sewer system (Figure 1-4) (Wade Trim 2015). Separated sewers in separate trenches have storm sewers and sanitary sewers in two separate but nearby trenches. For NEORSD, separate trench sewers account for 1,800 miles of the total sewer system. 


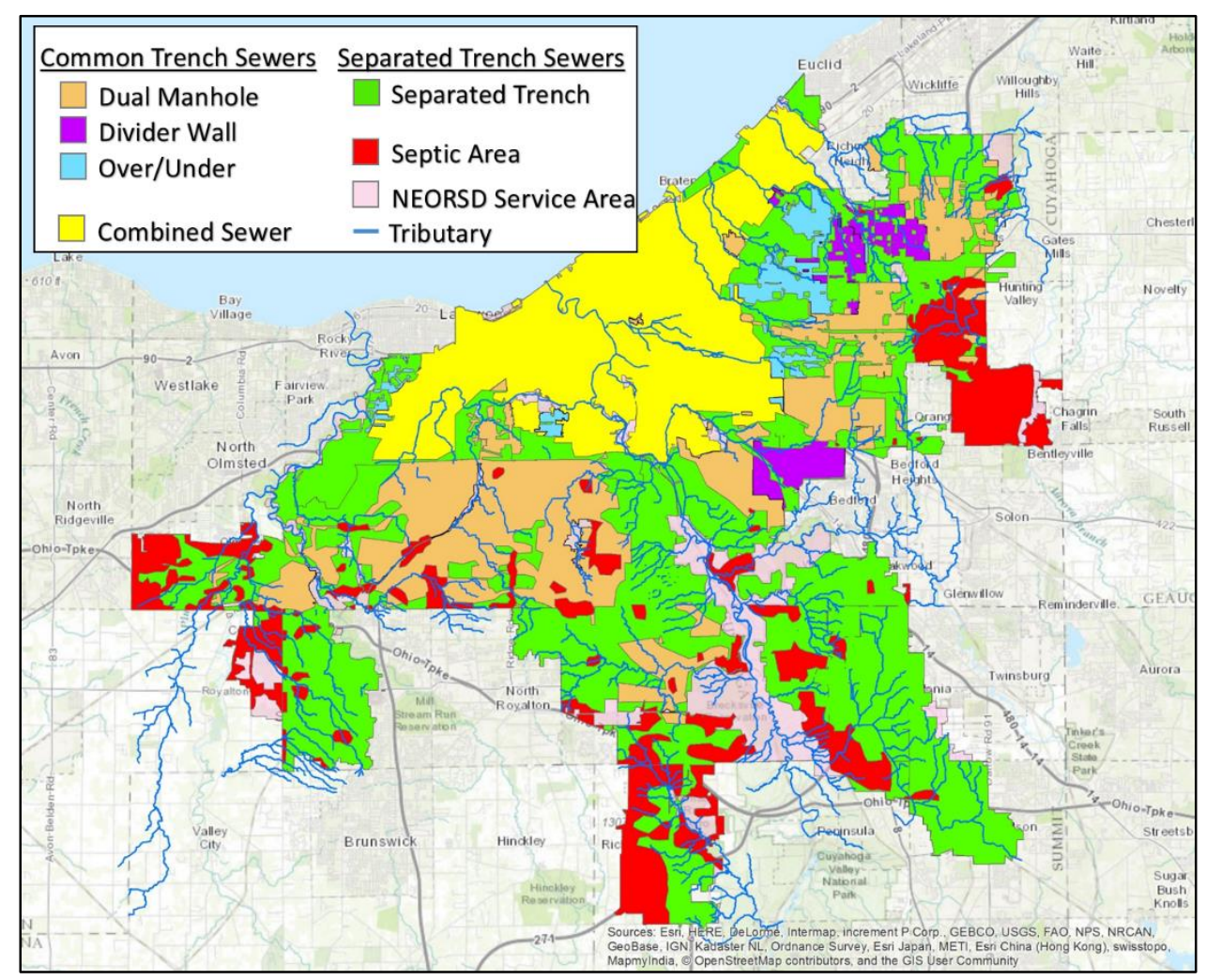

Figure 1-4: The spatial layout of NEORSD's various system types which handle sanitary and stormwater flow.

(Produced in ArcGIS 10.3 by Nathan Zgnilec)

While separated sewers are designed to keep stormwater and wastewater from having contact with one another, deteriorating infrastructure has allowed this interaction to occur. Cracked and broken sewers have resulted in untreated wastewater entering the stormwater systems, placing potentially harmful pollutants into the environment. In contrast, groundwater can enter into the sanitary sewer through these cracks and cause unintended overflows due to the excess volumes. Dry weather overflows are more often found in common trench sewers, where their storm and sanitary sewers are in close proximity. 
In the more rural regions of NEORSD, where providing the sewer services discussed above are less feasible, septic systems are often utilized (Wade Trim 2015). It is estimated that 14,000 septic systems are operated within NEORSD's service area (Figure 1-4) (Wade Trim 2015). When properly constructed and operated, septic systems offer a cost-effective method for handling sewage and maintaining water quality (U.S. EPA 2014). However, the EPA estimates that up to 20 percent of all septic systems in the United States malfunction. These malfunctions create the potential for contaminated groundwater and a public health concern, as they introduce pollutants to the environment. It is believed that failing septic systems are having an increasing impact on local water quality throughout NEORSD (Cuyahoga County Board of Health 2015).

Illicit, i.e. illegal, discharges have been identified across NEORSD along several tributaries. Illicit discharges create a water quality concern because they introduce waters other than stormwater into the collection system (U.S. EPA 2014). These stormwater systems typically discharge into waterways without any treatment. As a result, high levels of pollutants can enter into receiving waters. It is estimated by NEORSD that $30-40$ illicit discharges are present throughout the area (United States District Court 2010). However, since illicit discharges are undocumented and difficult to locate, there are likely many more throughout NEORSD. 
While NEORSD operates several sewer services throughout its service area, other communities also operate sewer systems which impact local surface waters. Multiple communities surrounding NEORSD independently operate WWTPs (Figure 1-5). Similar to NEORSD, these communities suffer from aging infrastructure and frequent discharges of raw sewage from combined and separated sewer systems.

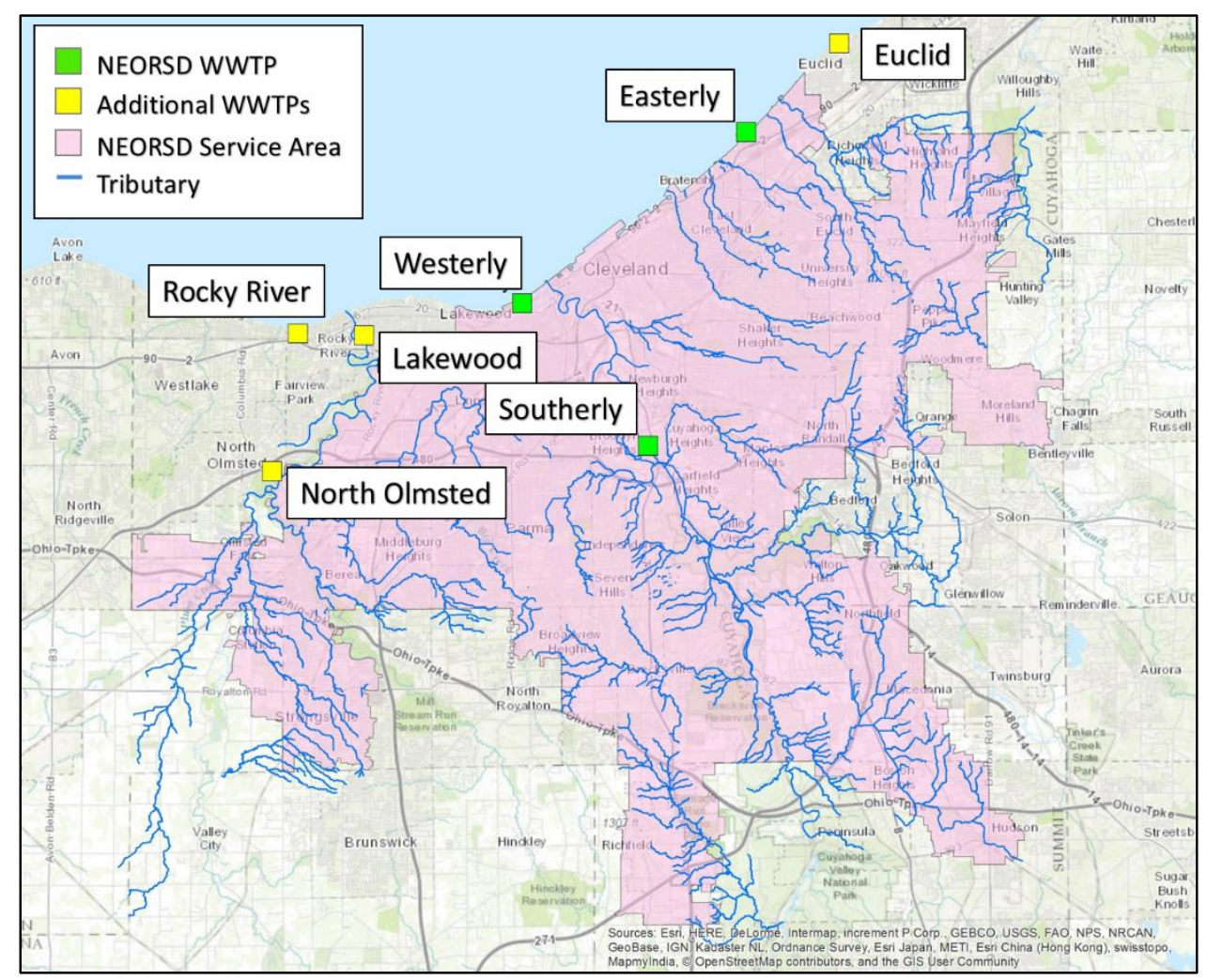

Figure 1-5: The location of WWTPs operated by communities surrounding NEORSD. (Produced in ArcGIS 10.3 by Nathan Zgnilec) 
At the western boundary of NEORSD's service area, the city of Lakewood operates its WWTP, which discharges to Rocky River approximately 1.5 miles upstream of Lake Erie (Ohio EPA 2014). This plant serves over 52,000 residents and has a design discharge of 18 MGD. Similar to NEORSD, Lakewood operates a combined sewerage system which includes 9 discharge locations. Six of these CSOs discharge to Lake Erie and three to the Rocky River.

Upstream from Lakewood and bordering NEORSD, North Olmstead operates a WWTP which discharges to Rocky River 11 miles from its mouth (Ohio EPA 2014). This plant has a design flow of 7 MGD and is fed entirely by a separated sewer system.

Further west, the city of Rocky River operates a WWTP which discharges into Lake Erie (Ohio EPA 2011). This plant has a design flow of 22 MGD which is entirely fed by a separated sewer system.

On the eastern boundary of NEORSD, the town of Euclid handles local waste services which discharge to Lake Erie (Ohio EPA 2009). This plant has a design flow of 22 MGD and is primarily fed by a separated sewer system and a small portion of combined sewers, which include 17 discharge locations. To mitigate the impacts of its separate and combined sewer overflows during wet weather flows, Euclid constructed a Wet Weather Auxiliary Treatment Facility in 1994. This facility provides partial treatment of the excess flow prior to its discharge to Lake Erie. 


\section{Description of Local System}

For northeast Ohio, the Cuyahoga River serves as one of the largest tributaries, discharging to Lake Erie, in downtown Cleveland (Figure 1-6). Discharging to Lake Erie's central basin, the Cuyahoga River is a leading contributor to frequent hypoxia experienced in the basin and lake-wide nutrient loads which have been responsible for outbreaks of harmful algae in the lake's western basin (U.S. EPA 2015). Its watershed drains 812 square miles located across six counties (U.S. EPA 2015). From its headwaters, the Cuyahoga River travels 85 miles through Akron, Kent, Cuyahoga Falls and, lastly, Cleveland. The Cuyahoga River received national publicity in the $20^{\text {th }}$ century as toxic, industrial discharges resulted in multiple fires on its surface (James Thomas 2015). The last of these fires occurred in 1969 and the river has since experienced a drastic improvement in water quality and is now home to the Cuyahoga Valley National Park. However, as it nears the city of Cleveland, it receives an abundance of urban runoff and municipal discharges (Ohio EPA, Division of Surface Water 2003). The Cuyahoga River enters the NEORSD service area approximately 25 miles upstream, where it begins to receive discharges from a variety of NEORSD operations. Treated effluent and untreated bypass from the Southerly WWTP discharge 11 miles upstream. Below this point, 27 CSOs discharge to the Cuyahoga River. In addition, three tributaries discharge into the Cuyahoga: Mill Creek, West Creek and Big Creek. With their watersheds entirely within NEORSD, each of these tributaries contribute to the cumulative water quality issues of the Cuyahoga River through urban runoff, CSOs and failing infrastructure (Ohio EPA, Division of Surface Water 2003). 


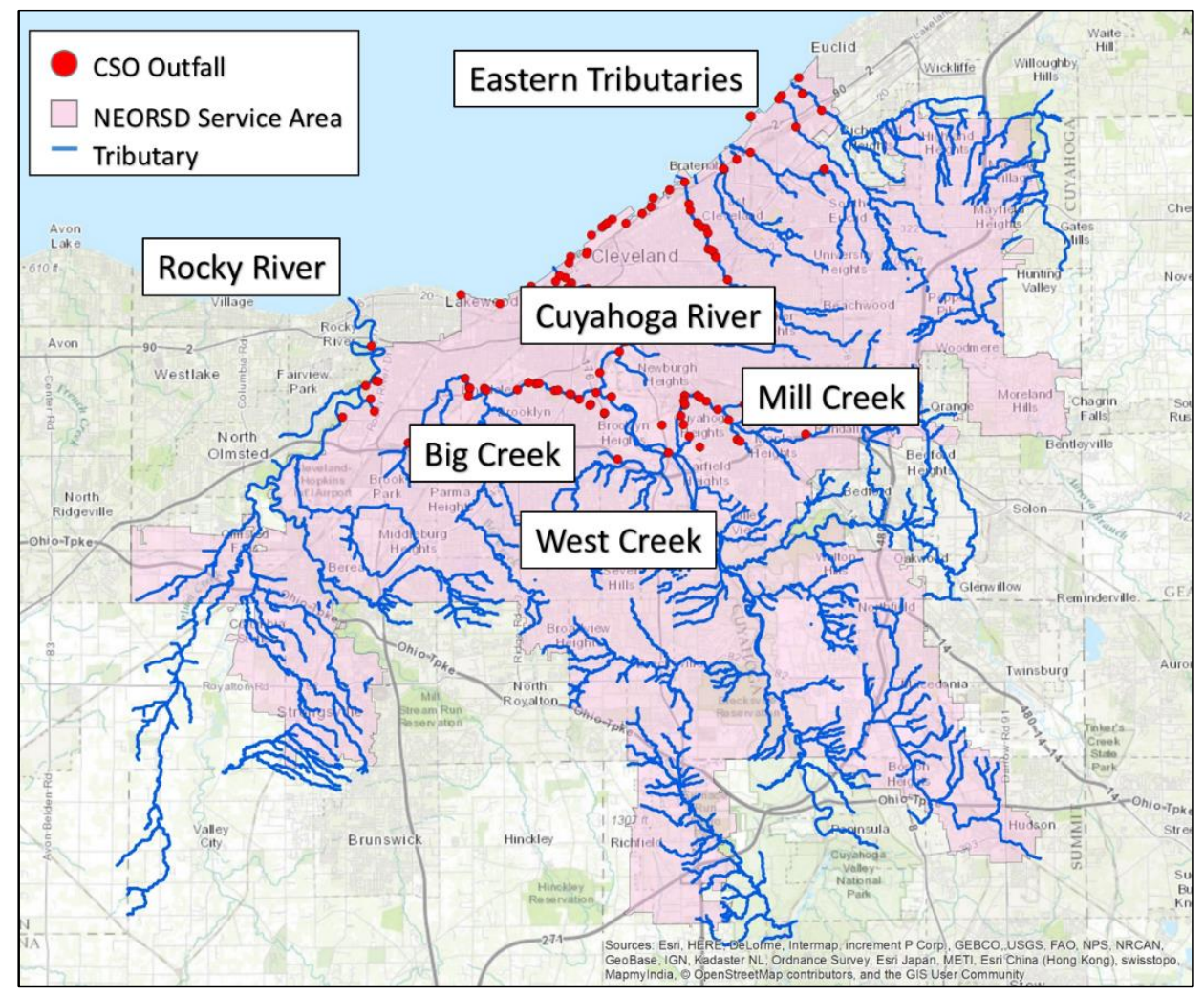

Figure 1-6: Tributaries within NEORSD's service area.

(Produced in ArcGIS 10.3 by Nathan Zgnilec)

Mill Creek enters the Cuyahoga River from the east, 11.5 miles upstream of Lake Erie, near the Southerly WWTP (Figure 1-6) (Ohio EPA, Division of Surface Water 2003). The creek is fed by a 20 square mile watershed which is heavily urbanized (NEORSD 2016). Mill Creek is impacted by CSOs, SSOs, and exposed landfills among other inputs. In 2008, NEORSD completed a large scale storage tunnel which captures flow from surrounding combined sewers and stores it for later treatment (United States District Court 2010). An estimated 500 million gallons of CSO discharges are stored by the tunnel and treated each year. Since the tunnel went into operation, Mill Creek has experienced a significant 
improvement in water quality. A study performed by NEORSD in 2015 revealed Mill Creek had reached its cleanest state in the last 20 years (McCarty 2015).

West Creek is located to the west and has its confluence with the Cuyahoga River 11 miles upstream of Lake Erie (Figure 1-6) (Ohio EPA, Division of Surface Water 2003). It is fed by a 14 square mile watershed. Unlike most of the NEORSD tributaries, West Creek receives discharge from only one CSO. Instead, dual manhole, separated sewers and septic systems serve as the main method for handling local sanitary flow and storm water.

Big Creek, the largest of the three streams discharging to the Cuyahoga River, enters the Cuyahoga River 7 miles upstream of Lake Erie (Figure 1-6) (Ohio EPA, Division of Surface Water 2003). It has a 37 square mile watershed feeding its 38 mile channel. Seventeen CSOs discharge into Big Creek, with the majority being located in its downstream river miles In addition to CSOs, Big Creek is impacted by a deteriorating sewer system which includes sanitary sewer overflows (SSO) and septic systems.

The Rocky River is the second largest tributary in the Cleveland area and forms the western boundary of NEORSD's service area (Figure 1-6). Rocky River has a watershed of 290 square miles which feeds its 56 mile channel. In its upstream waters, the Rocky River is split into an east and west branch. Both of these branches are surrounded predominantly by agriculture and woodsland. Following the confluence of the east and west branches, Rocky River travels for 12 miles and passes through North Olmsted and Lakewood. Both of these communities operate WWTPs which discharge into the Rocky River and 
Lakewood is responsible for three CSOs which discharge into Rocky River. Near its mouth, Rocky River receives discharges from seven CSOs operated by NEORSD.

The eastern portion of NEORSD is home to Euclid Creek and several smaller tributaries (Figure 1-7). Forming the eastern boundary of NEORSD, Euclid Creek drains a 23 square mile watershed through 48 miles of river channels (Ohio EPA, Divison of Surface Water 2005). The land which drains to Euclid Creek is heavily developed and receives discharges from three CSOs operated by NEORSD and numerous septic systems (Ohio EPA, Divison of Surface Water 2005).



Figure 1-7: Eastern tributaries and local CSOs.

(Produced in ArcGIS 10.3 by Nathan Zgnilec) 
A collection of small tributaries is located between the Cuyahoga River and Euclid Creek, along the Lake Erie shoreline (Figure 1-7). Referred to here as the Eastern Tributaries, five streams collectively drain 45 square miles of a heavily urbanized land along the Lake Erie shoreline. From west to east, these tributaries are Doan Brook, Dugway Brook, Shaw Brook, Ninemile Brook and Green Creek. Many of these tributaries have been altered to behave more as ditches for transporting wet weather flows than as natural waterways. Apart from Doan Brook, these eastern tributaries receive discharges from a total of seven CSOs. Doan Brook receives discharges from 15 CSOs, the most of any eastern tributary.

In addition to the 106 CSOs discharging to tributaries, 20 discharge directly to Lake Erie. These CSOs span the entire Lake Erie shoreline of NEORSD and many of them are located near local public beaches (Figure 1-8). Two beaches, Edgewater and Euclid, lie within the heart of the CSO service area (United States District Court 2010). As a result, these beaches often experience high levels of E.coli, creating potentially harmful conditions for beach goers. In recent years, NEORSD has monitored these beaches daily during the recreation season (May-October) and has found that conditions deemed unsafe for swimmers (E. coli $\geq 235 \mathrm{CFU} / 100 \mathrm{~mL}$ ) have occurred on up to 50 days per season. 


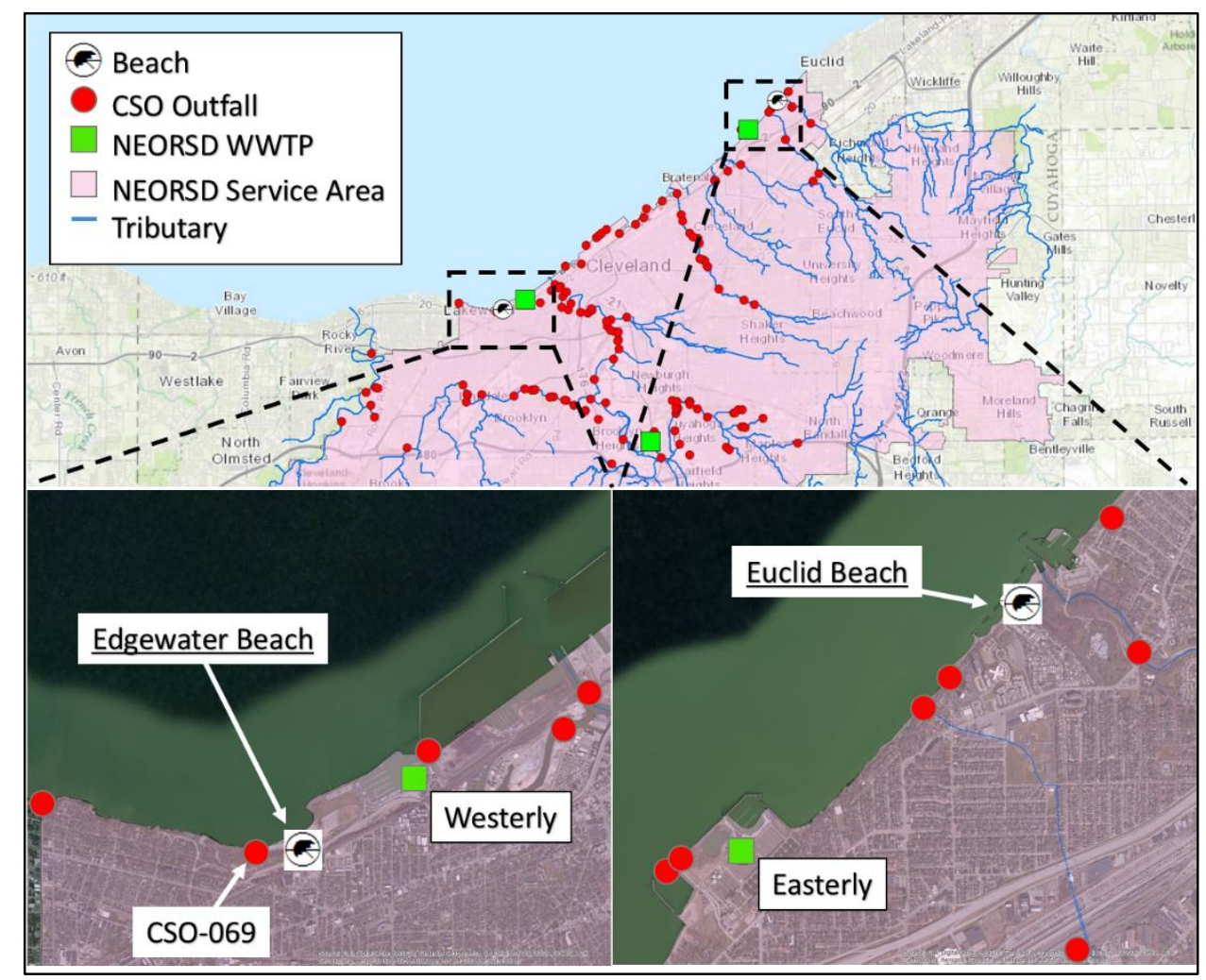

Figure 1-8: Edgewater Beach and Euclid Beach relative to local inputs. (Produced in ArcGIS 10.3 by Nathan Zgnilec)

Edgewater Beach is located in downtown Cleveland, slightly west of the Cuyahoga River mouth (Figure 1-8). It features 6,000 feet of Lake Erie shoreline. During times of rainfall, Edgewater Beach can be impacted by several immediate discharges, e.g. CSOs, Westerly WWTP Bypass and the Cuyahoga River. Several CSOs lie within close proximity to the beach, especially CSO-069. This is one of NEORSD's largest CSOs and discharges overland 1,000 feet from Edgewater Beach. In addition, the Westerly WWTP is located to the east of Edgewater Beach and contributes discharges from its treated effluent and, during wet weather periods, from its untreated bypass. 
Euclid Beach lies on the northeast shoreline of NEORSD in the town of Euclid (Figure 18). Here, the eastern tributaries, along with their CSOs, and the Easterly WWTP discharge to nearshore waters. Historically, Euclid Beach was a part of the Euclid Beach Amusement Park, one of Cleveland's largest attractions. In 1969, the year of the last Cuyahoga River fire, the amusement park was closed. Today, Euclid Beach is a local attraction for beachgoers and anglers.

While exceedances of the safe swimming standard (i.e. single daily sample of $235 \mathrm{CFU}$ or greater) receive much attention today, it is a topic that has shadowed the city for the past century. In 1912, Daniel D. Jackson reported beach closings due to elevated E.coli levels resulting from raw sewage discharges (Jackson 1912). Similarly, a 1949 E.coli survey reported elevated E.coli levels at several Cleveland beaches during periods of rainfall (Delos 1950). Today, the condition of Cleveland's and Ohio's beaches continues to suffer, as demonstrated by Ohio ranking the worst in beach water quality of any coastal state in 2013 (National Resources Defense Council 2014). The impacts from CSOs on bathing beaches is one of the many growing concerns surrounding NEORSD's sewer system. 
Since its inception, NEORSD has continued to expand its three WWTPs and implemented additional services to address the growing demands on its system. The three WWTPs now have the ability to handle over 200 MGD and five interceptor sewers were constructed throughout the service area, from 1911 to 2005, to assist in transporting sanitary sewage to WWTPs and reduce CSO discharges (NEORSD 2008). Additionally, a large-scale storage tunnel was completed in 2008, near Mill Creek, to provide temporary storage of up to 75 million gallons of sewage during wet weather periods, reducing CSO discharges in the Mill Creek watershed. While NEORSD has invested over \$2 billion in these facility and collection system improvements and nearly $\$ 1$ billion to reduce CSO discharges by $50 \%$, local waters have continued to experience high levels of potentially harmful pollutants (United States District Court 2010).

Today, nearly four decades after the establishment of NEORSD, Cleveland continues to face challenges in restoring and protecting local waters. Having a historically industrydriven economy, limited economic resources, and outdated sewer infrastructure, the challenge is no longer in establishing awareness to the importance of adequate wastewater treatment but in prioritizing capital investments to meet state and federal requirements, with limited financial ability. Shortcomings in meeting these challenges has led to growing conflicts between NEORSD and regulators, placing further pressure on NEORSD to mitigate its outdated means for handling raw sewage. 


\section{Water Quality Management}

\section{$\underline{\text { Regulatory Context }}$}

Since passage of the Clean Water Act in 1972, state and federal agencies have imposed regulatory requirements aimed at achieving water quality conditions deemed safe for fishing and swimming (U.S. EPA 1972). In this time, select pollutants have received considerable attention within the Great Lakes basin due to their high levels of discharge and impact on receiving waters.

A report written by Aubrey Scott, PhD. Candidate at Michigan Technological University, provides an in-depth review of Ohio's current and future standards regarding Escherichia coli, ammonia-nitrogen and total phosphorus (Table 1-1). In brief, Ohio's standards relating to NEORSD consider the water quality of tributaries and Lake Erie, in a nearshore (i.e. beaches) to offshore (whole lake) perspective.

Due to difficulties in assessing in-situ levels of pathogens in receiving waters, Escherichia coli $(E$. coli) is often used as an indicator organism, as it can be associated with warmblooded animals (U. S. Environmental Protection Agency 2000). For systems served by combined sewers, high levels of fecal indicator organisms are often present following rainfall or snowmelt events (McLellan 2007). This creates a public health risk, as they may carry pathogens and disease causing organisms. The State of Ohio has established standards for protecting users of recreational waters, including beaches, based on E. coli levels. Currently, the Ohio Department of Health is monitoring beach E. coli levels daily along the Cleveland waterfront of Lake Erie. Counts greater than of $235 \mathrm{CFU} / 100 \mathrm{~mL}$ are 
considered too high for safe, recreational use and are noted as an exceedance (U.S. EPA 2012).

Phosphorus and ammonia nitrogen are pollutants of concern in the Great Lakes Region, the latter especially so in areas served by combined sewer systems. Phosphorus has the potential to promote eutrophication and the attendant nuisance growth of algae. Ammonia nitrogen, at certain levels of $\mathrm{pH}$ and temperature, can create toxic conditions in receiving waters, resulting in chronic and acute impacts on aquatic life. The State of Ohio has established standards for managing these pollutants to avoid the aforementioned conditions. Both of these pollutants are associated with the discharge of treated and untreated sewage. As a result, WWTPs have strict limitations imposed on their effluents and other discharges. For municipal wastewater treatment facilities, similar to NEORSD, effluents are monitored for levels of total phosphorus and ammonia-nitrogen. 
Table 1-1: Standards for pollutants of concern within NEORSD (A. Scott 2015)

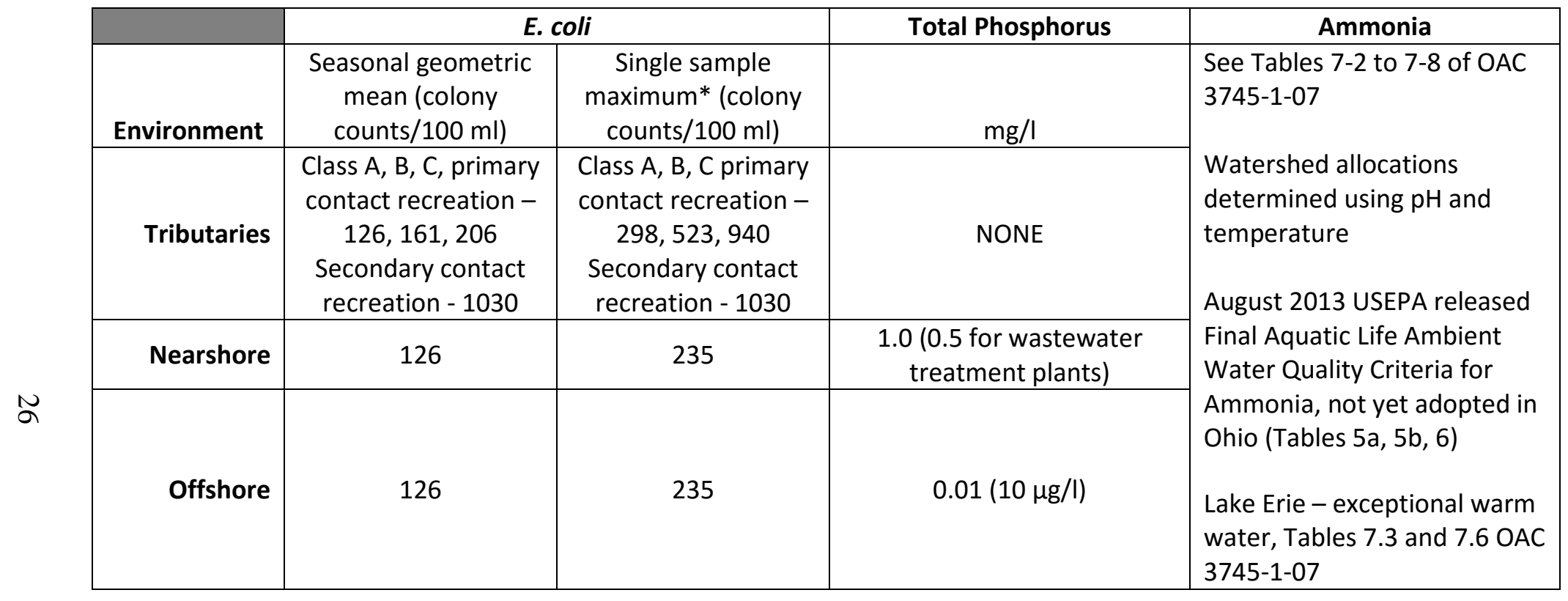


Assuming responsibility for the operation and maintenance of three WWTPs and over 2,000 miles of combined and separated sewers, the aforementioned standards have serious implications for NEORSD's day to day operations. With growing concerns surrounding eutrophication in Lake Erie, as discussed in the 2015 Recommended Phosphorus Loading Targets for Lake Erie, (U.S. EPA 2015) and the 2013 release of U.S. EPA's Final Aquatic Life Ambient Water Quality Criteria for Ammonia, calling for stricter regulations, it may be anticipated that these three pollutants of concern will remain of interest well into the future. As a result, it is desirable for NEORSD to evaluate the present standing of its operations in regards to current and future regulatory standards.

\section{Consent Decree}

In 2010, the U.S. EPA and the Ohio EPA determined NEORSD had violated Section 301(a) of the Clean Water Act through its discharge of pollutants at CSO outfalls and through wastewater flows bypassing primary and/or secondary treatment (Consent Decree, 2012). NEORSD denied any liability.

Shortly after these allegations were made, the parties agreed to enter into a consent decree, i.e. a non-negotiable agreement. Intended to place NEORSD in full compliance with the CWA, the Consent Decree required the control of $98 \%$ of current annual CSO volume through WWTP improvements and construction of seven largescale tunnels for capture, storage and subsequent treatment of CSO discharges (Figure 1-9). 


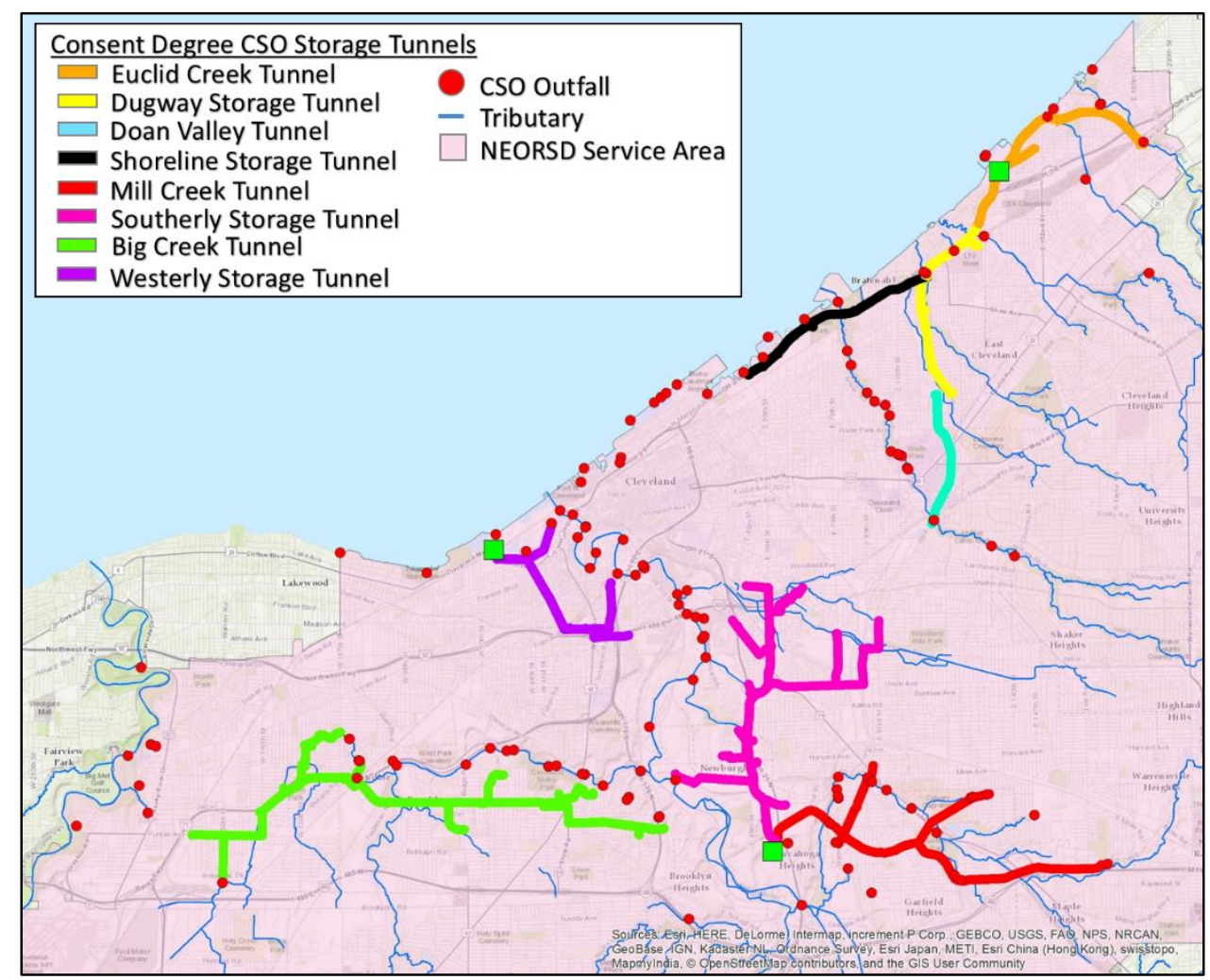

Figure 1-9: Location of the seven storage tunnels, as required by the Consent Decree. (Produced in ArcGIS 10.3 by Nathan Zgnilec)

In addition to meeting the requirements of the Consent Decree, NEORSD had previously committed to non-CSO related projects outlined in their Capital Improvement Plan (Consent Decree, 2012). These non-CSO related costs are in addition to those for CSO control measures set by the Consent Decree and are intended to meet non-CSO regulatory requirements mandated by the CWA.

NEORSD estimates that implementation of the CSO control measures agreed upon under the Consent Decree will cost approximately $\$ 3$ billion (2009 dollars) and require a period of 25 years to complete (Consent Decree, 2012). To fund the Consent Decree, NEORSD must increase sewer use rates. However, due to the current financial ability of its 
ratepayers, there are limitations on the magnitude of rate increases. According to the EPA's Financial Capability Assessment, these rate increases will place a 'high burden' on NEORSD's rate payers, creating a substantial financial impact (United States Environmental Protection Agency 2014).

\section{Community Infrastructure Program}

In order for NEORSD to efficiently allocate financial resources for improving its combined and non-combined sewer systems, the Community Infrastructure Program (CIP) was developed. The CIP was constructed using an approach similar to the EPA's Integrated Municipal and Wastewater Planning Framework. Under this approach, NEORSD is utilizing integrated planning to evaluate the environmental benefits which will result from various infrastructure improvements.

The Integrated Municipal Stormwater and Wastewater Planning Framework was released by the EPA in 2012 (U.S. EPA 2012). This framework was developed to provide guidance for municipalities in establishing and implementing integrated plans to ensure they efficiently satisfy requirements of the CWA through infrastructure improvements. For those choosing to take advantage of the Framework, there is the opportunity to more efficiently allocate capital investments and maximize public health and water quality.

As defined in the 2012 report, the intention of the Integrated Planning Framework is to offer municipalities the opportunity to restructure their critical paths to achieving the human health and water quality objectives of the CWA (U.S. EPA 2012). For the Integrated Planning process with respect to NEORSD, water quality refers to conformance to U.S. 
and Ohio EPA water quality standards for pollutants of concern (POC) in tributaries to Lake Erie and in the lake's nearshore and open waters. Achieving these objectives is pursued by "identifying efficiencies in implementing requirements that arise from distinct wastewater and stormwater programs, including how to best prioritize capital investments" (U.S. EPA 2012). Since the most pressing public health and environmental protection issues vary for each municipality, this approach allows them to plan their capital investments in a manner which most effectively satisfies regulatory standards. With Consent Decrees often focusing on individual CWA issues (e.g. CSOs), challenges arise in allocating schedules and capital investments for other CWA obligations. By utilizing the philosophies of integrated planning, NEORSD can better allocate capital investment to achieve the maximum environmental and public health benefits.

To provide direction for the Community Infrastructure Program, NEORSD has identified two primary issues, focused on public health and water quality requirements set by the CWA

1. Basement Flooding: due to sanitary sewer surcharges potentially exposing homeowners to pathogenic organisms, creating a public health concern; and

2. Pollutants of Concern (POCs)

a. E.coli: impacting water quality through the discharge of potentially pathogenic organisms to waters used for contact recreation;

b. ammonia nitrogen: as causing toxic water quality conditions for aquatic life, under certain levels of $\mathrm{pH}$ and temperature; and

c. phosphorus: due to its effects on water quality through stimulating eutrophication. 
In evaluating the consent decree and CIP, NEORSD is considering the benefits to receiving waters and other environmental and public health benefits associated with each infrastructure improvement throughout its 62 communities.

Concerns surrounding the non-CSO pollutant sources focus primarily on the age and deterioration of NEORSD's infrastructure. Common trench and separated trench sewers contain an abundance of cracks. These cracks cause an interaction between stormwater and sanitary pipes. Under wet weather periods, when rainfall is collected in the stormwater system, stormwater escapes through the cracks and enters into the sanitary pipe. The invasion of stormwater into the sanitary system increases the volume of influent to WWTPs and causes consumes unnecessary resources. In other instances, flow can escape the sanitary line and contaminate local groundwater which may enter the stormwater pipe. Since stormwater does not receive disinfection, the sanitary flow that enters the stormwater system results in potentially harmful levels of pollutants being discharged into streams and lakes.

Addressing the interaction between stormwater and sanitary systems will have two primary impacts. First, it will reduce infiltration of stormwater which will lower influent at WWTPs. This will result in increased stormwater discharges entering streams and lakes. Secondly, since the presence of sanitary flow in the stormwater collections will be removed, pollutant levels in discharged stormwater will be reduced. While the quantity of stormwater entering the streams will increase, the overall pollutant levels will be improved. 
Other aspects of the Community Infrastructure Program focus on addressing ILLDs and septic systems. These improvements will focus on incorporating ILLDs and septic systems into the sanitary system. Connecting ILLDs and septic systems to the sanitary system will reduce the presence of pollutants in the environment and increase the volumes of water directed to the WWTPs.

In evaluating the receiving water quality response of the consent decree and CIP a collection of unique scenarios will be simulated,

- baseline/existing conditions, i.e. prior to implementation of the Consent Decree

- full implementation of the consent decree; and

- each CIP improvement separately, following completion of the consent decree.

These scenarios will allow the impacts of the consent decree and CIP improvements to be compared to one another and the existing water quality conditions. Having the ability to form a baseline of the water quality in the Cleveland area will provide a basis from which improvements will be considered. 


\section{Motivation, Objectives and Approach}

Efforts to satisfy the objectives of the consent and CIP evaluation are being pursued by NEORSD, in collaboration with Wade Trim and Michigan Technological University. The overarching goal of this collaboration is to provide NEORSD with estimates of the expected water quality benefits arising from the consent decree and to explore potential non-CSO improvements through the CIP. This knowledge will guide the allocation of capital investments to satisfy CWA obligations, beyond those addressed through the consent decree. These goals will be achieved through a sequence of steps.

Figure 1-10 provides an overview of the steps taken in preparing and implementing the collection of tools developed to assist NEORSD. The initial step in this process will consist of characterizing the existing condition of surface waters surrounding the NEORSD with respect to current and future regulations of POCs. This will include a field sampling program focused on quantifying pollutant concentrations in the absence and presence of rainfall events throughout the recreation season (May-October). As discussed above, the pollutants which will be monitored are E.coli, phosphorus and ammonia nitrogen. Monitoring in tributaries will focus on quantifying pollutant levels prior to impact by NEORSD operations (i.e. upstream) and at their point of discharge to Lake Erie (i.e. downstream). Monitoring in the Lake Erie nearshore will seek to define baseline water quality conditions and track the magnitude and scale of discharges over the course of a rainfall event as they are transported throughout the nearshore and potentially to local beaches. Following the field monitoring, a suite of mathematical models will be utilized to predict improvements to water quality resulting from the $\mathrm{CD}$ and CIP. These models will 
provide predicted hydrologic and water quality conditions in NEORSD's collection system and local tributaries and, subsequently, the fate and transport of pollutants throughout the Lake Erie nearshore. Lastly, a framework will be developed to guide management decisions based on the predicted water quality improvements expected from the consent decree and each CIP improvement.

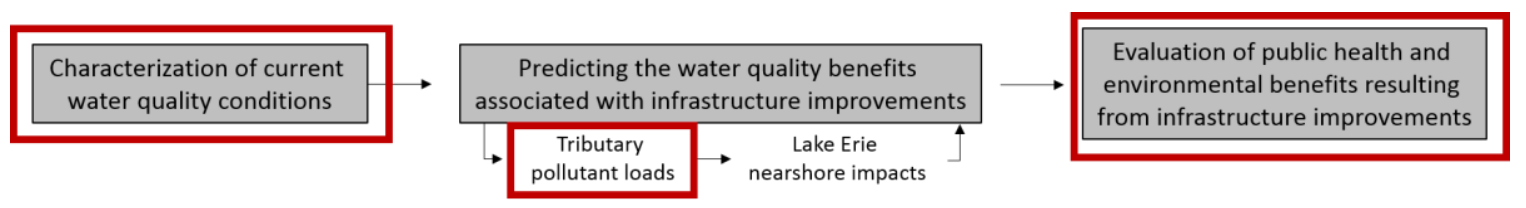

Figure 1-10: Overview of Project Tasks and those discussed in this thesis

The remaining sections in this thesis will provide an overview of the steps discussed above, followed by an in-depth review of the current water quality conditions, the calibration and confirmation of the hydrologic and water quality loading models, and the application of the loading models to assist in the evaluation of infrastructure improvements.

\section{Modeling for Management Support}

To support NEORSD's efforts to efficiently perform infrastructure improvements, Michigan Technological University and Wade Trim Consulting have collaborated to develop a set of tools which allow the water quality and public health benefits to be assessed. These efforts have resulted in the development of several mathematical models and a decision support system. By applying this set of tools, NEORSD has gained the ability to compare the impacts on water quality and benefits to public health resulting from 
their current system, full implementation of the consent decree and improvements to nonCSO related inputs (i.e. the CIP).

The water quality response of the consent decree and CIP is evaluated by applying a suite of mathematical models which quantify tributary POC loads (Collection System Model, CSM; Stormwater Management Model, $P C$-SWMM) and define their transport (Finite Volume Coastal Ocean Model, FVCOM) and fate (General Biological Model, GBM; and Great Lakes Cladophora Model, GLCM) throughout the Lake Erie nearshore. POC loads were calculated using distributed rainfall-based hydrology and POC concentrations measured throughout NEORSD's infrastructure. Water quality models then predict the transport and fate of the POC loads in the tributaries (ammonia-nitrogen) and along the Lake Erie nearshore (E.coli and phosphorus), allowing the impacts on receiving waters to be evaluated for each scenario (Figure 1-11). The POC loading models and the water quality models were calibrated and/or confirmed using a combination of historical measurements and tributary and lake monitoring data collected specifically for this effort.

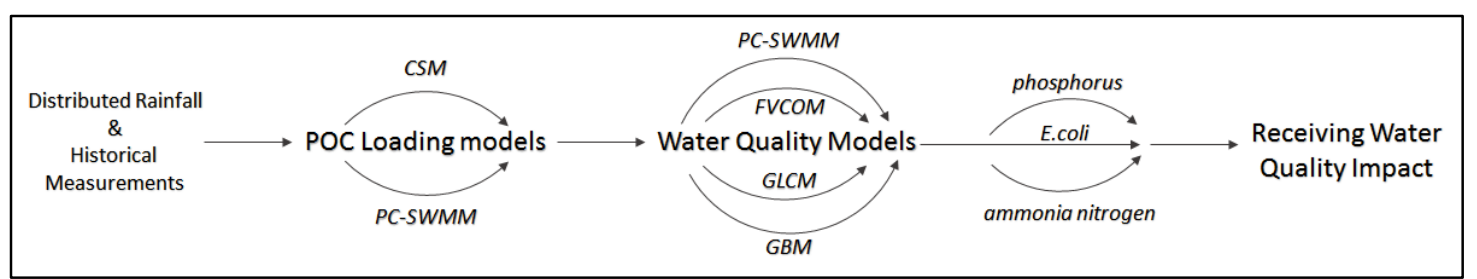

Figure 1-11: Approach taken in modeling the water quality impacts of the Consent

Decree and CIP to guide the allocation of financial resources. 


\section{Evaluation and Decision Support}

Model simulations characterizing water quality impacts associated with the consent decree and CIP require specification of a Representative Period of analysis. A year is selected as being representative of long-term hydrologic conditions and for which meteorological forcing conditions are available for hydrodynamic modeling of Lake Erie. Use of a representative period will provide a basis for evaluating the scenarios under the same hydrologic and environmental conditions.

Water quality impacts for each alternative will be evaluated based on three POC-specific metrics:

1. frequency of violation of regulatory guidelines for ammonia toxicity;

2. number of days with beach postings due to elevated $E$. coli concentrations; and

3. exceedance of phosphorus guidelines for stimulation of nuisance algal growth.

These metrics will then be used within a decision-support framework to value, score and rank infrastructure improvements and compare them to baseline conditions and full implementation of the Consent Decree. Through application of the decision-support system, NEORSD will possess the tools necessary for understanding the benefits resulting from $\mathrm{CSO}$ and non-CSO investments. 


\section{Characterization of Current Water Quality Conditions}

\section{Field Monitoring for Management Support}

As an initial step in undertaking the integrated planning approach, it was necessary to perform a comprehensive survey of current POC levels, for E. coli, ammonia nitrogen and phosphorus, throughout NEORSD. The survey, known as the Integrated Planning Field Monitoring Program, occurred during the beach seasons (May-October) of 2014 and 2015. There were two primary motives for performing this survey. The first was to provide insight on the current water quality conditions throughout NEORSD and the Lake Erie nearshore. This knowledge would characterize baseline, i.e. current, water quality, from which the integrated planning scenarios would be compared. The second was to provide the necessary measurements for the development of POC load and water quality models. These measurements are necessary for establishing confidence in the credibility and reliability of the models to predict the water quality impacts of each integrated planning scenario.

POC levels in local surface waters vary drastically in the absence and presence of rainfall. Since it was desirable to characterize water quality under both conditions, sampling was performed during dry and wet periods. Measurements taken during dry weather periods provided an understanding of POC levels in the absence of CSO discharges and other rainfall related inputs. This allowed low-flow POC concentrations to be observed in tributaries and ambient concentrations in Lake Erie nearshore and offshore waters. In contrast, measurements taken in the presence of rainfall, i.e. wet weather periods, allowed 
the impacts of CSOs and other storm related discharges (e.g. WWTP bypasses) to be quantified.

Conditions for dry-weather sampling required an absence of rainfall and baseline discharges at local tributaries in the days preceding the event. Stream gauges, operated by the United States Geological Survey (USGS), were used for monitoring baseline discharges. Euclid Creek and Mill Creek offer downstream gauges, near their mouths, and the Cuyahoga River and Rocky River have upstream gauges near the NEORSD boundary. Based on historical measurements from these gauges, baseline discharges were considered as those equal to or less than the historical median measurement.

Wet-weather conditions required periods of rainfall resulting in CSO discharges. To identify the rainfall intensity and accumulation needed to trigger wet-weather conditions, an analysis of historical rainfall, CSO discharges and local water quality measurements was performed. Since CSO discharges are directly related to rainfall, a threshold was established which defined wet-weather events based on the intensity and accumulation of rainfall. This required a thorough understanding of the response to rainfall throughout the CSO system. In other words, the amount of rainfall (in/day) required to trigger CSO discharges (MGD) resulting in POC levels in the nearshore. Since the impacts of CSO discharges on beaches are of interest, an underlying goal of the wet-weather criteria was to capture storms which provided a volume of CSO discharges large enough that violations of the Ohio Department of Health's E.coli standard could be expected at Edgewater and Euclid Beaches. 
Sampling stations were located along several tributaries to capture POC loadings, throughout the Lake Erie nearshore to track the transport and fate of POCs, and beach stations, to capture local POC impacts.

Land sampling stations focused on tributaries that receive CSOs discharges and discharges from other NEORSD operations (Figure 2-1). Major tributaries (Cuyahoga River, Rocky River, Big Creek, Mill Creek, West Creek and Euclid Creek) and minor tributaries (Green Creek, Ninemile Creek, Shaw Brook, Dugway Brook and Doan Brook) were sampled at varying frequencies upstream and downstream of NEORSD operations.

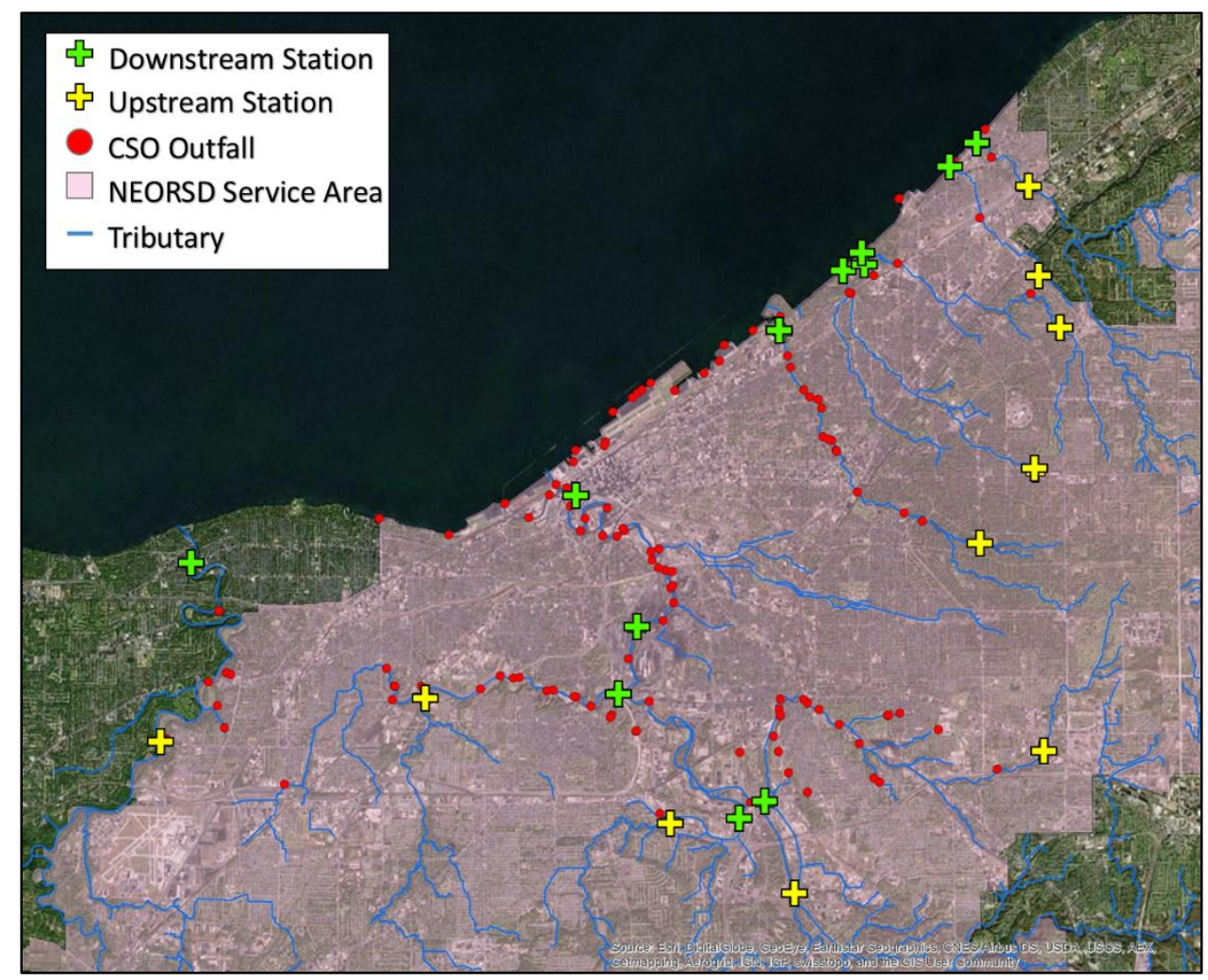

Figure 2-1: Upstream and Downstream sampling stations along local tributaries. (Produced in ArcGIS 10.3 by Nathan Zgnilec) 
Upstream sampling sought to capture water quality conditions prior to influence by NEORSD operations (e.g. WWTP effluent, CSOs). The Cuyahoga River and Rocky River have headwaters beyond NEORSD's service area. To quantify the levels of pollutants entering NEORSD, sampling took place at upstream locations prior to CSO inputs and, when possible, other NEORSD inputs. For tributaries with their entire watershed within the NEORSD, upstream sampling occurred prior to CSO discharges. During dry weather, these stations provided baseline measurements of POCs when the primary contributors of POCs are believed to be ground water, illicit discharges and septic tanks. Upstream wet weather sampling then provided insight on the impacts of storm sewer overflows and local runoff, prior to CSO discharges.

While upstream sampling sought to capture POC levels prior to NEORSD discharges, downstream sampling targeted water quality conditions at the mouth of each tributary following impact by NEORSD operations and other upstream inputs. Downstream sampling allowed the level of pollutants from NEORSD inputs to be quantified. In addition, downstream sampling provided the maximum pollutant loads from the tributaries, immediately prior to their discharge into Lake Erie. Understanding the magnitude of these loads will benefit lake modeling efforts focused on nearshore pollutant levels.

Lake sampling stations were designed to track the transport and fate of POCs across the nearshore (Figure 2-2). Three levels of lake stations were used 1) nearshore-offshore transects, 2) beach clusters, and 3) beaches. Lake transect stations were arranged in a nearshore to offshore fashion with the spacing and frequency of stations determined by reviewing the rate of transport and dimensions of plumes observed in satellite images 
following large rainfall events. Beach cluster stations were assigned near Edgewater and Euclid Beach to provide a means of identifying the source of POCs as they approached and potentially impacted recreation waters surrounding the beaches. Lastly, sampling occurred in waters proximate to the land-water interface at Edgewater and Euclid Beach (Figure 23). Similar to land sampling, lake stations were visited on a daily basis, beginning on the day of the wet-weather event and continuing until the system had returned to baseline POC levels.

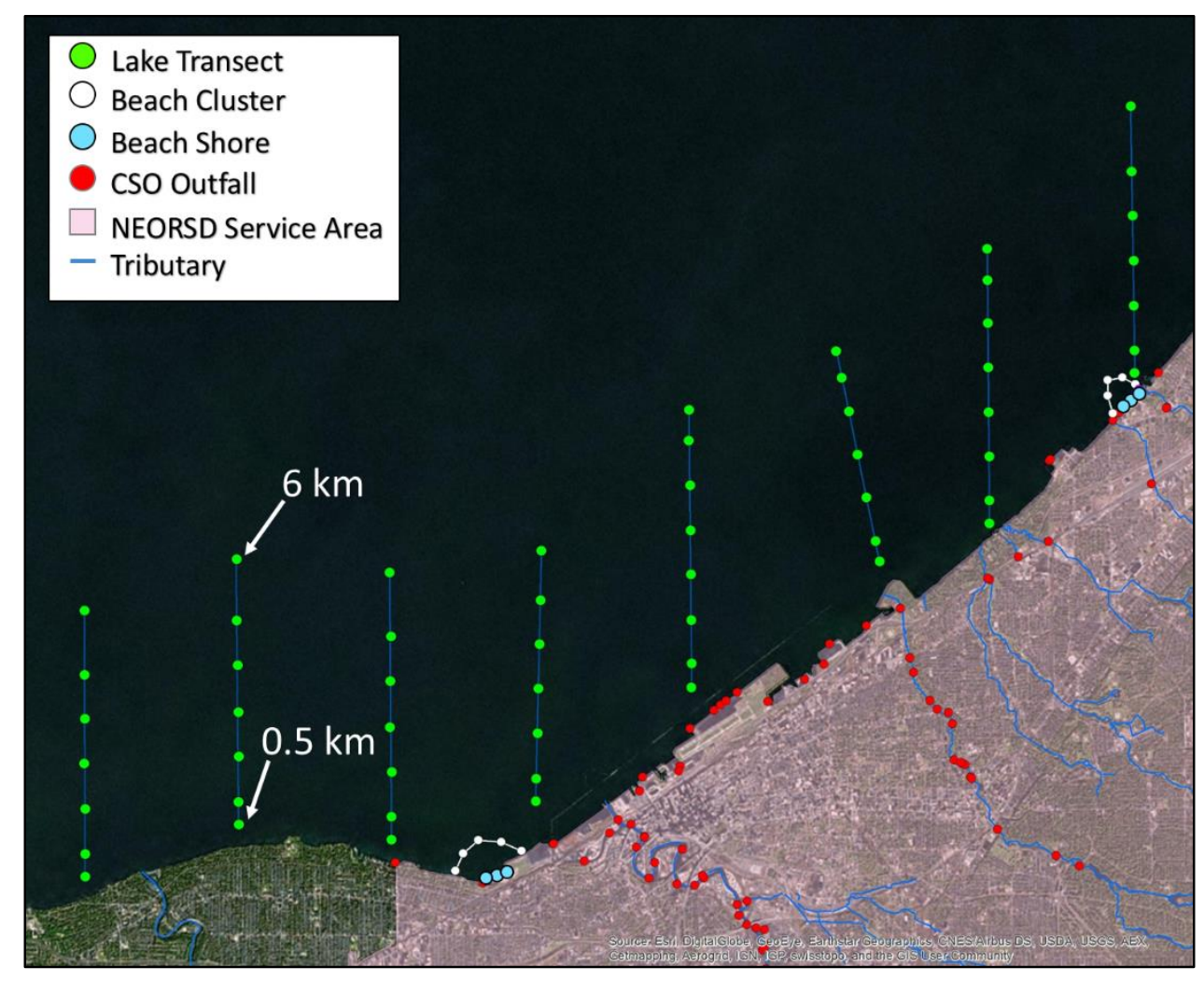

Figure 2-2: Nearshore Lake Erie sampling stations.

(Produced in ArcGIS 10.3 by Nathan Zgnilec) 


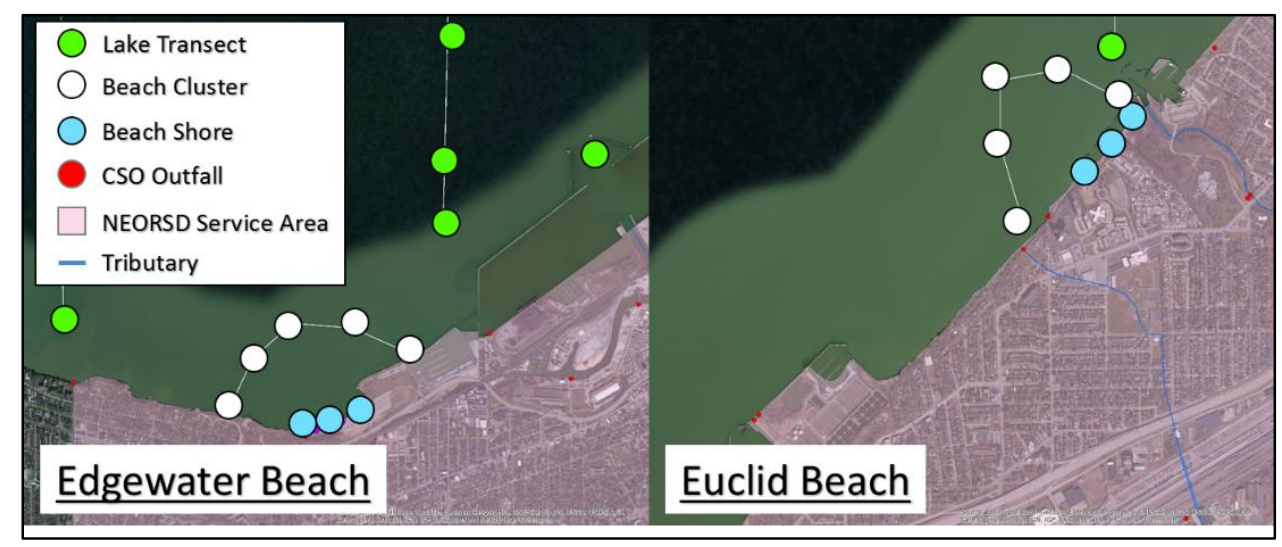

Figure 2-3: Sampling stations near Edgewater Beach and Euclid Beach. (Produced in ArcGIS 10.3 by Nathan Zgnilec)

\section{Timeline of Monitoring Events}

Characterization of the current water quality surrounding NEORSD was performed through the series of field sampling events outlined above. Since NEORSD's system is highly dynamic during periods of rainfall, it was desirable to observe the system under varying conditions (i.e. dry weather and wet weather periods). Sampling occurred during dry weather periods, when the impacts of rainfall were absent. One sampling event occurred during a modest wet weather period and two events took place during significant rainfall events. 


\section{a. Pre-sampling - initial observations and sampling logistics}

To support the development of the Integrated Planning Field Monitoring Program and the understanding of POC levels in Cleveland's surface waters, a pre-sampling trip occurred in June of 2014. Dry weather conditions were well represented by the hydrologic conditions preceding this event.. This trip consisted of sonde measurements (i.e. $\mathrm{pH}$, temperature, conductivity and turbidity) at downstream tributary stations and lake stations at beach clusters and lakeward transects. These measurements provided an initial look at baseline levels of water quality indicators (conductivity, turbidity, temperature and $\mathrm{pH}$ ) throughout the system. In addition, an algae survey was also performed using a remotely operated vehicle. The intention of this survey was to assess the density of attached, filamentous, green algae (Cladophora) and to examine the role of water clarity in limiting the distribution of the algae.

\section{b. Dry-weather sampling}

Dry weather sampling occurred on 25-July, 2014. The days preceding sampling were free of rainfall and tributaries were at baseline flows. Land sampling occurred at all local tributaries at downstream sampling stations. Lake sampling was performed at the 0.5 and $6 \mathrm{~km}$ transect stations. This provided nearshore (within the area impacted by Cleveland) and offshore baseline POC levels. Beach sampling was performed at the cluster stations and along the shore, the latter in three feet of water, to provide insight on the potential for poor water quality conditions in bathing regions in the absence of CSO discharges. 
The second sampling event focused on quantifying tributary POC levels in upstream waters. This sampling was performed on 9-September, 2014 by NEORSD. There was an absence of rainfall in the days preceding the sampling and baseline, dry weather flows were observed throughout NEORSD. This allowed upstream POC levels to be captured during a period when rainfall related discharges were inactive (e.g. CSOs). Since the Cuyahoga River was sampled at an upstream station during the first dry weather sampling event, it was not re-sampled during this event. Due to the underground diversion of Shaw Brook, upstream sampling was not possible. All of the other tributaries were sampled at upstream stations.

\section{c. Wet-weather sampling}

The first rainfall event captured for wet weather sampling occurred on 30-September, 2014. This was a modest storm with total rainfall accumulations of approximately 0.4 inches across NEORSD. Using NEORSD's collection system model, CSO discharges on this day were estimated to be 23 MG. USGS stream gauges showed peak discharges at Euclid Creek, Mill Creek and the Cuyahoga River of 118, 135 and 917 cfs.

The 2015 sampling season commenced on 1-June, consistent with the start of NEORSD's routine beach monitoring programing. On June 27 , an extreme rainfall event, delivering 2.4 inches over a 2-day period occurred across NEORSD, offering the opportunity for monitoring of tributary discharge and POC levels under high flow conditions. Paired measurements of tributary discharges and POC concentrations were made across the area. USGS stream gauges showed peak discharges at Euclid Creek, Mill Creek and the Cuyahoga River of 3,580, 3,150 and 11,900 cfs, the highest discharges of the 2015 beach 
season. Due to the high volume of rainfall occurring over a relatively short period of time, flooding occurred throughout NEORSD.

The second storm captured for wet weather sampling occurred on 9-July, 2015. This event offered significantly more rainfall than the first wet weather event in 2014. Total accumulations averaged 1.0 inches across NEORSD. USGS stream gauges showed peak discharges at Euclid Creek, Mill Creek and the Cuyahoga River of 1,270, 530 and 3,440 cfs. Adjustments had been made to the 2014 sampling regimen for this wet weather event which focused on the location and frequency of stream measurements (e.g. upstream vs. downstream stations and once-daily vs. multi-daily sampling).

\section{Water Quality Monitoring - Lessons Learned}

The following section focuses on selected observations made during the review of field monitoring data. During the 2014 and 2015 field years, distinct behaviors were observed under varying hydrologic conditions throughout the NEORSD system. These behaviors have assisted in the characterization of current water quality conditions: providing insight regarding baseline, dry weather POC levels, system wide response to varying levels of rainfall and attendant wet-weather POC concentrations and the ability of the system to recover from high POC, wet weather events.

\section{a. Dry weather conditions}

Dry weather conditions, i.e. those in the absence of rainfall and subsequent impacts (e.g. CSO discharges), were characterized through land and lake sampling. POC loads within tributaries were observed at locations upstream of CSOs and, when possible, NEORSD 
operations and the most downstream location, immediately prior to discharge into Lake Erie or receiving tributary. Dry weather sampling in the Lake Erie nearshore sought to capture the transport and dilution of tributary loads and to define offshore POC levels, where impacts from NEORSD operations are absent. Using NEORSD's collection of rain gauges throughout the service area, 40 days during the 100 day, 2014 beach season experienced an absence of rainfall. Similarly, considering dry weather tributary discharges, the USGS stream gauge on Euclid Creek showed dry weather flows, i.e. those below the $25^{\text {th }}$ percentile, occurred just over $20 \%$, of the 2014 beach season.

\section{Dry weather upstream vs. downstream tributary comparison:}

Dry weather tributary measurements provided insight to the changes in POC levels between upstream and downstream waters (Figure 2-4). In order to quantify the impacts of NEORSD operations on the total POC loads, it was necessary to understand the magnitude of loads in upstream waters. For each POC, unique behaviors have been identified in upstream and downstream waters. Several tributaries were found to have high upstream POC levels that experienced dilution as their waters traveled through NEORSD.

For tributaries having their entire watersheds within NEORSD's service area (Big Creek, Mill Creek, West Creek and all Eastern Tributaries), E.coli and phosphorus levels in upstream waters were primarily found to be higher than downstream levels. Contributors of E.coli and phosphorus in upstream waters are believed to be the result of failing septic systems and illicit discharges. Dilution of the upstream waters was likely the result of cleaner inputs, such as groundwater inflow, entering the tributaries. Of the eleven tributaries measured, only Ninemile Creek and Green Creek were found to have higher 
levels of E.coli in downstream waters, pointing to downstream inputs having high concentrations of POCs.

Ammonia levels in tributaries lying within NEORSD showed a relationship opposite to that observed of E.coli and phosphorus. Here, ammonia levels were found to be significantly lower in upstream waters. The increasing concentration through NEORSD points to dry weather inputs, downstream, containing high levels of ammonia. However, these inputs are believed to contain low levels of E.coli and phosphorus, due to their contrasting behaviors. Unique to these tributaries, Dugway Brook and Ninemile Creek showed ammonia levels that were highest in downstream waters.

The Eastern Tributaries were found to have consistently higher concentrations, both upstream and downstream, when compared to Rocky River, Cuyahoga River and Mill, West and Big Creeks. The minimal POC levels observed in Mill Creek are likely due to the recently completed Mill Creek tunnel. While it was designed to capture wet weather CSO discharges, it has also reduced dry weather overflows resulting from high volumes of groundwater inflow.

As the largest tributaries within NEORSD, the Cuyahoga River and Rocky River have their headwaters located beyond the extent of the service area. Both of their upstream waters receive inputs from an array non-NEORSD operations which contribute to POC levels entering NEORSD and, ultimately, Lake Erie. Prior to entering NEORSD, the Cuyahoga River travels through Akron, Ohio, where it receives sanitary and stormwater discharges from the local sewer system. In addition, the upstream portions of the Cuyahoga River 
contain runoff from agricultural landuse, further contributing to upstream POC levels. While much of upstream Rocky River remains in its natural state, it travels through suburbs of Cleveland which contribute to its upstream POC levels. As both of these tributaries begin their descents through NEORSD, they receive discharges from smaller tributaries and WWTPs.

The Cuyahoga River was sampled upstream near the USGS gauge at Independence, Ohio, which is located downstream of the NEORSD service area boundary and upstream of the Southerly WWTP. Upstream sampling on Rocky River was performed above NEORSD CSOs and downstream of the service area boundary and the North Olmsted WWTP. At these locations, both tributaries were found to have elevated levels of E.coli and phosphorus, while ammonia levels were minimal. Immediately prior to their discharge into Lake Erie, levels of E.coli and phosphorus were attenuated, when compared to the elevated concentrations entering NEORSD. In contrast, ammonia levels were found to increase as both tributaries traveled through NEORSD. The reduction in E.coli may be due to the discharge of treated WWTP effluents which contain low levels of bacteria. While a reduction in phosphorus was observed in downstream waters, it was relatively minimal when compared to upstream concentrations. Treated WWTP effluents are likely the cause of this minimal reduction, as they typically contain elevated levels of phosphorus. 


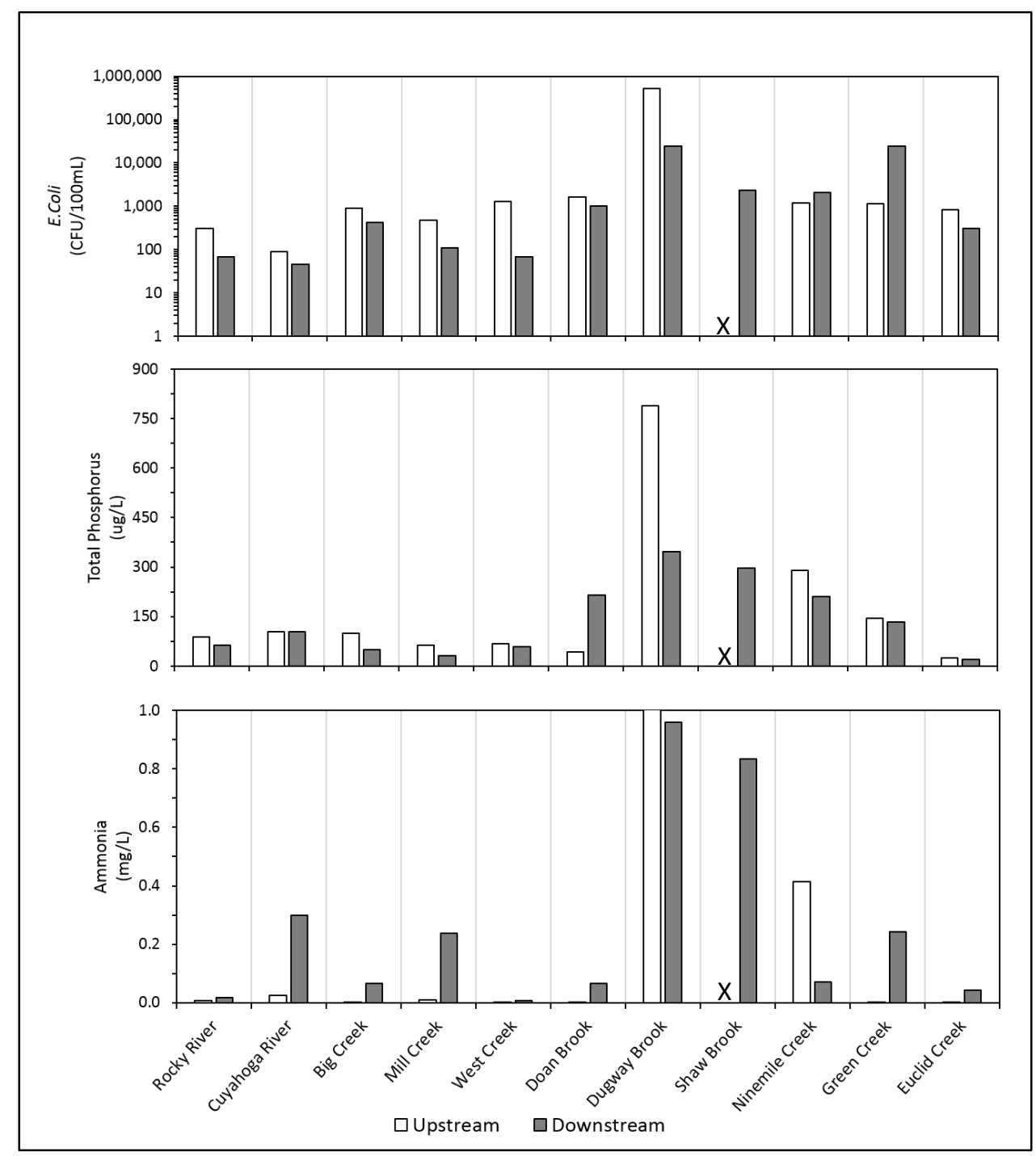

Figure 2-4: Dry weather pollutant levels observed at upstream and downstream tributary stations. 
High concentration vs. low load:

Due to a lack of runoff, tributary discharges are known to be lowest during dry weather periods. At the same time, the dry weather tributary sampling found pollutants to remain elevated. This is believed to be the result of inputs, such as illicit discharges and failing sewers, continuing to deliver high concentrations of POCs, regardless of rainfall. Due to low flows in receiving tributaries, the high levels of POCs from dry weather inputs cannot be diluted by tributary flows, resulting in high dry weather concentrations. While these concentrations may remain elevated during periods of low flow, their pollutant loads, i.e. the product of their flow and pollutant concentration, delivered to the Lake Erie nearshore are minimal. Due to low background concentrations in the nearshore, these loads are quickly diluted by the ambient lake water. This rapid attenuation of dry weather loads moderates the offshore and longshore distances which are impacted.

Results of the dry weather monitoring support the above hypothesis. At stations along the greater Cleveland waterfront, approximately $0.5 \mathrm{~km}$ offshore, dry weather POC levels were found to be similar to levels farther offshore, at $6 \mathrm{~km}$, (Figure 2-5). The similarity in the nearshore and offshore waters indicates that dry weather POC loads are quickly attenuated by nearshore waters.

When considering nearshore POC concentrations to those in the offshore waters, there was relatively little difference. Offshore waters were found to have background E.coli levels of less than $1 \mathrm{CFU}$, aside from a single outlier of $36 \mathrm{CFUs}$. Measurements taken in the nearshore showed E.coli levels as being no greater than 10 CFUs, indicating little impact from POC tributary loads and closely resembling offshore conditions. While nearshore 
phosphorus levels were found to be consistently higher than those in offshore waters, they held an average difference of $5 \frac{\mu g}{L}$. Similarly, ammonia levels in the nearshore were found to be comparable to those in the offshore.

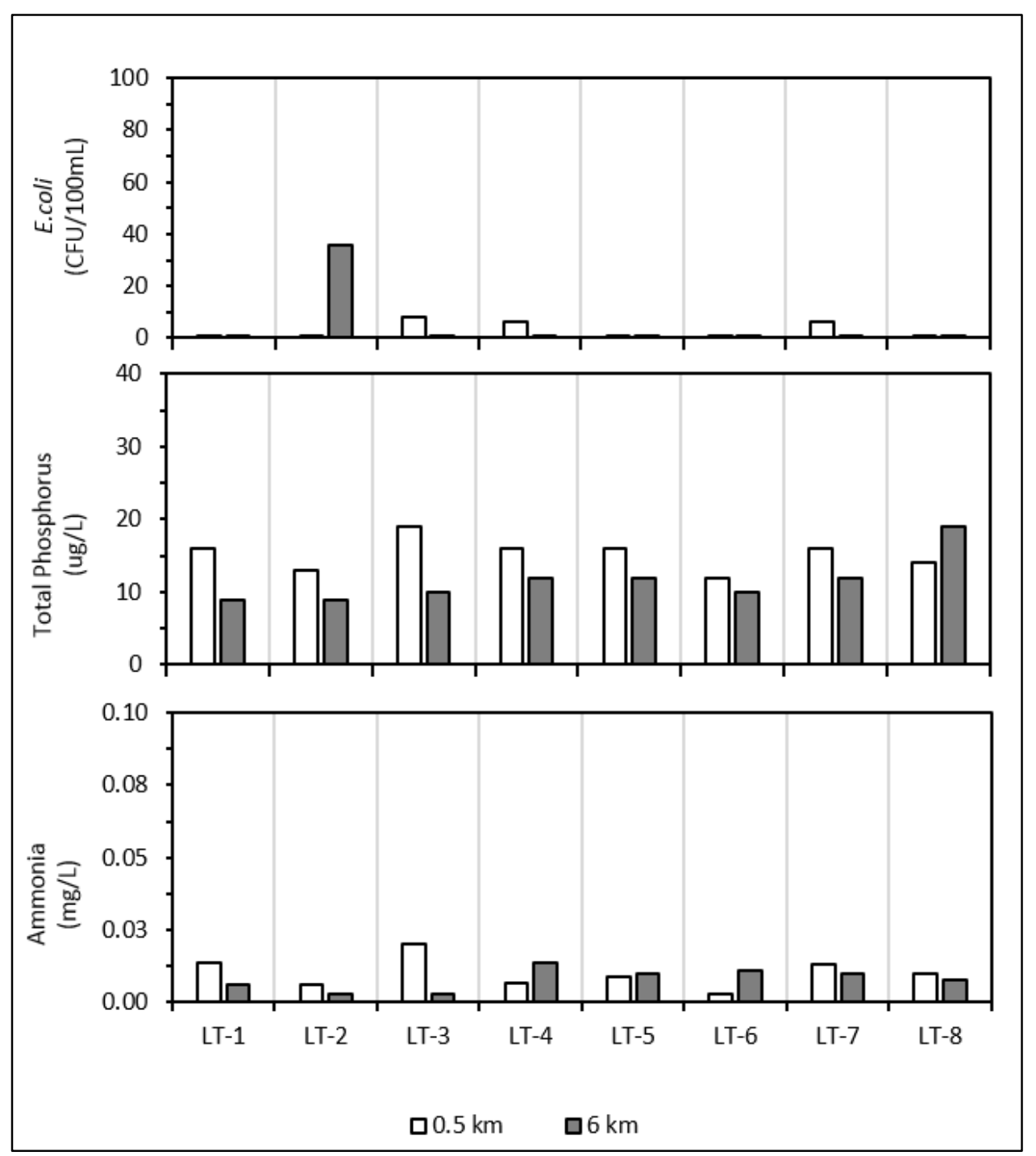

Figure 2-5: Observed dry weather pollutant levels at Lake Erie nearshore $10.5 \mathrm{~km}$ offshore) and offshore (6 km offshore) stations. 
While no substantial differences were found between nearshore and offshore waters, minor impacts from tributary inputs were observed along the nearshore, at the $0.5 \mathrm{~km}$ stations, (Figure 2-6). The three POCs behaved consistently across the nearshore, having high and low concentrations at equal locations. When considering the location of tributary discharges and the high nearshore concentrations, a relationship can be made. All POCs showed elevated nearshore levels at the station immediately west of the Cuyahoga River mouth. Phosphorus was found to be highest at this location, with a concentration of $19 \frac{\mu g}{L}$. The high level of phosphorus observed may be associated to the Southerly WWTP's large volume of effluent discharging 11 miles upstream. Ammonia was also found to be highest here, with a concentration of $0.02 \mathrm{mg} / \mathrm{L}$, over twice the nearshore average. To the east, near Euclid Creek and the Eastern tributaries, a slight increase in POC levels was observed. Here, the increase could be the results of the Eastern Tributaries delivering an accumulation of POC loads or impacts from the Easterly WWTP.

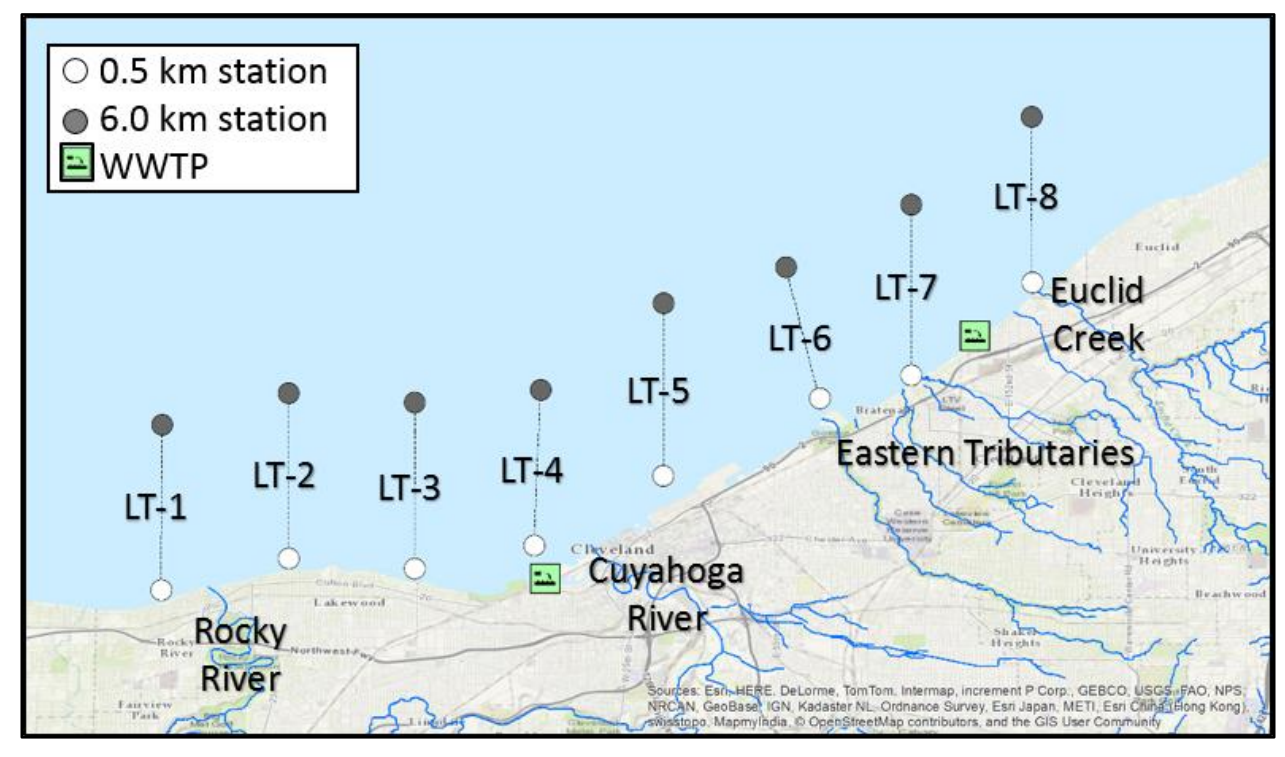

Figure 2-6: Lake transect stations relative to tributaries discharge points. 


\section{Dry weather beach $E$. coli concentrations:}

On a finer scale, beach sampling was performed along Edgewater and Euclid Beaches in approximately three feet of water. Since $E$. coli is the primary pollutant of concern for beaches, ammonia and phosphorus were not sampled. Consistent with observations made in the nearshore, E. coli levels were found to be minimal at the beaches and far below the Ohio Department of Health's standard of 235 CFU/100mL, (Figure 2-7). However, E. coli levels on this day far exceeded nearshore levels, which were all below $10 \mathrm{CFU} / 100 \mathrm{~mL}$. Two preliminary conclusions can be made from this observation.

First, there are dry weather impacts on the beaches which are not associated with rainfall. Possible sources for the elevated dry weather E. coli at beaches include excretion from birds and other animals and re-suspension of E. coli harboring sediments (U.S. Geological Survey 1998). Second, these dry weather impacts are quickly manifested by nearshore waters, explaining why they were not observed at the $0.5 \mathrm{~km}$ stations.

While measurements on this day showed levels of E. coli at Edgewater and Euclid Beaches which did not exceed the safe swimming standard, it cannot be ruled out that beaches can be considered safe for users during all dry weather periods. Previous monitoring by NEORSD found that E. coli levels which exceed the Ohio Department of Health's standards of 235 occur often during dry weather periods. The presence of $E$. coli in the absence of rainfall further complicates the manner in which E. coli can be transported there. 


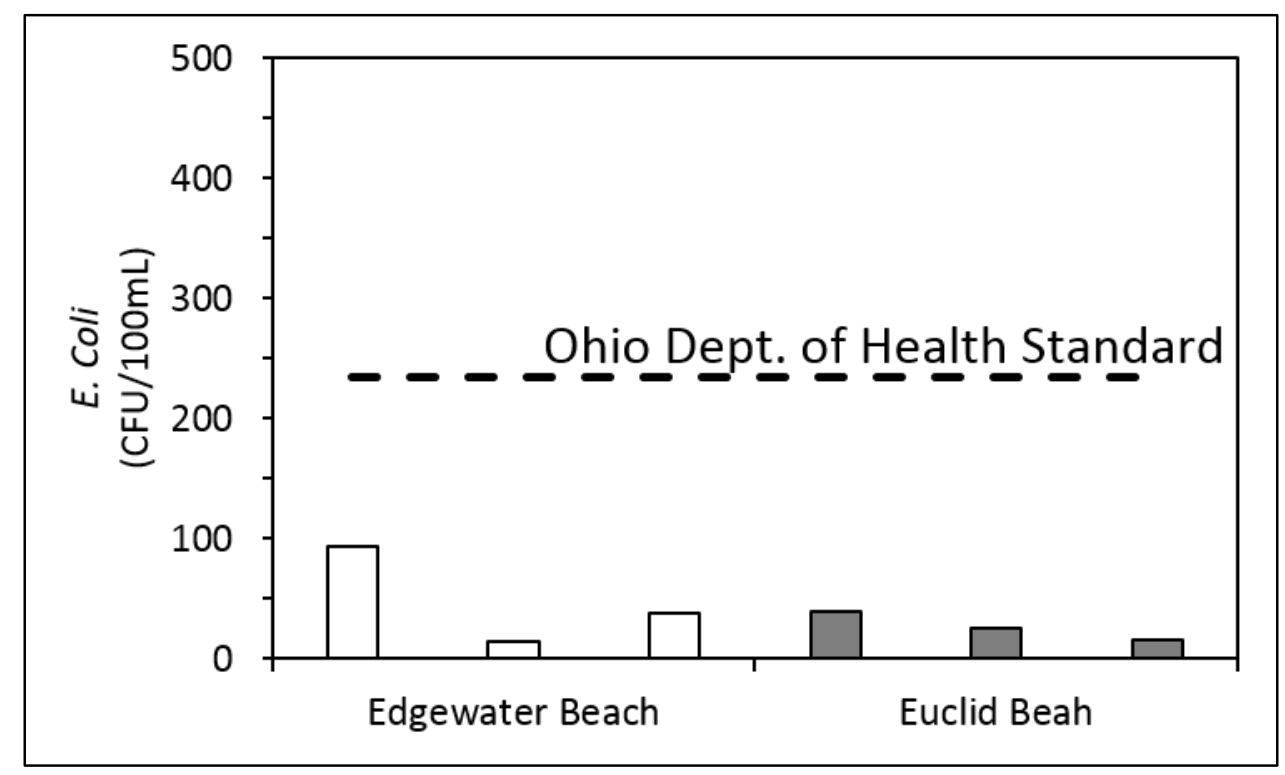

Figure 2-7: Observed pollutant levels at Edgewater Beach and Euclid Beach during dry weather sampling.

\section{$\underline{\text { b.Wet weather conditions }}$}

Observations of wet weather conditions, i.e. those in the presence of rainfall, were necessary to define rainfall related POC levels and aide in the development of POC load and water quality models. The impacts of CSO discharges, rainfall runoff, WWTP bypasses, and other related discharges all contribute to tributary POC levels during the presence of rainfall. To assist model development, interest lied in observing the initial hydrological and water quality response to rainfall in tributaries. Peak levels of both were sought, followed by the recovery of flow and POC levels as the rainfall subsided. Upon discharge to Lake Erie, tributary POC loads are consumed by ambient lake water through mass transport and dilution. However, within this process, POC loads create the potential for high pollutant levels in nearshore waters, resulting in environmental and public health 
concerns. To monitor nearshore POC levels, the eight lake transects were monitored at distances close to shore, beginning on the day of rainfall and continuing until baseline POC conditions were achieved. As POC levels throughout the nearshore pose a threat to shoreline conditions, Euclid and Edgewater Beaches were monitored at beach cluster and shallow water stations. These stations allowed pollutants to be tracked as they approached and ultimately impacted beach water quality.

Two wet weather events were monitored for the Integrated Planning Field Monitoring Program. The first event occurred in September, 2014 and resulted in modest rainfall accumulation. The second, in July of 2015, was significantly larger. The drastic difference in rainfall between those two storms resulted in varying degrees of hydrologic and water quality conditions in tributaries and the Lake Erie nearshore.

\section{Water quality response to rainfall events}

The NEORSD system has been found to respond almost instantaneously to rainfall events. Being heavily urbanized, the city of Cleveland and surrounding communities deliver high volumes of rainfall runoff to sewer systems and inner-city tributaries. NEORSD's collection system responds shortly after rainfall begins, by delivering system overflows to tributaries and Lake Erie. High levels of pollutants are introduced into the environment through these overflows. Following the response throughout the collection system, upstream rainfall runoff begins to increase tributary flows. While upstream runoff may introduce lower levels of pollutants into tributaries, the resulting high flows produce large pollutant loads. 
For the 2014 wet weather event, Storm 1, paired measurements of flow and pollutant levels on Euclid Creek display this rapid response to rainfall (Figure 2-8). On this day, rainfall began at 7:00 AM and continued for 3 hours. Total accumulations in this period totaled 0.4" across NEORSD. By 8 AM, USGS flow measurements on Euclid Creek began to show flows increasing from their baseline of 9 cfs. Less than 4 hours later, the flow had peaked at $112 \mathrm{cfs}$ and began to return to its pre-storm flow.

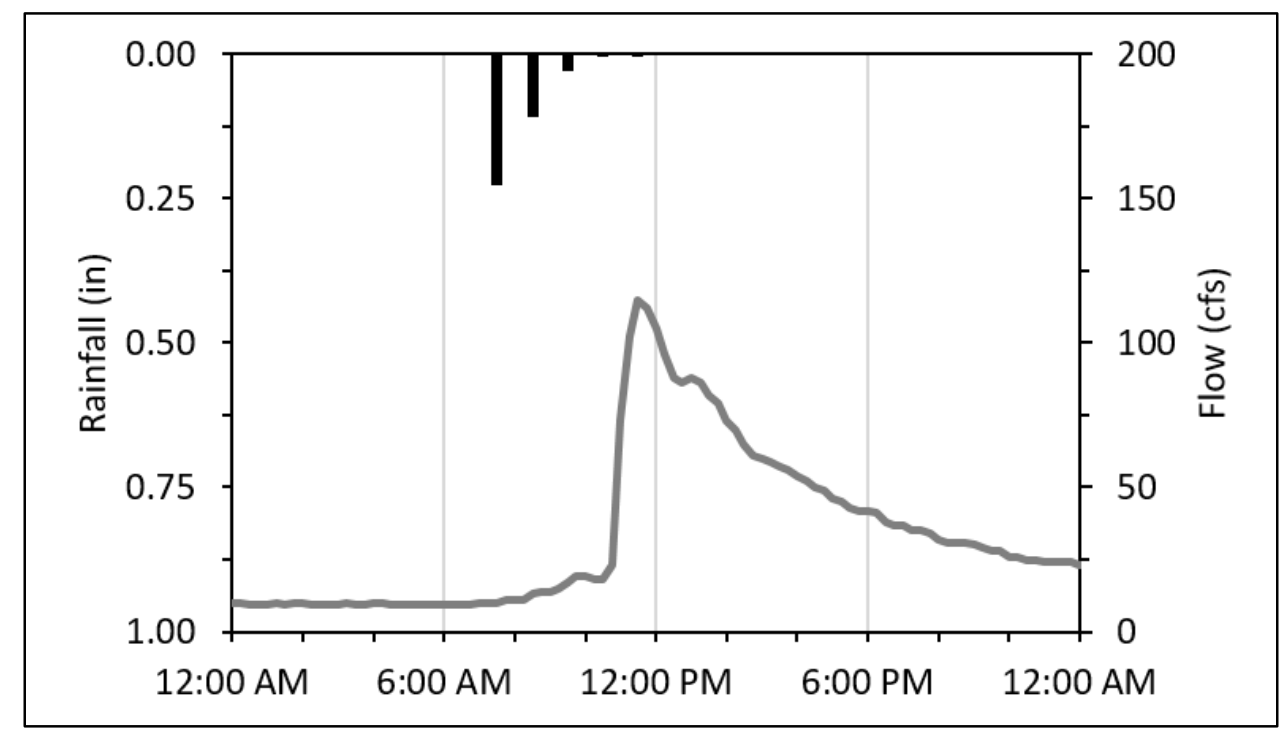

Figure 2-8: Hydrologic response of Euclid Creek following Storm 1 rainfall on

September 30, 2014. 
Similar to the hydrologic response, water quality measurements showed POC levels to increase rapidly (Figure 2-9). Sampling on the day of Storm 1 occurred at 15 minute intervals beginning at 9:45 $\mathrm{AM}$ and continued to 2:15 PM. The initial POC measurements showed steady concentrations, higher than those observed in dry weather sampling. Consistent with the hydrologic response, POC levels soon began to increase, reaching their peak at 11:30 AM. E. coli concentrations began at 3,000 CFUs and increased to 24,000 CFUs in 30 minutes. In a similar manner, total phosphorus levels more than doubled, from 40 to $92 \mathrm{mg} / \mathrm{L}$, and ammonia tripled, from 0.3 to $1 \mathrm{mg} / \mathrm{L}$. While high frequency sampling was not performed on other eastern tributaries, the behavior observed in Euclid Creek would be expected in tributaries sharing its location, surrounding land use, and proximity to NEORSD's sewer system. 


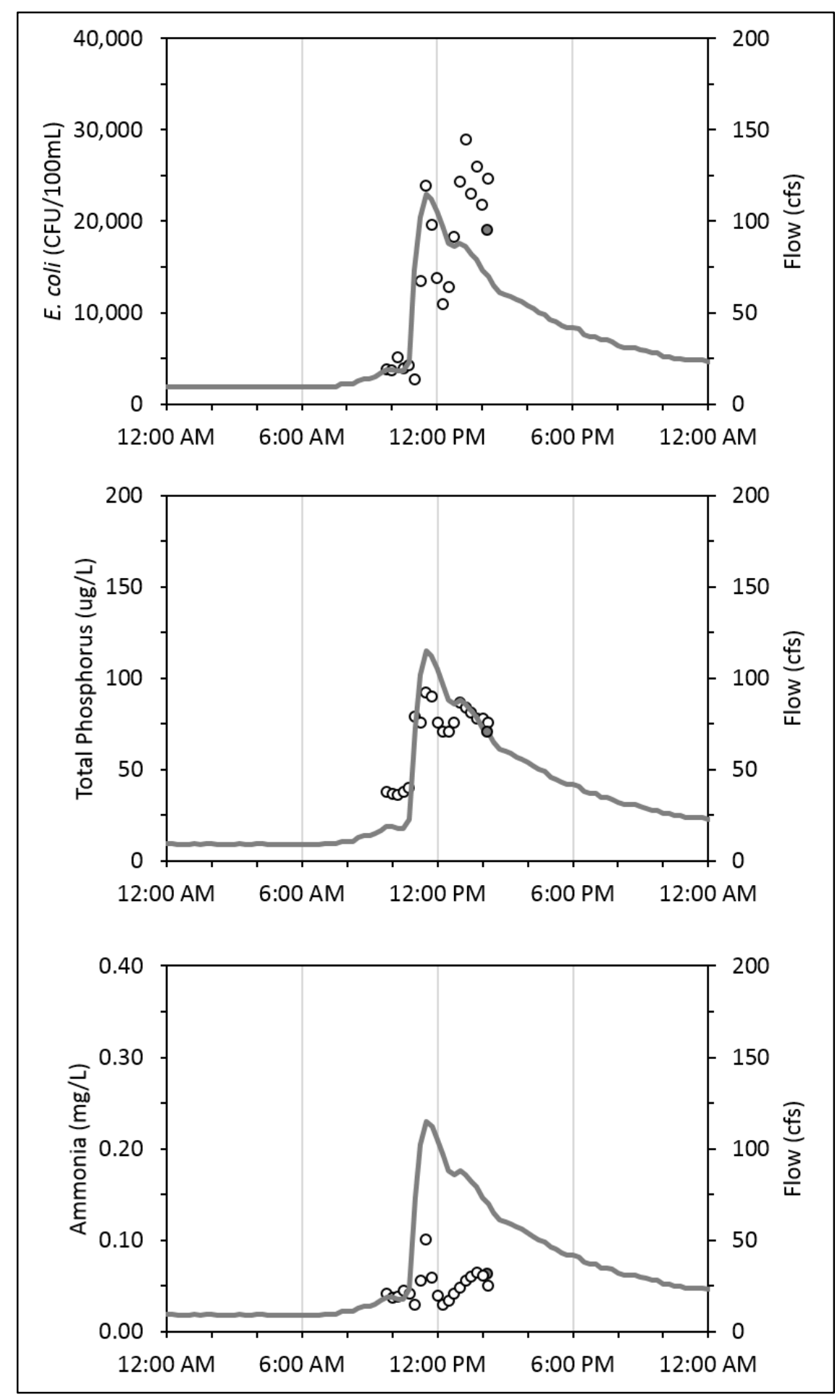

Figure 2-9: Water quality response of Euclid Creek following Storm 1 rainfall on September 30, 2014 
In contrast to Euclid Creek and smaller tributaries within NEORSD, the Cuyahoga River and Rocky River receive much of their inputs from upstream watersheds. Land cover in these upstream watersheds are far less urbanized than those within NEORSD and Cleveland. This results in a hydrologic and water quality response which is independent to that observed in Euclid Creek. As shown in the comparison between USGS flow measurements at Independence Ohio, 13 miles upstream, and the timing of rainfall during Storm 1, the response to rainfall is much prolonged (Figure 2-10). While rainfall began at 7:00 AM, upstream flows gradually increase for nearly 10 hours, from $350 \mathrm{cfs}$ to $850 \mathrm{cfs}$. It is not until 4:00 PM that peak discharges are reached.

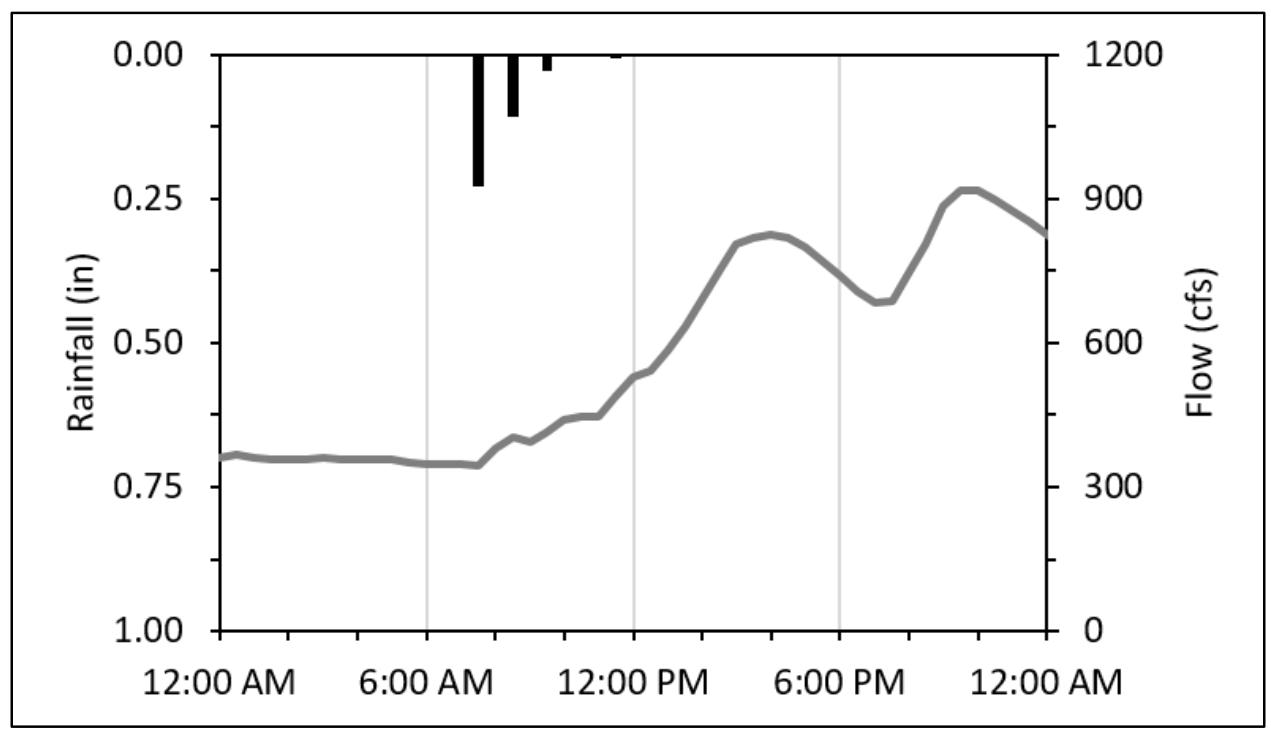

Figure 2-10: Hydrologic response of Cuyahoga River following Storm 1 rainfall on September 30, 2014 
On the day of rainfall for Storm 1, water quality measurements were taken at 1-hour intervals near the mouth of the Cuyahoga River, from 9:45 AM to 4:45 PM, (Figure 2-11). All POCs showed minimal response to the rainfall and associated discharges. E.coli levels changed from a minimum of 90 CFUs to a maximum of 272 CFUs. Similarly, total phosphorus and ammonia varied by only 24 and $0.02 \mathrm{mg} / \mathrm{L}$, respectively. This lack of response indicates that high POC inputs resulting from rainfall within NEORSD are unable to impact the overall water quality of the Cuyahoga River. Due to its large volume of flow, wet weather inputs within NEORSD account for a minimal portion of the overall inputs to the Cuyahoga River. 


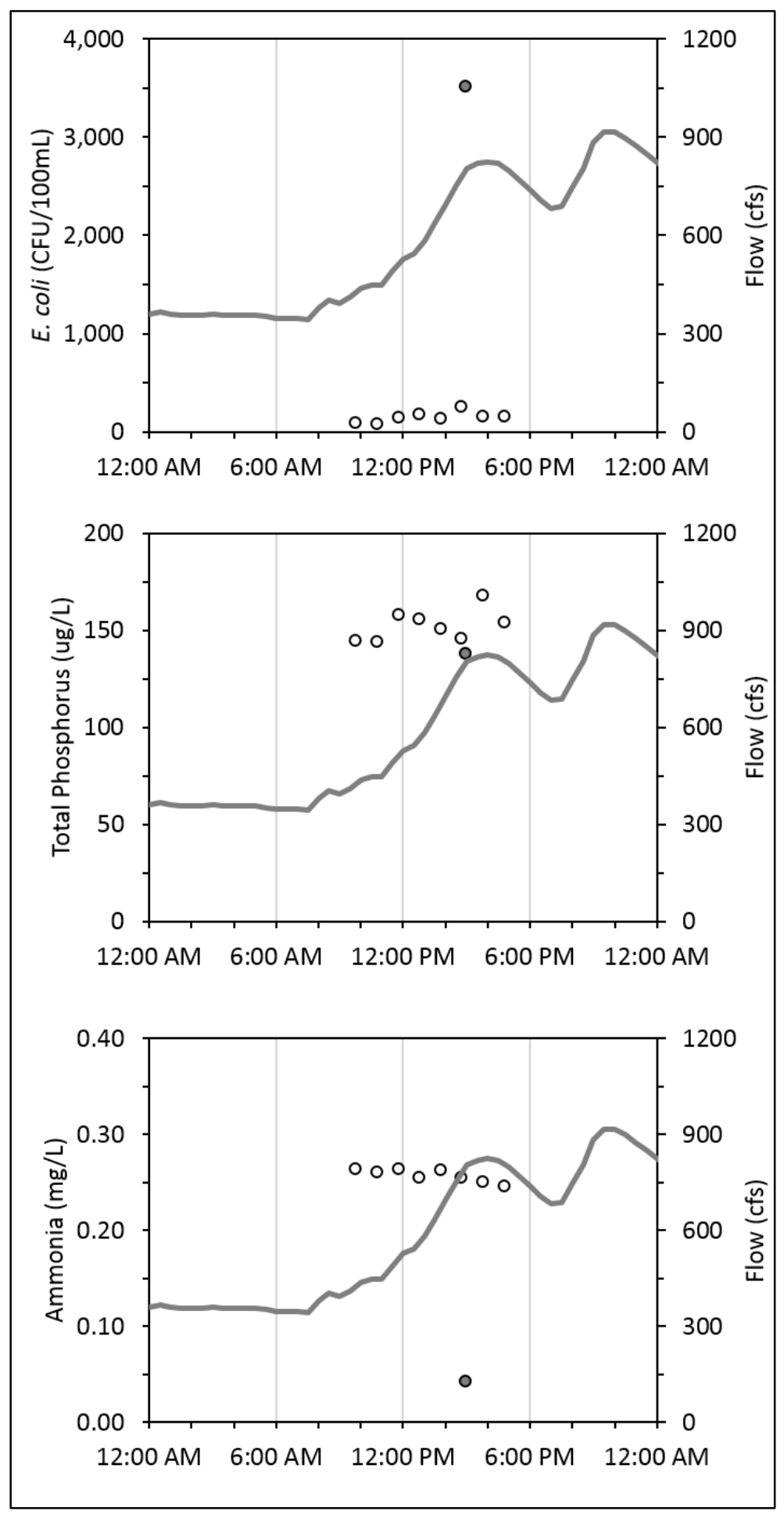

Figure 2-11: Water quality response of Cuyahoga River following Storm 1 rainfall on September 30, 2014 
Wet weather upstream vs. downstream tributary comparison

Rainfall impacts across NEORSD are known to result in elevated POC levels in local tributaries. The magnitude of these POC levels varies along tributaries, in upstream and downstream waters. Due to the spatial distribution of point source discharges (e.g. CSO outfalls, WWTP effluents), pollutant levels can change drastically in only a short segment of the river. CSOs contribute the highest concentrations of pollutants and often control water quality downstream of their outfalls.

Upstream and downstream tributary measurements were taken throughout NEROSD on the day of rainfall for Storm 1. As discussed above, upstream POC levels are predominantly due to rainfall runoff. In contrast, most tributaries have their downstream waters within NEORSD's collection system, as a result, they receive significant inputs from sewer outfalls. These inputs carry high levels of pollutants. Pollutant measurements found, in general, concentrations in upstream waters to be lower than those in downstream waters (Figure 2-12).

Small tributaries, like Euclid Creek and other Eastern Tributaries, have relatively little drainage area upstream of CSO outfalls. As a result, the volume of low POC, rainfall runoff is limited. This causes pollutant levels in the tributary to increase drastically upon discharge of point sources. Overall, the Eastern Tributaries were found to have low concentrations of E. coli in upstream waters. However, at the mouth the tributaries, following CSO discharges, concentrations were found to have increased. Doan Brook, for example, showed $433 \mathrm{CFU} / 100 \mathrm{~mL}$ of $E$. coli in upstream waters. At the mouth, however, concentrations rose to $387,300 \mathrm{CFU} / 100 \mathrm{~mL}$. The length of river between these locations 
receives discharges from 16 CSOs, among other point sources. Similarly, Green Creek experienced an increase in concertation from $3,183 \mathrm{CFU} / 100 \mathrm{~mL}$ to $66,700 \mathrm{CFU} / 100 \mathrm{~mL}$ between upstream and downstream waters.

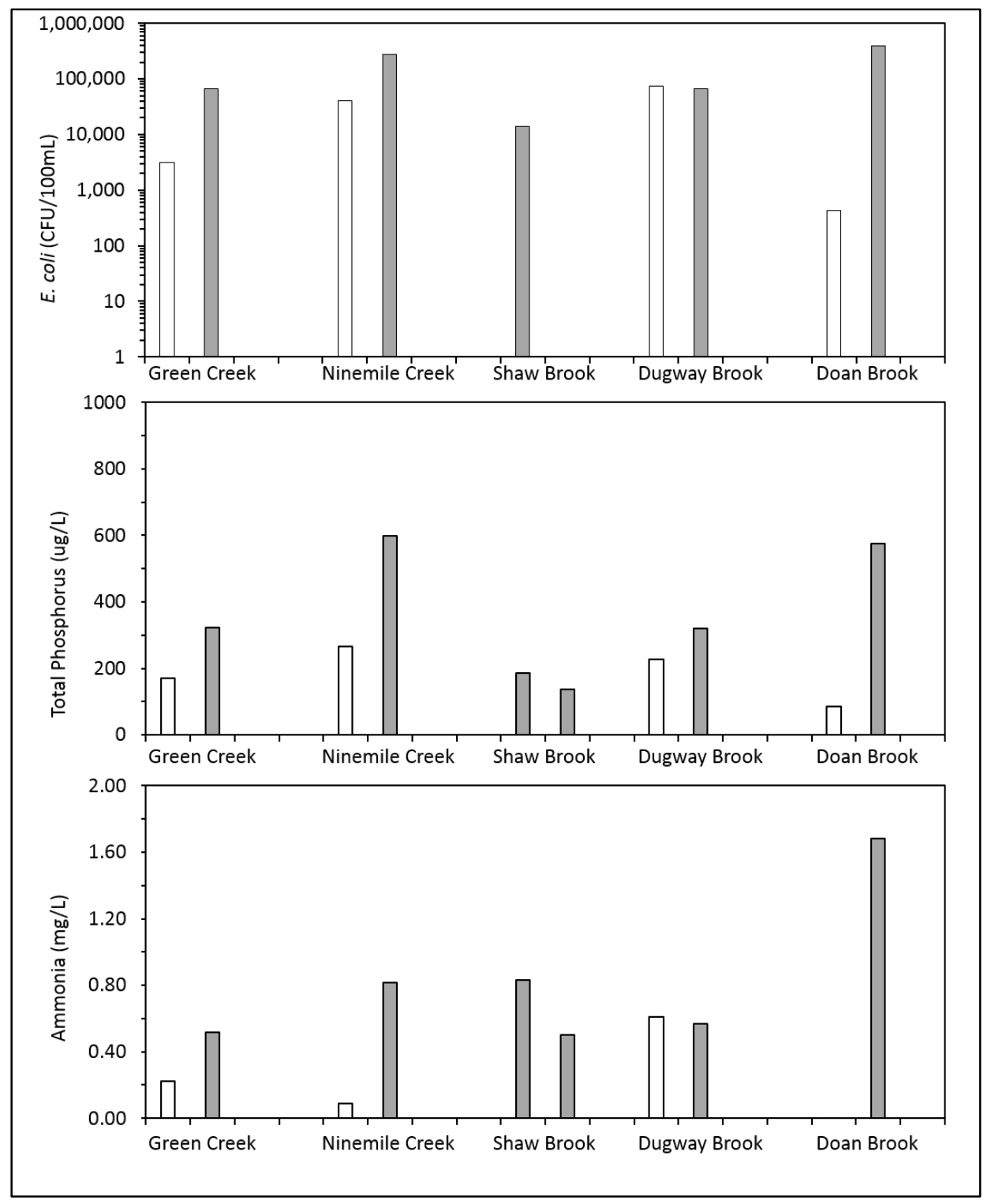

Figure 2-12: Observed pollutant levels in upstream and downstream waters from Storm 1 on September 30, 2014 
Larger tributaries, such as Rocky River and those entering the Cuyahoga River, receive higher volumes of rainfall runoff in their upstream watershed. As a result, there is more opportunity for this runoff to impact the overall water quality in downstream waters. In contrast to smaller tributaries, $E$. coli levels were found to be comparable between upstream and downstream waters (Figure 2-13). For example, Mill Creek had a difference of only $600 \mathrm{CFU} / 100 \mathrm{~mL}$ between upstream and downstream waters. Similarly, West Creek was found to be $11,000 \mathrm{CFU} / 100 \mathrm{~mL}$ higher in upstream waters. As for Big Creek, which receives discharges from $18 \mathrm{CSOs}$, upstream waters showed elevated POC levels but levels were far elevated at the mouth. This may be due to several CSOs discharging high loads of pollutants into the tributary which, collectively, drive the downstream water quality. On the other hand, Rocky River, which drains a significant area of land and receives minimal CSO input, showed high POC levels in upstream waters, prior to NEORSD impact. 


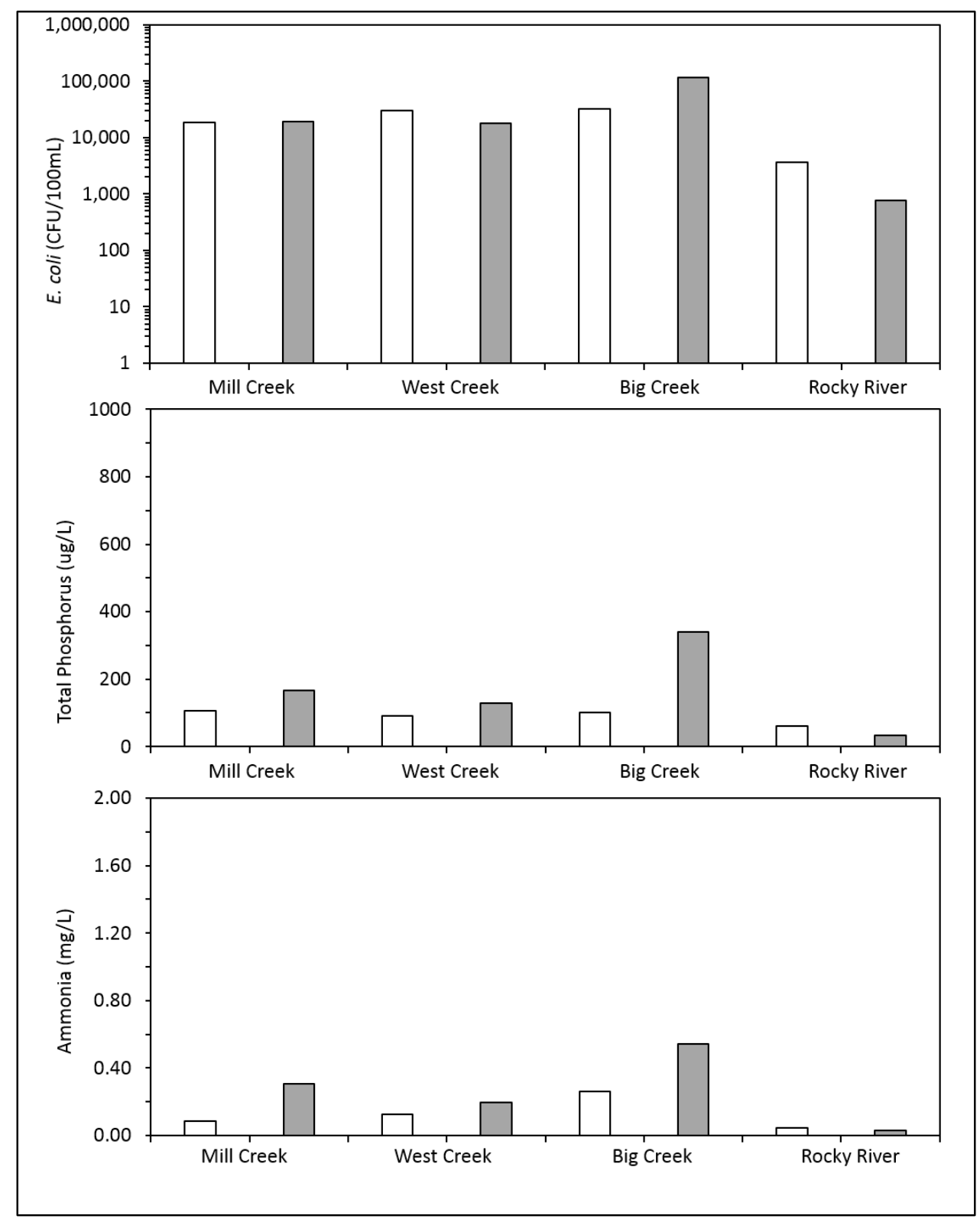

Figure 2-13: Observed pollutant levels in upstream and downstream waters from Storm 1 on September 30, 2014 


\section{System-wide recovery following rainfall events}

Similar to the rapid hydrological and water quality response observed in the minor tributaries at the start of rainfall, the recovery following rainfall events also occurred within a small duration. Both tributaries and the Lake Erie nearshore demonstrated the ability to attenuate rainfall related impacts and quickly return to dry conditions.

With many tributaries having smaller, developed watersheds, runoff can be collected and transported in a short period of time. USGS stream gauges have shown that flows on Euclid Creek and Mill Creek often return to baseline discharges in less than 24 hours. Elevated POC levels are directly linked to the rainfall related inputs which drive flows. As a result, POC levels also return to baseline levels in a timely manner. Twice daily sampling on multiple tributaries during Storm 2 showed baseline concentrations of POCs to be achieved during the day following rainfall (Figure 2-14). Morning and afternoon sampling on the day of rainfall showed elevated POC levels in Euclid Creek, Doan Brook and West Creek. The day following rainfall showed a rapid recovery of POC concentrations. By Day 2, POC levels had reached their pre-storm conditions and remained there through the balance of sampling. 


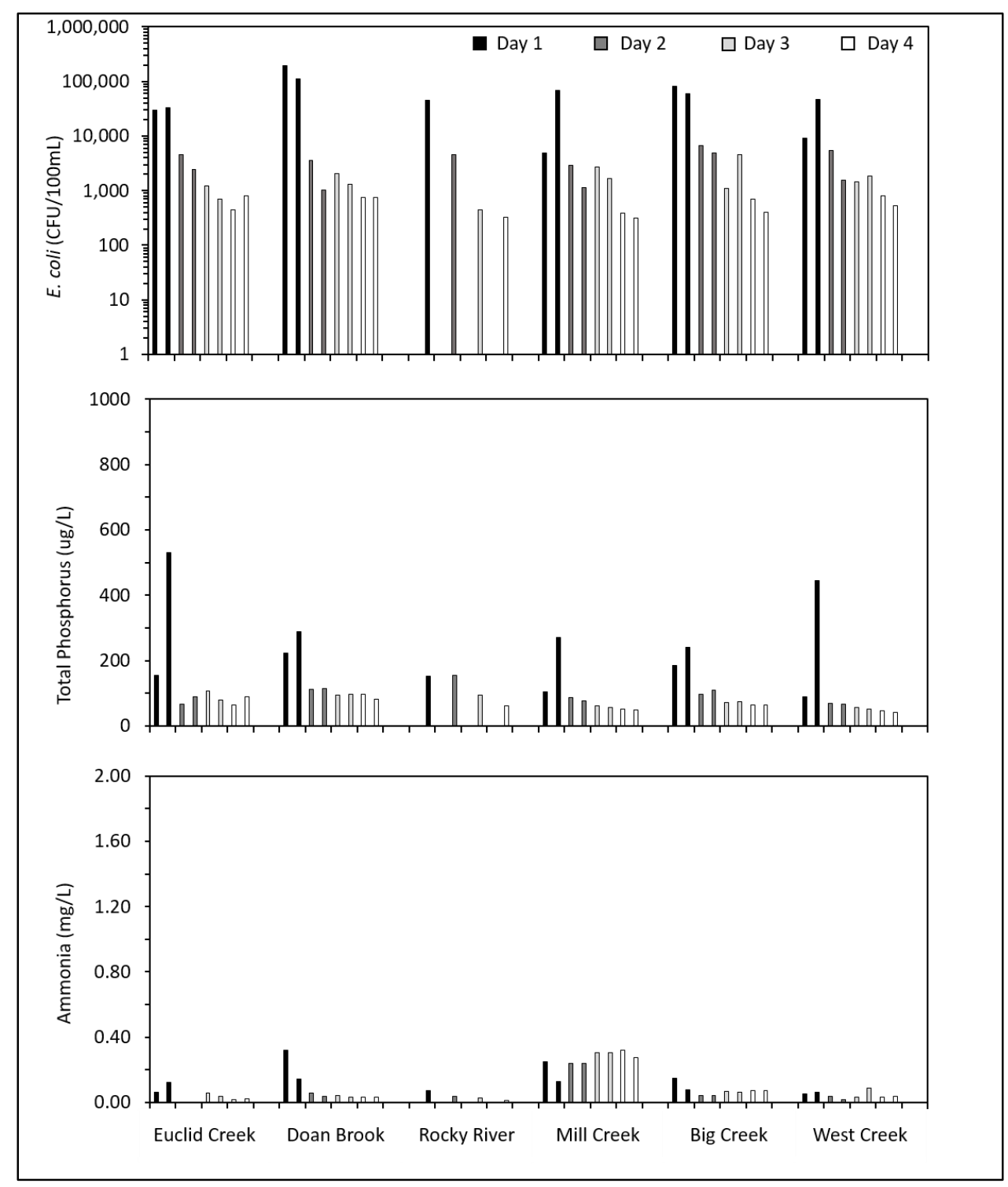

Figure 2-14: Observed pollutant levels resulting from Storm 1 rainfall. 
Impacts from the high POC loads in tributaries were observed throughout the Lake Erie nearshore. However, the duration of their presence was found to be brief. Once daily sampling during Storm 2 along the shoreline, at 0.5 and $1 \mathrm{~km}$ offshore stations, provided insight to the temporal impacts of tributary loads.

On the day of rainfall, day $1, \mathrm{POC}$ levels in water $0.5 \mathrm{~km}$ offshore were considerably higher than those in water $1 \mathrm{~km}$ offshore (Figure 2-15). The $0.5 \mathrm{~km}$ water averaged an $E$. coli of $133 \mathrm{CFU}$ while $1 \mathrm{~km}$ water averaged $35 \mathrm{CFU}$. In less than 1 kilometer, Lake Erie was able to reduce POC levels by nearly four times. This shows that while high tributary loads deliver elevated concentrations of pollutants to Lake Erie, the pollutants are quickly manifested by ambient lake water.

On the day following rainfall, POC levels remained elevated from the previous day's rainfall. E. coli concentrations doubled in the $1 \mathrm{~km}$ offshore water and $0.5 \mathrm{~km}$ water remained the same. However, in the days following, a steady reduction of POC levels was observed in 0.5 and $1 \mathrm{~km}$ offshore water. Sampling on days three and four showed POC levels had dropped from their elevated concentrations in the days preceding. Within three days of the rainfall, nearshore water had returned to its pre-rainfall condition. 


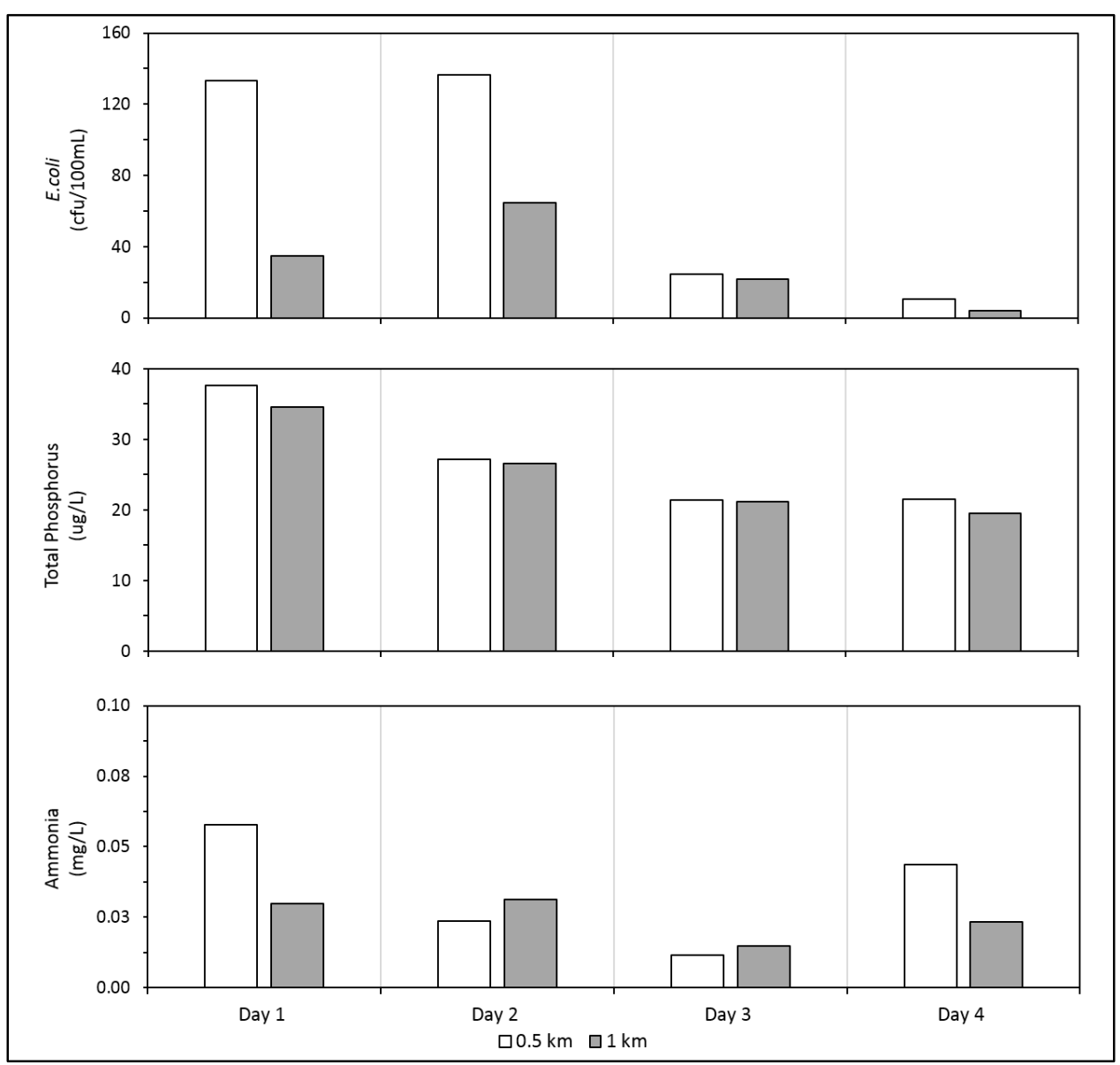

Figure 2-15: Average nearshore pollutant levels following Storm 2 rainfall. 


\section{SWMM Loading Models}

\section{Application}

The capabilities of EPA-SWMM and PC-SWMM have been used in predicting the hydrological and water quality loads resulting from the Consent Decree and CIP improvements. Developed by the Environmental Protection Agency (EPA), SWMM has become a recognized tool for analyzing and designing stormwater runoff systems, evaluating combined and sanitary sewers, and evaluating other urban based drainage systems ((SWMM) n.d.). SWMM has the ability to simulate runoff quantity and quality of short, single events, or continuous, long term periods having multiple events. Rainfall is used to generate runoff across defined sub catchments which feed into a stream network. Pipes, channels, and other features then assist in the transport of the runoff throughout the system.

Pollutant loads can be simulated for rainfall runoff and point source inputs. SWMM has the ability to model various forms of pollutant inputs and processes including pollutant buildup, street sweeping, and pollutant reductions due to natural processes. Land uses can be defined for each subcatchments and representative pollutants can be associated to each land use. This feature was vital in evaluating the CIP improvements since each improvement focused on a unique system type, or land use.

In 1984, Computation Hydraulics International (CHI) coupled the features of EPA-SWMM with a GIS based system and user-friendly interface to form PC-SWMM. This program has 
since become a leading decision support system for projects focused on green infrastructure design, sanitary system evaluation, and wet weather analysis.

\section{Method}

Simulation of the load models for the consent decree and CIP improvements were performed and evaluated using PC-SWMM for 11 tributaries in northeast Ohio. These tributaries include: Abrams Creek, Big Creek, Cuyahoga River, Dugway Brook, Doan Brook, Euclid Creek, Green Creek, Mill Creek, Ninemile Creek, Rocky River and West Creek. The models were originally developed by NEORSD during past studies. Upon the start of Michigan Tech's involvement, these models were updated from SWMM-4 to SWMM-5 versions.

To simulate past storm events, rainfall was used as the driving hydrologic force. Rainfall was represented across northeast Ohio using a collection of rain gauges operated by NEORSD. All of the models, except Rocky and Cuyahoga, had their watersheds fully represented by these gauges. For the Rocky and Cuyahoga rivers, USGS stream gauges were used to represent upstream flow conditions, where their watersheds extend beyond the SWMM models. NEORSD's CSM used the same collection of rain gauges to simulate CSO, SSO and WWTP flows during past periods.

Watersheds for each stream were defined and divided into smaller sub catchments. Land uses, i.e. system types, were assigned to each sub catchment for common trench dual manhole, common trench divider wall, common trench over/under, separated trench, septic area, and combined sewers. In addition, point source inputs were placed within each model 
for CSOs, SSOs, ILLDs, septic systems, and WWTPs. Knowledge gained through past studies performed by NEORSD and Wade Trim were used in determining a constant hydrology for ILLDs and septic systems.

\section{Calibration and Confirmation}

\section{$\underline{\text { Overview }}$}

Before the PC-SWMM models were applied for consent decree and CIP evaluation, calibration and confirmation of hydrologic and water quality loads was necessary. Since the predicted loads served as the primary inputs for pollutants, the SWMM model's ability to accurately represent the timing and magnitude of flow and pollutant levels was vital to the integrity of the overall project.

\section{$\underline{\text { Hydrological Loads }}$}

Previous efforts made by Michigan Tech and Wade Trim focused on adjustments to the model's hydrologic parameters to provide acceptable level of predictability of the SWMM models. USGS stream gauges were available on four of the streams: Mill Creek, Abrams Creek, Euclid Creek and Cuyahoga River. Observed flows over the summers of 2012, 2013 and 2014 were used for confirming the timing and magnitude of predicted flows. For streams not having USGS gauges, adjustments were made consistent with those made at the gauged streams. At the completion of this work, it was shown that for the SWMM models having measured flow data, predicted flows were consistently matching the timing and magnitude of those observed. Results from this analysis are discussed in Zoe Miller's thesis. 


\section{Pollutant Loads}

During the original development of the SWMM-4 models, water quality predictions were not of interest and therefore the models lacked this capability. As a result, it was necessary to incorporate water quality abilities into the SWMM-5 models. This was achieved by representing all of the known inputs throughout these streams which contribute to E.coli, ammonia nitrogen, and phosphorus levels. Sub catchment delineation was performed to allow land uses to be defined throughout each watershed. Point source inputs were based on estimated locations, for ILLDs and septic systems, and known geographic locations, for CSOs, SSOs, and WWTPs.

Pollutant inputs can be categorized into three groups (Figure 3-1). The first being dry weather inputs that are not impacted by the presence or absence of rainfall. These include ILLDs and failing septic systems, and are considered to have constant flow and pollutant inputs. During dry weather periods, when rainfall is absent, ILLDs and septic systems are believed to be the primary source of pollutants in the streams. 


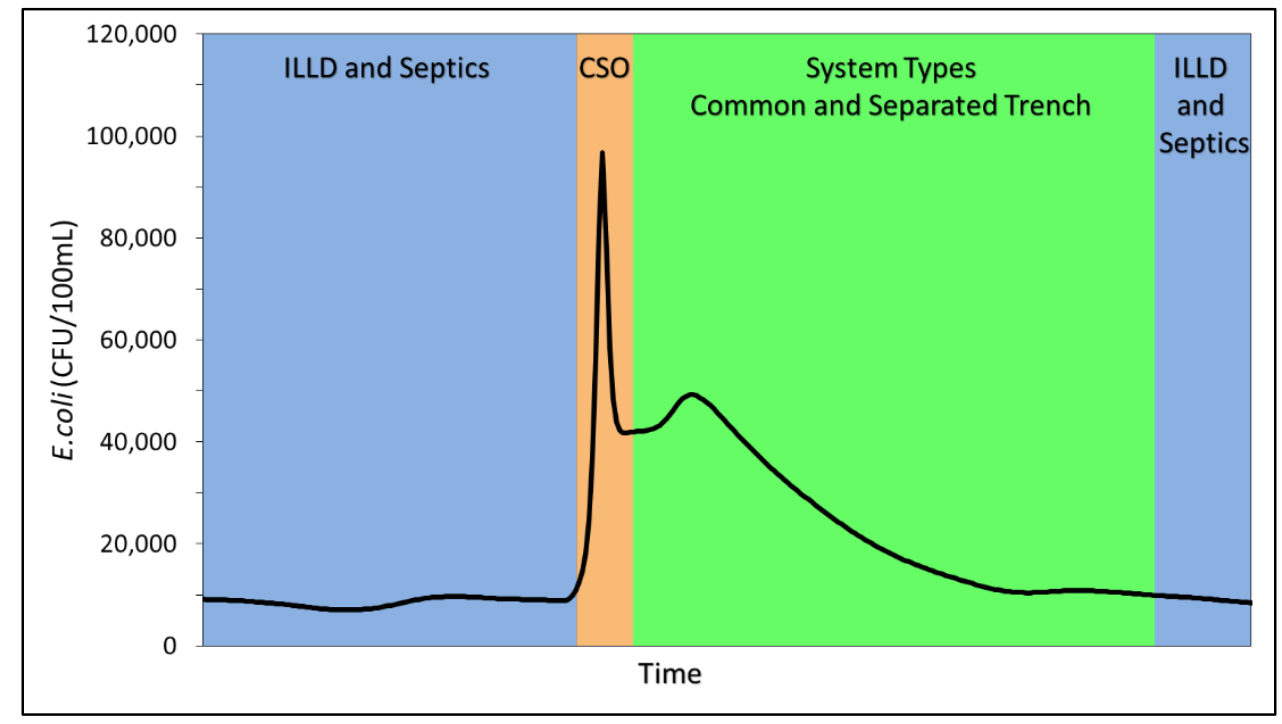

Figure 3-1: Characterization of tributary pollutant levels during rainfall events.

The second source of pollutants is from point sources which vary based on rainfall. These time variable inputs consist of CSOs, SSOs and WWTP. Due to the behavior of NEORSD's sewer system, CSOs and SSOs respond rapidly to rainfall. Since their point of input is typically in downstream sections of the streams, a sudden spike in pollutant levels is often observed during wet weather events.

The third source of pollutant inputs is associated with runoff, generated from the rainfall captured within sub catchments. All rainfall which results in runoff, i.e. not lost to infiltration or evaporation, is handled by the system type within that subcatchments. This results in all runoff collecting pollutants before discharging into the stream. In a system that is working properly, runoff would be captured by the stormwater system and discharged at a designated location. However, due to the failing infrastructure throughout NEORSD, stormwater frequently interacts with neighboring sanitary systems, causing sanitary overflows which deliver high levels of pollutants in to receiving waters. Unlike 
CSOs and SSOs, the pollutant impact from stormwater runoff occurs more gradually during wet weather events, due to the greater travel time from sub catchments.

Since tributary POC levels are attributed to multiple inputs (e.g. CSOs, WWTPs, system types), unique, representative POC concentrations were required for each input. While variation in POC concentrations vary geographically and with rainfall patterns, each input was assigned constant concentrations across all of NEORSD. For example, all CSOs contribute the same concentration of E.coli, ammonia nitrogen, and total phosphorus. While, in reality, concentrations would vary with locations and rainfall intensity, it was not feasible to assign unique concentrations at each the 126 CSOs. Similarly, all areas of separated trench sewers were assigned the same concentrations. Each of these pollutant inputs were assigned an average, representative POC concentrations, prior to model calibration. These values were based on past studies performed by NEORSD and a review of literature values.

ILLDs and septic systems were represented as constant inputs, regardless of rainfall. Average flow and water quality were determined for ILLDs, from measurements taken throughout NEORSD. Since the true behavior of each ILLD is unknown, this method provided a general representation of ILLDs across NEORSD's service area. Similar to ILLDs, septic systems experience high variability in their treatment ability and subsequent impacts on groundwater. Past studies have shown that of the local septic systems in northeast Ohio, 23\% are considered properly functioning, $20 \%$ are failing and the remainder's performance is unknown. As a result, septic systems were assigned a constant, 
annual loading of pollutants, which resembled the treatment quality within several drain wells of functioning septic systems (Katz 2010).

\section{Method}

During the 2014 and 2015 beach seasons, the field program captured three periods of wet weather and one period of dry weather concentrations. While sampling was performed at upstream and downstream locations, calibration focused on the most downstream pollutant levels for each tributary. Dry weather and wet weather measurements were used to evaluate the models' handling of various inputs. Model simulations were performed for each tributary during the dry and wet periods. Conditions predicted by the models were compared to observations for each of the POCs.

The calibration process focused on each of the three pollutant inputs separately, during dry and wet weather periods. This distinction allowed the impacts of ILLDs and septic systems to be observed, without interference from rainfall related inputs. Dry weather conditions were first considered. At these times, pollutant inputs consist of ILLDs, septic systems, and WWTP effluents on the Rocky and Cuyahoga Rivers. Aside from the WWTP effluents, dry weather inputs have constant flows and pollutant inputs and therefore do not fluctuate during rainfall events.

Observed concentrations at the tributaries were compared to the initial dry weather concentrations predicted by the models. Incremental adjustments were made to dry weather inputs until an acceptable fit was reached across all of the models. Since, concentrations at 
inputs did not fluctuate between models, trade-offs were made in order to achieve the best overall fit.

The distribution of ILLDs and septic systems varies greatly across northeast Ohio. On many of the streams, septic systems have an unnoticeable impact on dry weather concentrations. In contrast, other streams have a significant number of septic systems which drive the overall dry weather pollutant levels. Dry weather, downstream POC observations show there is a significant range in baseline pollutant concentrations. Considering this range in pollutants, ILLD and septic concentrations were adjusted incrementally until an acceptable prediction was achieved across the 11 models.

Once dry weather pollutant inputs had been adjusted to produce an acceptable match between observed and modeled concentrations, wet weather pollutant levels were evaluated. Unlike dry weather periods, wet weather concentrations consist of multiple inputs from point sources and system type runoff. As discussed previously, the response of CSOs and SSOs to rainfall occurs very rapidly. Coupling this sudden response with their high pollutant levels, the impact of CSO and SSO discharges can be quickly identified. Following this response in the collection system, pollutant levels experience a prolonged elevation, as upstream runoff progresses downstream. As the rainfall and runoff conclude, flows and pollutant levels gradually return to dry weather concentrations. 


\section{$\underline{\text { Results }}$}

Upon completion of calibrating and confirming the predicted loads for E.coli, ammonia nitrogen and total phosphorus, it was found that an acceptable match for the timing and magnitude of loads was achieved in the PC-SWMM models. This conclusion was determined after reviewing the predictability of each model in comparison to observed loads. While it was desirable to evaluate the models' predictability through a quantitative metric (e.g. root mean square errors), scarcity in POC observations limited this analysis to a qualitative review of the loads. Limitations on the frequency of sampling confined the review of this process. However, the behavior of pollutants during observed wet weather events, allowed for the timing and magnitude of PC-SWMM predictions to be reviewed.

Final POC input concentrations were determined for each of the pollutant inputs (e.g. CSOs, ILLDs) (Figure 3-2). Reported values in literature and past studies provided a starting point for pollutant input values. Incremental adjustments during various hydrologic periods were then made to these values and reviewed across the 11 PC-SWMM models. Since input concentrations were consistent across the models, the best overall fit was targeted. This required sacrifice in the predictability of some models, in order to benefit the predictability of others. SSO and CSO discharges were found to have the highest pollutant levels. Of the system types, over/under and divider walls have the highest concentrations. 
Table 3-1: Pollutant Input Concentrations Resulting from Confirmation of the PCSWMM Models

\begin{tabular}{|r|c|c|c|}
\hline \multicolumn{1}{|r|}{ Pollutant Input } & $\begin{array}{c}\text { E.coli } \\
(\mathrm{CFU} / 100 \mathrm{~mL})\end{array}$ & $\begin{array}{c}\text { Ammonia } \\
(\mathrm{mg} / \mathrm{L})\end{array}$ & $\begin{array}{c}\text { Phosphorus } \\
(\mathrm{mg} / \mathrm{L})\end{array}$ \\
\hline SSO-Separate Trench & 187,000 & 1.26 & 0.60 \\
\hline SSO-common Trench & 184,482 & 5.00 & 2.00 \\
\hline Common Trench - Dual Manhole & 60,000 & 0.15 & 0.53 \\
\hline Common Trench - Diver Wall & 100,000 & 0.20 & 0.30 \\
\hline Common Trench - Over/Under & 100,000 & 0.20 & 0.30 \\
\hline Separated Trench & 19,325 & 0.10 & 0.10 \\
\hline ILLDs & 20,000 & 0.50 & 0.60 \\
\hline Septic Systems & $20,476,462$ & 0.06 & 0.08 \\
$($ CFU/unit/year $)$ & $(\mathrm{lbs} / \mathrm{year})$ & $(\mathrm{lbs} / \mathrm{year})$ \\
\hline
\end{tabular}

Adjustments to the pollutant input concentrations are supported by observed concentrations for similar systems. Past studies performed by NEORSD found CSO E.coli concentrations to range from 867,700 to $29,000 \mathrm{CFU} / 100 \mathrm{~mL}$. Similarly, ammonia nitrogen and total phosphorus have ranged of 3.69 to $1.14 \mathrm{mg} / \mathrm{L}$ and 0.4 to $0.8 \mathrm{mg} / \mathrm{L}$, respectively. Knowing this range in CSO pollutants, final concentrations were found to be acceptable. SSO concentrations match those from the Report to Congress on impact and control of CSOs and SSOs Appendix H/WEF Collection Systems 2004.

System type concentrations (e.g. common trench dual manholes, separated trench) were largely driven through past studies performed by NEORSD. In these studies, NEORSD 
measured pollutant levels in various system types throughout NEORSD, during multiple wet weather periods. For example, over/under and divider wall concentrations discharging to Rocky River ranged from 199,000 to $1,000 \mathrm{CFU} / 100 \mathrm{~mL}$ for E.coli, and 0.5 to $1.2 \mathrm{mg} / \mathrm{L}$ for ammonia nitrogen. Separated trench measurements taken near Mill Creek reported a range in E.coli from 220,000 to $<1,000 \mathrm{CFU} / 100 \mathrm{~mL}$, ammonia nitrogen of 5.0 to $<0.1$ $\mathrm{mg} / \mathrm{L}$, and total phosphorus of 1.48 to $0.18 \mathrm{mg} / \mathrm{L}$.

Since the modeled pollutants are known to be non-conservative substances, their losses were considered in the calibration process. To guide efforts in representing the death rate of E.coli in the streams, a study performed by Auer and Niehaus was referenced (Auer 1993). In this study, the first-order dark death rate coefficient at $20^{\prime} \mathrm{C}$ was found to be $\mathrm{k}_{\mathrm{d}}$ $=0.73$ per day. Applying this death rate in the PC-SWMM models resulted in a reduction of E.coli which improved comparisons to observations. The death rate has the most impact during dry weather periods when residence time in the streams is greater and on system type runoff. Since CSO and SSOs are typically located in downstream sections of streams, E.coli from their discharges is not held in the streams long enough for significant losses to occur.

Losses were also considered for ammonia nitrogen through nitrification. Based on the results of a study performed by Pauer and Auer, a first-order loss of 0.048 per day was first simulated in the models (Pauer 2000). This level of loss produced a half-life of 14.5 hours. While residence time in the streams varies, they are typically much shorter than 14.5 hours. As a result, the losses due to nitrification was not able to make a considerable impact on in-stream ammonia concentrations. Further simulations were performed using faster rates 
of nitrification. However, nitrification continued to have only minor impact on ammonia concentrations. Due to nitrification's inability to impact in-stream ammonia concentrations, it was determined that ammonia could be accurately represented without the presence of nitrification.

Comparison of observed wet weather pollutant loads and PC-SWMM loads can be performed in three steps. The first focuses on the ascending limb of the storm. In other words, the rate at which pollutant levels increase following rainfall. Behavior during this period of time displays the model's ability to accurately represent the rate of response from rainfall related inputs. The second step is to consider peak pollutant levels. These values represent the model's timing and magnitude of the maximum pollutant levels commonly associated with COS and SSO discharges. Lastly, the rate of recovery in the stream is evaluated. This period shows the rate at which the stream is able to return to dry weather pollutant levels. Failure to accurately represent a return to baseline conditions can result in an over-estimation of pollutant loads.

Results from calibration and confirmation at Euclid Creek are shown below (Figure 3-2). Three wet weather events were available for comparison. Storm-1, from, 2014, was used as the calibration event. Pollutant input concentrations were then carried over to the 2015 storms for further comparison. These storms varied in rainfall accumulation and subsequent pollutant loads. As a result, these storms provided the opportunity to assess the model's predictability during minor, average, and significant rainfall periods. 
Considering pollutant loads during these three events, Figure 3-2 demonstrates the model's behavior in comparison to observations. Due to the timing of observations, review of the model's predictability is limited. However, it is shown that the model is able to simulate a behavior of pollutant loads which agree with those observed. The highest pollutant inputs in Euclid Creek are CSOs. Knowing this, peak concentrations during rainfall events can likely be attributed to CSO discharges. Considering these peak pollutant levels from the model, it can be concluded that peak model concentrations agree with maximum observations and occur closely in time. 


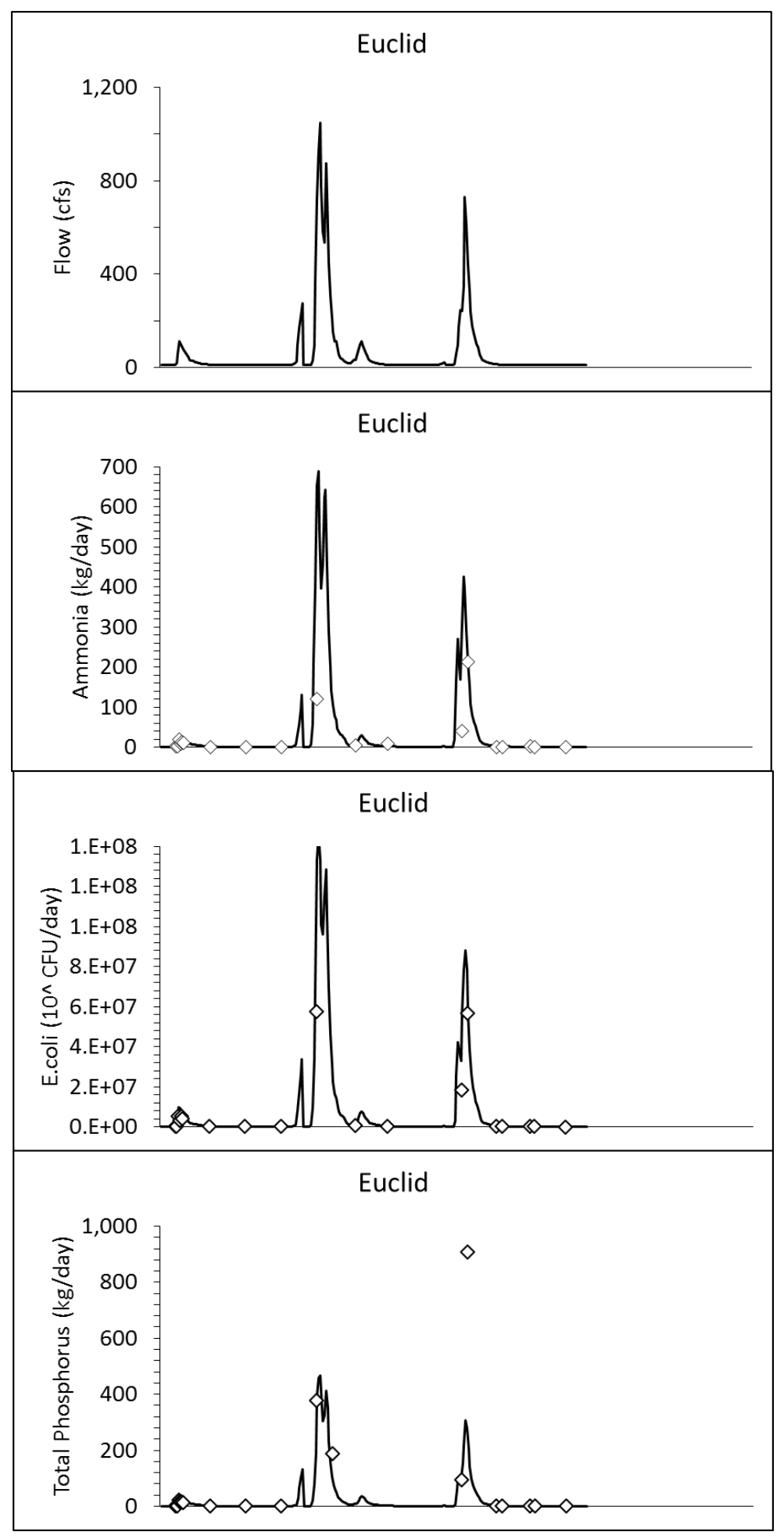

Figure 3-2: Comparison of Euclid Creek PC-SWMM loads and observed loads during 2014 and 2015 wet weather events. 
Similar to Euclid Creek, Big Creek predictions can be compared to observations for the ascending limb of storms, peak concentration levels, and the rate of recovery (Figure 3-3). For all three of these metrics, it was determined that under the final pollutant input values, the model was able to accurately represent pollutant levels. Observation during storm 1 provide peak pollutant levels which are accurately matched by PC-SWMM. Predictions during Storm 2 show a return to dry weather conditions which agrees with measurements from this storm. Lastly, peak pollutant levels and recovery rate of storm 3 shows a strong match between observations and PC-SWMM predictions. 

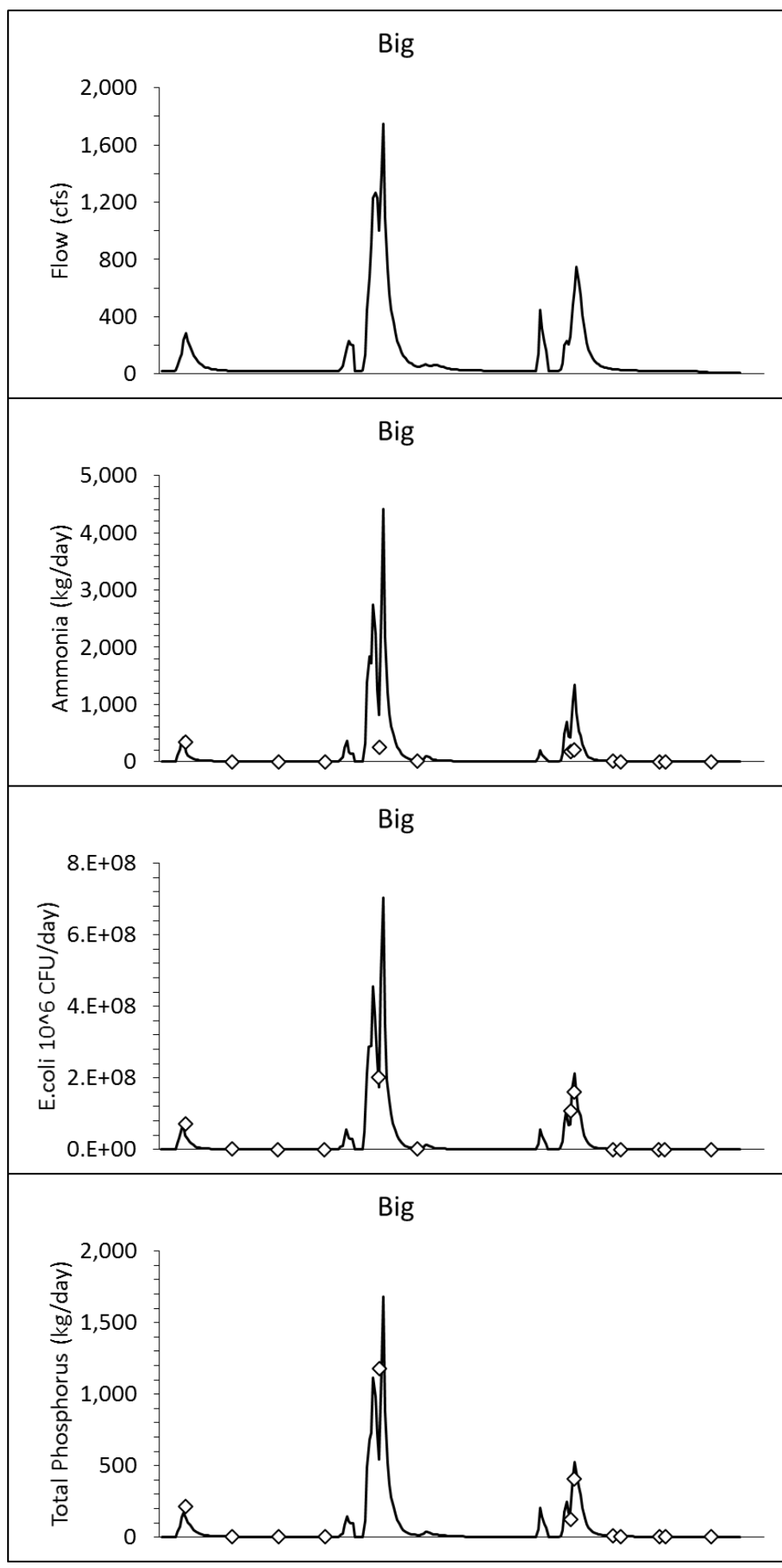

Figure 3-3: Comparison of Big Creek PC-SWMM loads and observed loads during 2014 and 2015 wet weather events. 
When compared to one another, the magnitude of pollutant loads ranges drastically across the 11 streams (Figure 3-4 and Figure 3-5). Maximum pollutant loads are typically observed in the Cuyahoga River. While pollutant levels are not necessarily highest here, the high flows result in large pollutant loadings. The smallest loads are found within the eastern tributaries, specifically at Green Creek. Here, pairing Green Creek's high pollutant concentrations with its minor flows results in pollutant loads that are essentially unobservable at the scale shown below. This variation in pollutant loads has a significant role in determining the area impacted in the Lake Erie nearshore. While concentrations in the Cuyahoga River are notably lower than those in Green Creek and other eastern tributaries, its high flows result in a larger area of impact in the nearshore. In contrast, Green Creeks high concentrations are quickly attenuated by low lake levels since its flows are minor. 


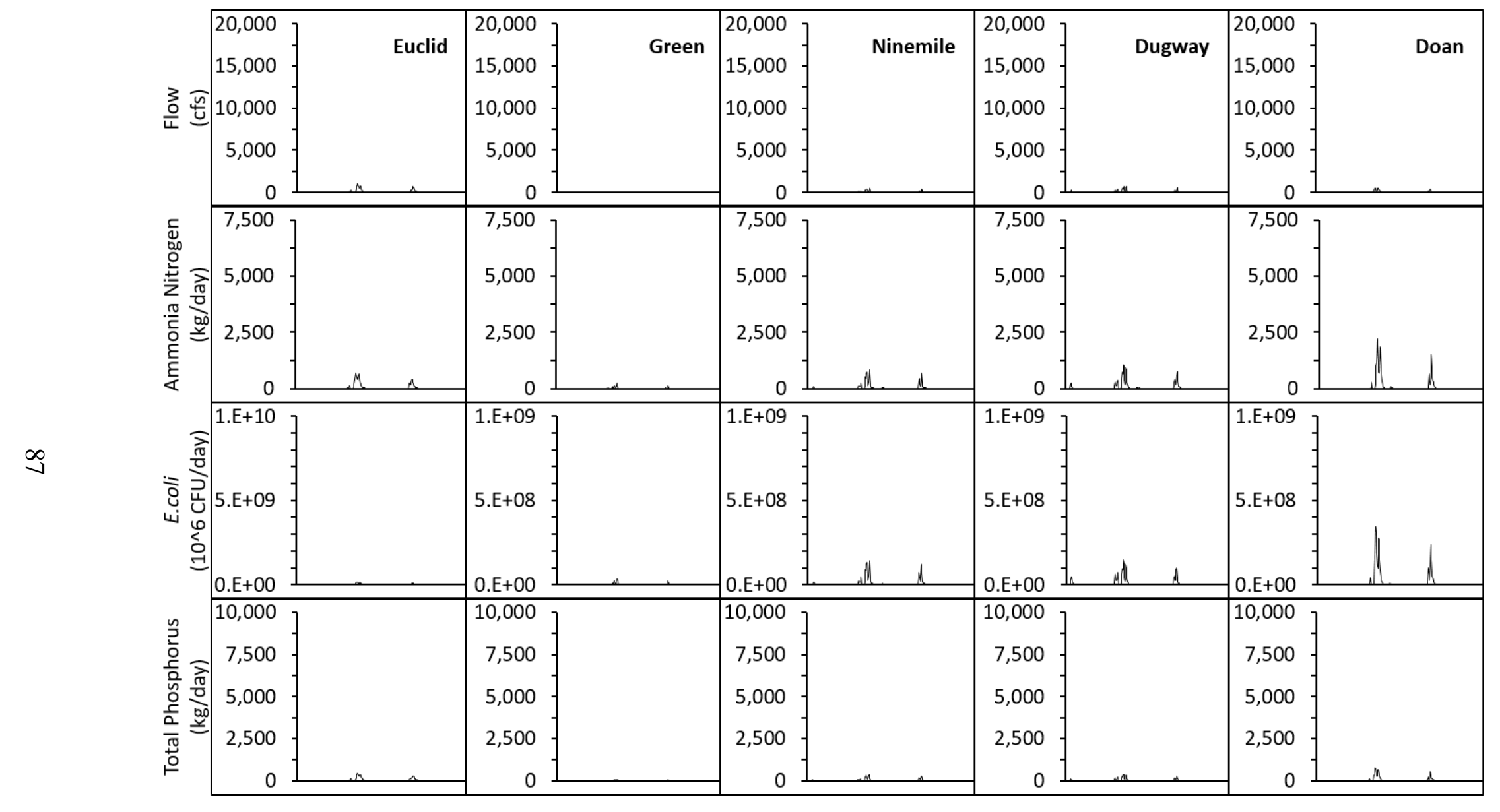

Figure 3-4: Comparison of Eastern Tributary Pollutant Loads Predicted by PC-SWMM 


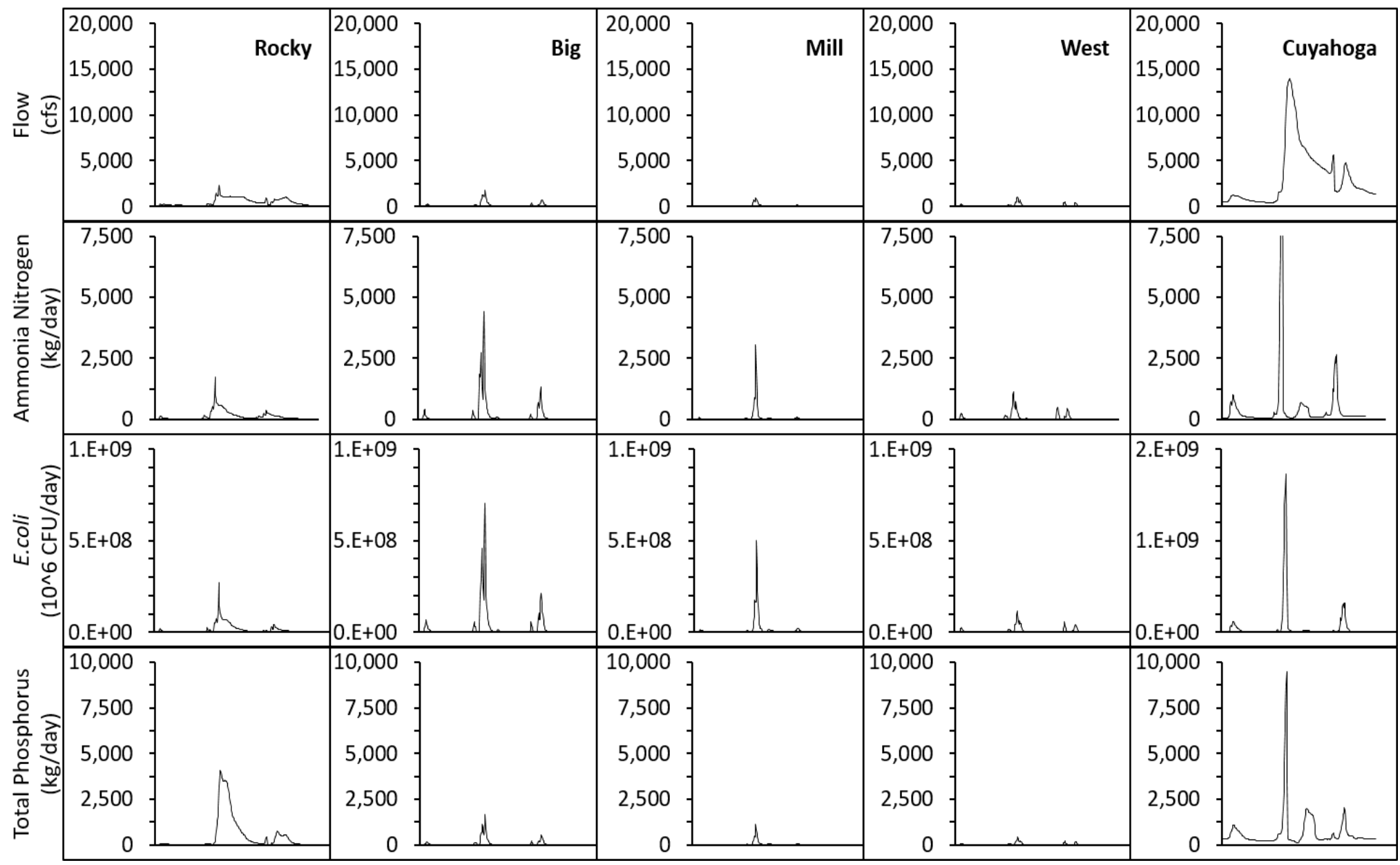

Figure 3-5: Comparison of Western Tributary Pollutant Loads Predicted by PC-SWMM 


\section{Evaluation of Pollutant Load Reductions}

Following the development and confirmation of the PC-SWMM models, NEORSD has gained the ability to accurately simulate infrastructure improvements, prior to the investment of limited financial resources. In addition to the requirements set by the consent decree, NEORSD also has the responsibility of improving other aspects of their infrastructure. Before identifying the focus of these improvements, it is desirable for NEORSD to understand the local and regional impacts that various aspects of its sewer system is having and will. Possessing a collection of SWMM models, which have the ability to run in series with the CSM and Lake Erie model, NEORSD now has the ability to accurately understand the impacts of capital investments, prior to making physical adjustments to their current infrastructure. The ability offers NEORSD a means for efficiently scheduling the location and focus of infrastructure investments. Over time, this ability will assist NEORSD in most efficiently improving their sewer system to meet state and federal regulations and improving life for residents of northeast Ohio.

Examples of the benefits associated with this ability are demonstrated in the figures below. By further evaluating the pollutant characteristics of Euclid Creek and Big Creek, the varying response to infrastructure improvements can be observed. Euclid is fed by an 18,779 acre watershed (Figure 4-1). The majority of its watershed is served by separate trench sewers (65\%). The next largest system type is over/under common trench sewers, which serve $23 \%$ of its watershed. Combined sewers account for only $4 \%$ of its total watershed and offer discharge from three CSOs. 


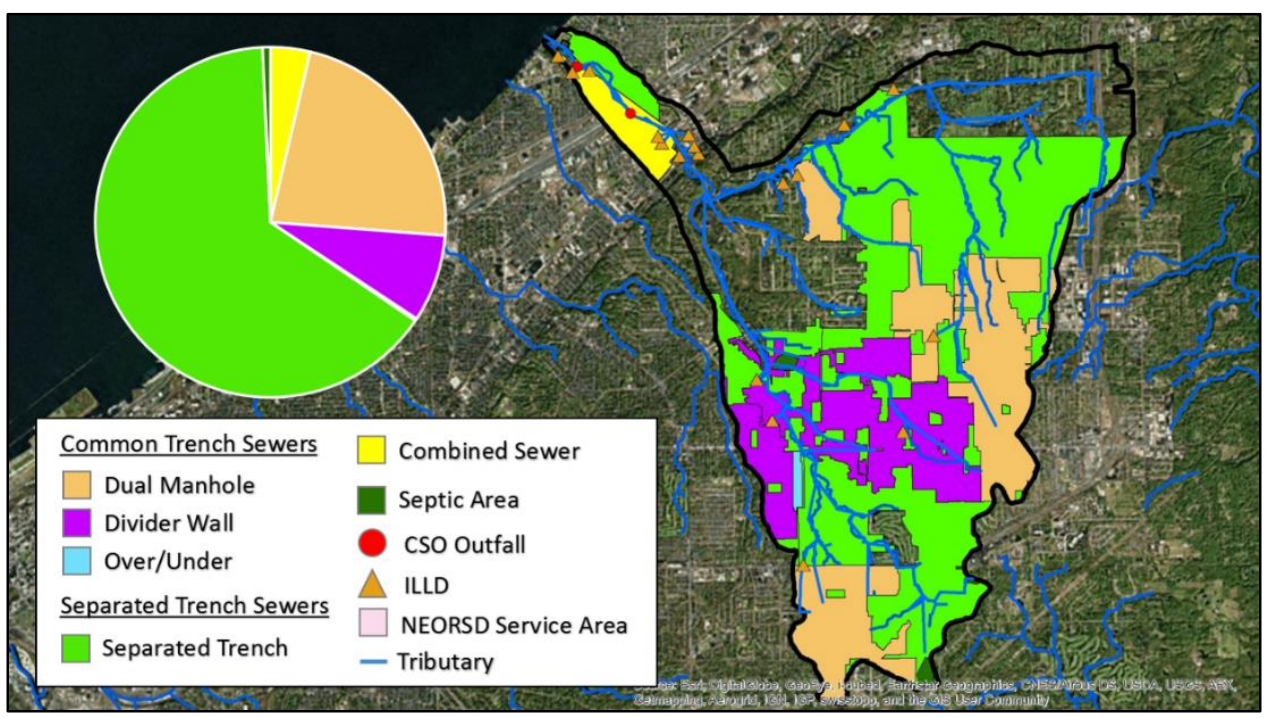

Figure 4-1: Euclid Creek System Types and Pollutant Inputs.

(Produced in ArcGIS 10.3 by Nathan Zgnilec)

Under the current infrastructure, prior to CSO control through consent decree improvements, PC-SWMM determined $5.8 * 10^{\wedge} 15$ CFU of E.coli were discharged from Euclid Creek during the 204 Beach Season (Figure 4-2). Of the total E.coli discharged, CSOs delivered only $27 \%$. The remainder came from dual manhole (26\%), divider wall $(28 \%)$ and separate trench sewers $(18 \%)$. 


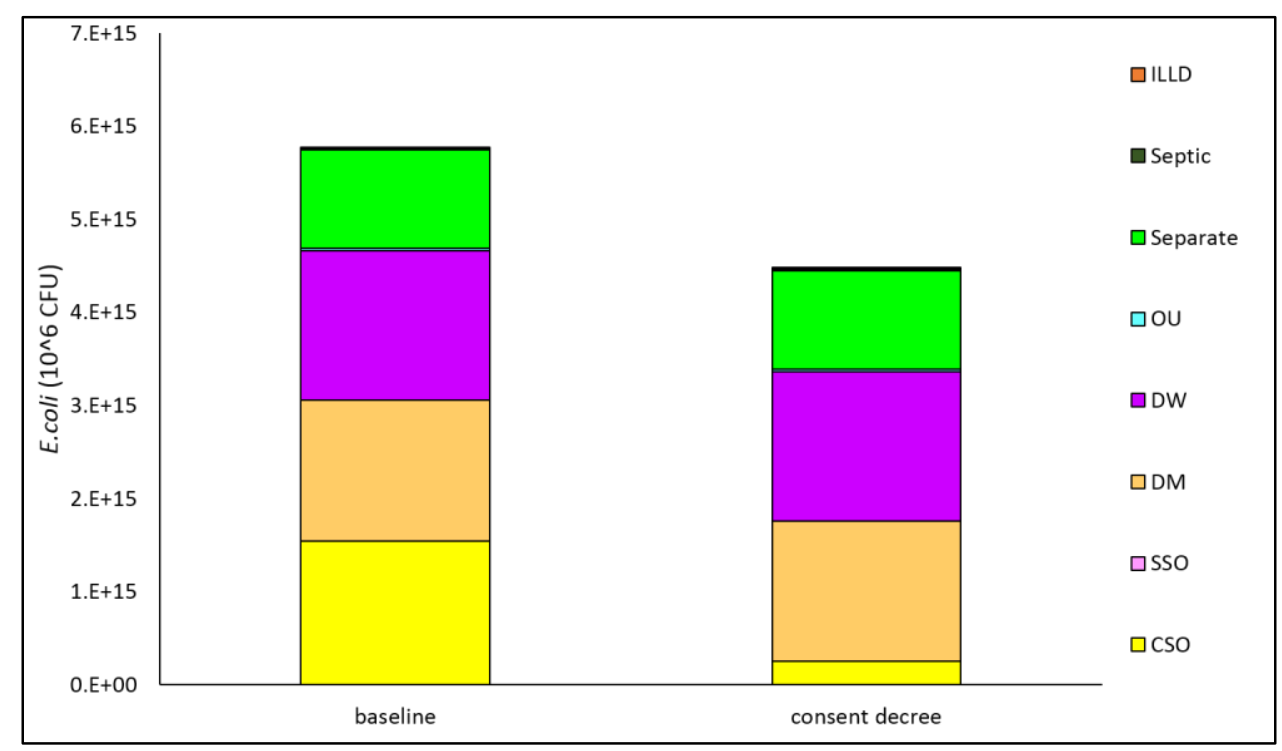

Figure 4-2: Baseline and Consent Decree E.coli contributions during 2014 Beach Season

Following completion of the consent decree, PC-SWMM showed a reduction in 2014 E.coli of 22\% (Figure 4-2). This reduction represents the impact of the Euclid Creek Tunnel which provides control for the three CSOs discharging into Euclid Creek. Prior to the consent decree, these CSOs delivered 145 MG to Euclid Creek during 27 wet weather events. Having storage from the Euclid Creek Tunnel, these CSOs discharged only 4 times and delivered a total volume of $23 \mathrm{MG}$. Under full completion of the consent decree, CSO discharges account for only $10 \%$ of the overall E.coli.

Big Creek is fed by a 23,565 acre watershed (Figure 4-3). System types cover the majority of this area, with $47 \%$ served by dual manhole sewers and $25 \%$ served by separated trench sewers. The remainder is largely handled by combined sewers, which cover $26 \%$ of the Big Creek watershed. The area served by combined sewers are relieved through 18 outfalls, 
which are primarily located in downstream portion of its channel. In addition, five SSOs discharge to Big Creek.

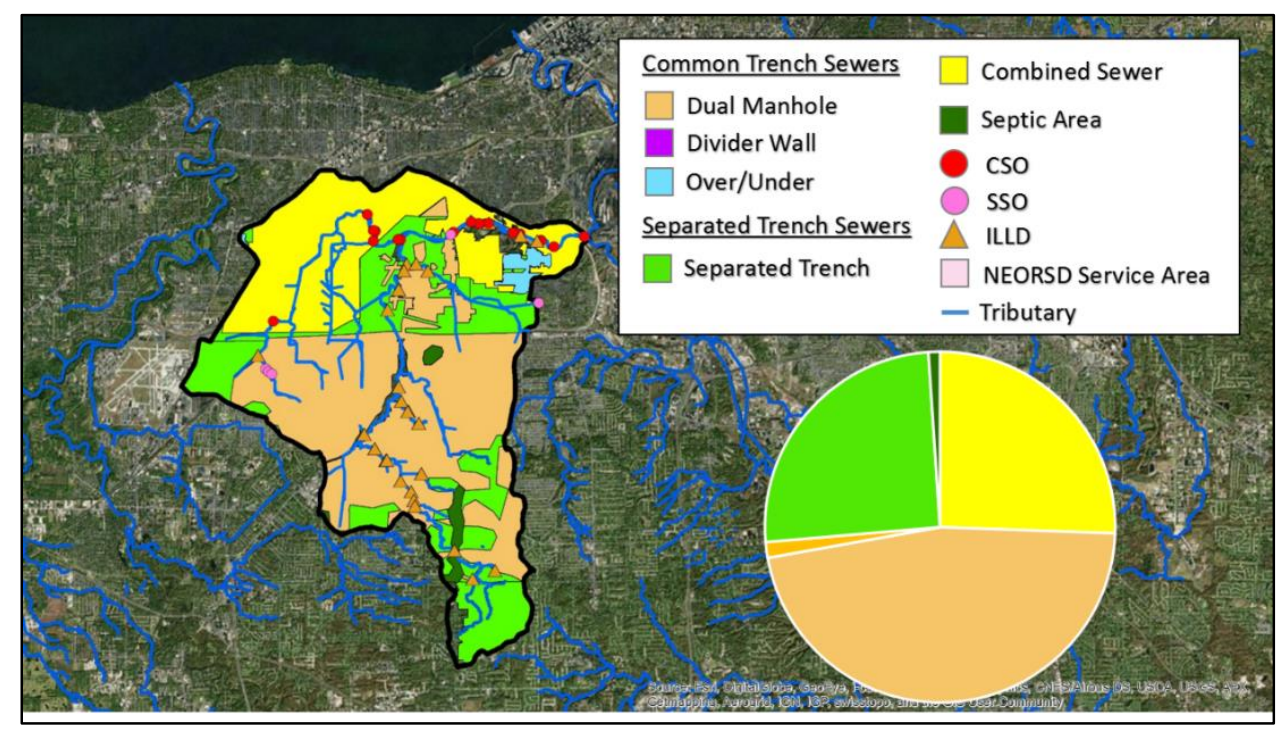

Figure 4-3: Big Creek System Types and Pollutant Inputs.

(Produced in ArcGIS 10.3 by Nathan Zgnilec)

PC-SWMM simulations determined $1.5^{*} 10^{\wedge} 16 \mathrm{CFU}$ of E.coli were discharged through Big Creek during the 2014 Beach Season (Figure 4-4). Of the total E.coli discharged, 58\% were attributed to CSO discharges, which occurred during 34 wet weather periods and discharged 796 MG. Dual manhole sewers were found to contribute the second most E.coli, at $21 \%$. While SSOs deliver the highest concentrations of E.coli for all of the pollutant inputs, their total discharges totaled only $31 \mathrm{MG}$, which accounted for $1 \%$ of the 2014 E.coli. 


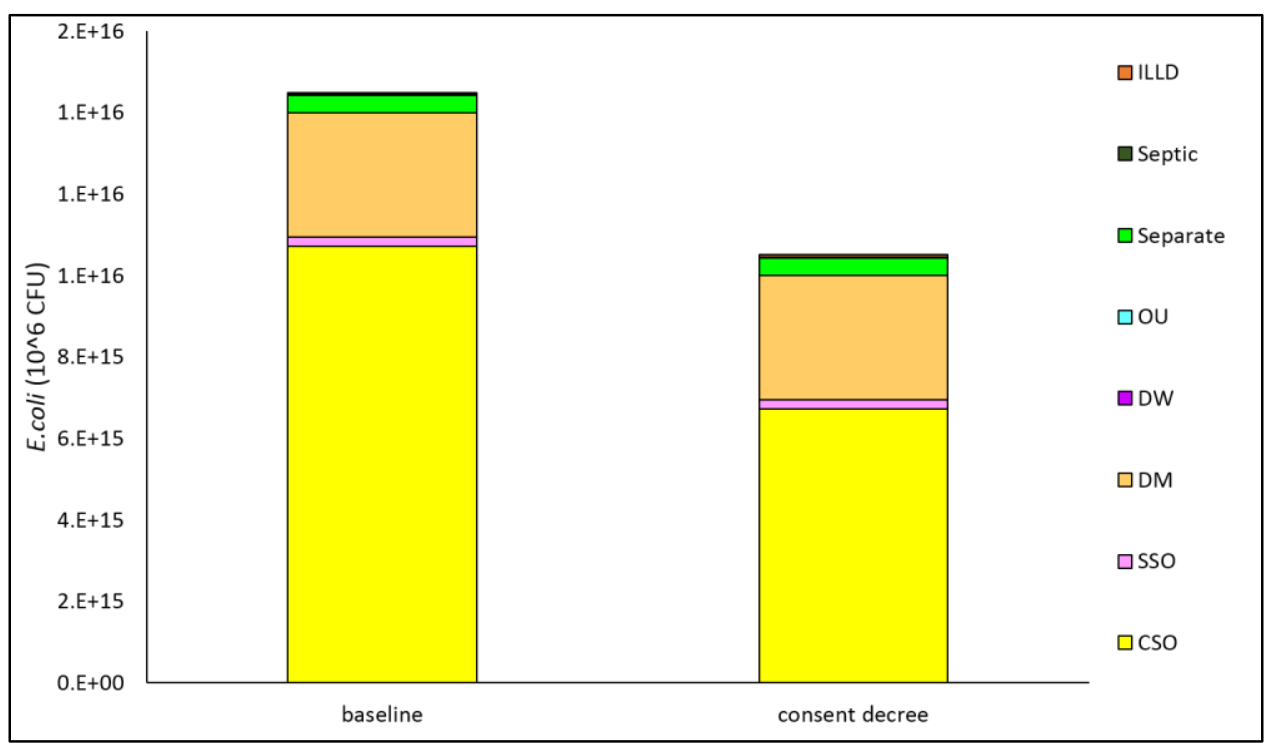

Figure 4-4: Baseline and Consent Decree E.coli Loads during 2014 Beach Season

Under full completion of the consent decree, E.coli was found to be reduced over the 2014 beach season. With storage tunnels complete, CSOs on Big Creek discharged 420 MG over 8 wet weather events. Total E.coli from CSO discharges dropped 47\%, which resulted in a $28 \%$ overall reduction for Big Creek. Dual manhole sewers now contribute $29 \%$ of the total E.coli. 
As shown through the Euclid Creek and Big Creek evaluations, efficient use of financial resources will require unique infrastructure improvements which focus on stream specific sewer systems. It has been shown that the benefits stemming from the consent decree, i.e. CSO control, will vary across NEORSD. In systems receiving minimal discharge from CSOs, capital investments which focus on non-combined sewers will likely have greater impacts on reducing pollutant inputs. In contrast, streams such as Big Creek demonstrate the potential benefits resulting from the consent decree on streams receiving significant CSO discharges. 


\section{References}

(SWMM), USEPA. n.d. "Storm Water Managemenet Model."

Alewitz, Sam. 1997. "Sanitation." The Encyclopedia of Cleveland History. July 22. Accessed September 3, 2015. http://ech.case.edu/cgi/article.pl?id=S1.

Auer, Martin. 1993. "Modeling Fecal Coliform Bacteria--I. Field and Laboratory Determination of Loss Kinetics." Water Resources.

Consent Decree. 2010. 1:10-cd-02895 (United States District Court for the Northern District of Ohio, December 22).

Cuyahoga County Board of Health. 2015. "Household Seweage \& Small Flow Sewage Systems." CCBH.net.

Delos, John S. 1950. "Bacterial Survey of Streams and Bathing Beaches of Cleveland." Sewage and Industrial Wastes (Water Environment Federation) 22 (12): 16181624.

Flower, George E. 1957. "Solving Metropolitan Cleveland's Sewerage Needs." Sewage and Industrial Wastes (Water Environment Federation) 29 (1): 6-17. Accessed September 3, 2015. http://www.jstor.org/stable/25033246.

Jackson, Danial D. 1912. "Sanitary condition of the Cleveland Water Supply on the Probable Effect of the Proposed Changes in Sewage Disposal and on the Various Sources of Typhoid Fever in cleveland."

James Thomas. 2015. "Cuyahoga River Fire." OhioHistoryCentral.org. Accessed November http://www.ohiohistorycentral.org/w/Cuyahoga_River_Fire?rec=1642.

Jon C. Schladweiler. 2002. "Tracking Down the Roots of Our Sanitary Sewers." Sewerhistory.org. January 15.

Katz, Brian. 2010. "Fate of Effluent-Borne Contaminants beneath Septic Tank Drainfields Overlying a Karst Aquifer." Journal of Environmental Quality.

McCarty, James F. 2015. "Sewer district's big tunnel credited with improving Mill Creek's water quality." cleveland.org. October 30. Accessed 2016.

McLellan, Sandra L. 2007. "Distribution and Fate of Escherichia coli in Lake Michigan Following contamination with Urban Stormwater and Combined Sewer Overflows." Journal of Great Lakes Research 33: 566-580. 
National Resources Defense Council. 2014. "Testing the Waters." Accessed November 10, 2015.

NEORSD. 2013. "Combined Sewer Overflow and how it affets you."

—. 2016. "Mill Creek Watershed." NEORSD.org.

NEORSD. 2008. Our History and Heritage. Cleveland, OH: Communications and Community Relations, Northeast Ohio Regional Sewer District.

Northeast Ohio Regional Sewer District. 2015. Easterly Wastewater Treatment Plant. http://www.neorsd.org/easterly.php?a=read_more.

- 2015. Southerly Wastewater Treatment Plant. http://www.neorsd.org/southerly.php?a=read_more.

- 2015. Westerly Wastewater Treatment Plant. http://www.neorsd.org/westerly.php?a=read_more.

Ohio EPA. 2009. "National Pollutant Discharge Elimination System (NPDES) Permit Program." Euclid WWTP FACT SHEET, Colombus, Ohio.

Ohio EPA. 2011. "National Pollutant Discharge Elimination System (NPDES) Permit Program." Rocky River WWTP FACT SHEET, Columbus, Ohio.

Ohio EPA. 2014. "National Pollutant Discharge Elimination System (NPDES) Permit Program." Lakewood FACT SHEET, Columbus, Ohio.

Ohio EPA. 2014. "National Pollutant Discharge Elimination System (NPDES) Permit Program." North Olmsted WWTP FACT SHEET, Columbus, Ohio.

Ohio EPA, Division of Surface Water. 2003. "Total Maximum Daily Loads for Lower Cuyahoga River." Columbus. Ohio.

Ohio EPA, Divison of Surface Water. 2005. "Total Maximum Daily Loads for the Euclid Creek Watershed." Columbus, Ohio.

Pauer, James. 2000. "Nitrification in the Water Column and Sediment of a Hypereutrohphic Lake and Adjoining River System." Water Resources.

Scott, Aubrey. 2015. "Standards for Pollutants of Concern Within NEORSD."

Scott, Michael. 2009. "Freshwater mussels found in Cuyahoga River, indicating improved water quality." Cleveland.com. August 22.

Trim, Wade. n.d. "Imad Clinic." 
U. S. Environmental Protection Agency. 2000. "Improved enumeration methods for recreational water quality indicators: enterococci and Escherichia coli." Washington, DC.

U.S. EPA. 2015. About Cuyahoga River AOC. August 31. Accessed September 2015. http://www2.epa.gov/cuyahoga-river-aoc/about-cuyahoga-river-aoc.

U.S. EPA. 1972. "Clean Water Act." Washington D.C.

-. 2014. Combined Sewer Overflows (CSO) Home. December 15. Accessed September 2015. http://water.epa.gov/polwaste/npdes/cso/.

U.S. EPA. 2014. "Financial Capability Assessment Framework." Washington D.C.

-. 2014. Illicit Discharge Detection and Elimination. July 1. Accessed October 15, 2015. http://www.epa.gov/npdes/stormwater/menuofbmps/illicitdischarge.

U.S. EPA. 2012. "Integrated Municipal Stormwater and Wastewater Planning Approach Framework."

U.S. EPA. 2015. "RECOMMENDED PHOSPHORUS LOADING TARGETS FOR LAKE ERIE."

U.S. EPA. 2012. "Recreational Water Quality Criteria." Office of Water, Washington D.C. Accessed November 16, 2016.

—. 2014. Septic (Onsite/Decentralized) Systems. December 12. Accessed October 15, 2015. http://water.epa.gov/infrastructure/septic/.

U.S. Geological Survey. 1998. "Factors Affecting Escherichia coli Concentrations at Lake Erie Public Bathing Beaches." Water Resources, U. S. Geological Survey, Columbus, $\mathrm{OH}$.

United States Environmental Protection Agency. 2014. "Financial Capability Assessment Framework." Office of Water, Washington, DC.

Wade Trim. 2015. "Presentation by Imad Salim (Wade Trim) on NEORSD Infratructure." April. 